Portland State University

PDXScholar

Summer 7-13-2018

\title{
Neighbor Perceptions of Psychiatric Supportive Housing : the Role of Knowledge, Attitudes, and Behaviors
}

Amy Leigh Shearer

Portland State University

Follow this and additional works at: https://pdxscholar.library.pdx.edu/open_access_etds

Part of the Disability Studies Commons, and the Psychology Commons Let us know how access to this document benefits you.

\section{Recommended Citation}

Shearer, Amy Leigh, "Neighbor Perceptions of Psychiatric Supportive Housing : the Role of Knowledge, Attitudes, and Behaviors" (2018). Dissertations and Theses. Paper 4501.

https://doi.org/10.15760/etd.6385

This Dissertation is brought to you for free and open access. It has been accepted for inclusion in Dissertations and Theses by an authorized administrator of PDXScholar. Please contact us if we can make this document more accessible: pdxscholar@pdx.edu. 
Neighbor Perceptions of Psychiatric Supportive Housing:

The Role of Knowledge, Attitudes, and Behaviors

by

Amy Leigh Shearer

A dissertation submitted in partial fulfillment of the requirements for the degree of

Doctor of Philosophy

in

Applied Psychology

Dissertation Committee:

Greg Townley, Chair

Eric Mankowski

Keith Kaufman

Paula Carder

Portland State University

2018 


\begin{abstract}
Purpose: Historically, communities have opposed the development of residential programs for adults with psychiatric disabilities. In the last two decades, national and local campaigns have made targeted efforts to improve public knowledge about mental illness, and attitudes and behaviors towards mental health clients. Supportive housing policies have also been revised to better facilitate integration and independence for clients with psychiatric disabilities. Despite these changes, the number of studies on perceptions of psychiatric supportive housing has dramatically declined in recent years. Little is known about how neighbors currently perceive psychiatric housing and neighbors with mental illness, or the role that mental health knowledge, attitudes, and behaviors play in neighborhoods where housing clients live.
\end{abstract}

Methods: Knowledge, attitudes, and behaviors of 139 neighbors living in close proximity to psychiatric supportive housing sites were assessed. Follow up qualitative interviews were conducted with 16 neighbors who correctly identified the housing site in their neighborhood to understand the perceived impact of the housing site and elicit suggestions for improving relations between clients and their neighbors. Individual and neighborhood social experiences of neighbors are compared with those of 68 clients living in the referent housing sites.

Results: Neighbors had high rates of personal experience with mental illness and were familiar with mental health diagnoses and facts. Neighbors had positive opinions about and neighboring intentions towards neighbors with mental illness. Increased mental health knowledge and close relationships with individuals with mental illness were 
associated with decreased stigma. Being able to correctly identify the housing and population was not associated with differences in opinions about individuals with mental illness. Compared to clients, neighbors perceived the neighborhood as being less safe. Clients were lonelier than their neighbors. Neighbors reported the housing had a positive impact on the neighborhood and had few concerns. They suggested awareness, education, and social contact strategies to improve relations with housing clients.

Conclusions: Suggestions for improving client integration and public acceptance of psychiatric supportive housing are discussed, as well implications in light of recent policy changes and ongoing public anti-stigma campaigns. 


\section{Acknowledgements}

There are many people to thank for the successful completion of this project. First, thank you to my advisor, Dr. Greg Townley, for inviting me to start his research group with him and for his guidance throughout my graduate studies. Thank you to my committee members, Drs Eric Mankowski, Keith Kaufman, and Paula Carder, for their invaluable advice throughout this process. I am grateful to the Cascadia Behavioral Healthcare staff, clients, and their neighbors, for their support and participation in this project.

Thank you to everyone who pounded the pavement with me to make this data collection possible: Katricia Stewart, Camilla Cummings, Laurel Fuson, and Melissa Ulrich, and especially Rachel Terry for her additional assistance reviewing qualitative codes.

I am grateful to my loved ones for providing so much encouragement, cheer, advice, and support. Thank you especially to my parents who have always believed in and supported me, and to whom this document is dedicated. I could not have done this without you! 


\section{Table of Contents}

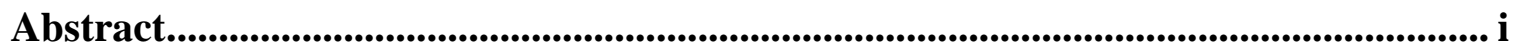

Acknowledgements ........................................................................................................................ii

List of Tables ......................................................................................................... vi

List of Figures............................................................................................................... vii

Chapter 1. Introduction .................................................................................................................. 1

Origins of Mental Illness Stigma and Discrimination................................................... 2

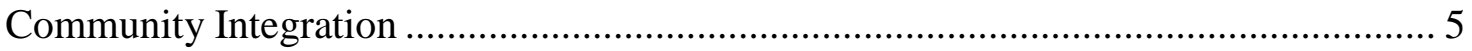

Community Perceptions of Psychiatric Housing ………............................................. 21

Chapter 2. Study Overview........................................................................................................... 37

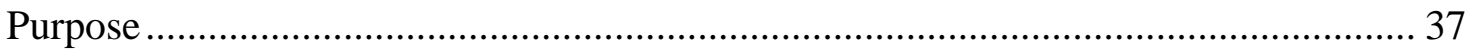

Aim 1: Understanding Knowledge, Attitudes, and Behaviors..................................... 40

Aim 2: Linking Knowledge to Attitudes........................................................................ 44

Aim 3: Linking Attitudes to Behaviors.................................................................... 49

Aim 4: Client and Neighbor Comparisons ................................................................ 50

Chapter 3. Methods ................................................................................................................... 53

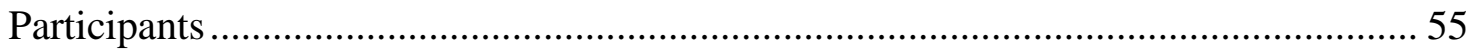

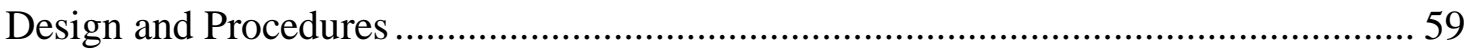

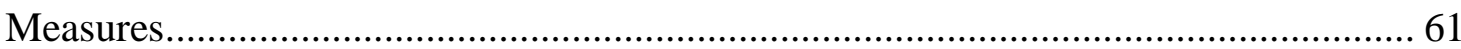

Chapter 4. Analysis and Results .............................................................................66

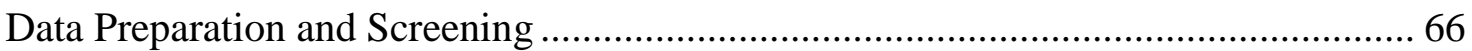

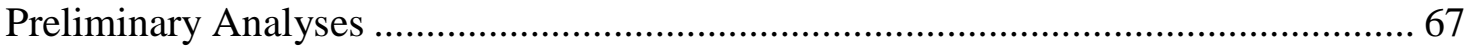

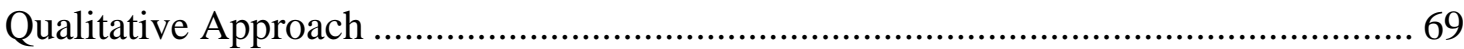

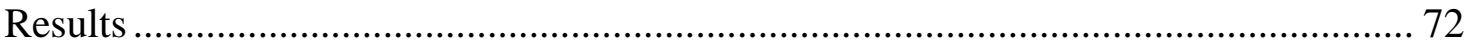

Aim 1: Understanding Knowledge, Attitudes, and Behaviors .................................... 72

Aim 2: Linking Knowledge to Attitudes ..................................................................... 80

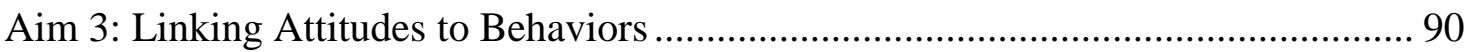

Aim 4: Client and Neighbor Comparisons ............................................................. 94 
Chapter 5. Discussion ..................................................................................................................... 97

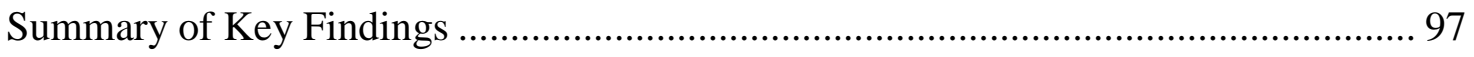

Personal Experience, Mental Health Literacy, and Attitudes ........................................ 98

Relationship Between Attitudes and Neighboring Intentions .................................... 105

Experiences of the Neighborhood as a Housing Client or Neighbor ........................... 108

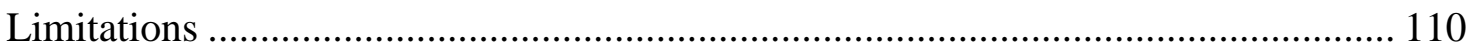

Contributions to Theory, Practice, and Policy ............................................................. 115

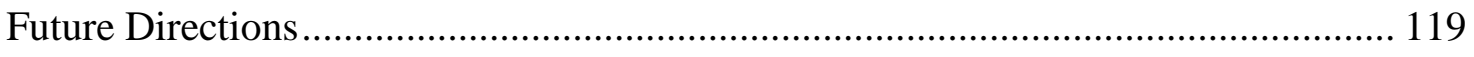

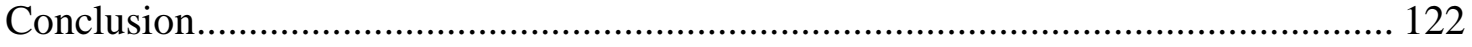

References............................................................................................................................ 143

Appendix. Measures ................................................................................................................ 156 
NEIGHBOR PERCEPTIONS OF SUPPORTIVE HOUSING

\section{List of Tables}

Table 1 NASH participant breakdown by race ……………........................................ 124

Table 2 CHARP participant breakdown by race …………………….......................... 125

Table 3 Measures: Aims 1 through 3 ........................................................................ 126

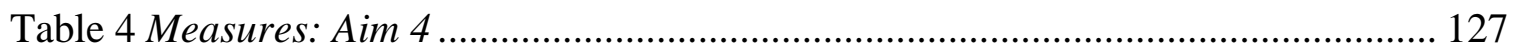

Table 5 Mental Health Knowledge Schedule (MAKS) - Part A ..................................... 128

Table 6 Mental Health Knowledge Schedule (MAKS) - Part B ..................................... 129

Table 7 All neighbors: Housing population identified .................................................. 130

Table 8 Correct identification of location by population identified ................................ 131

Table 9 Neighbor attitudes towards individuals with mental illness............................. 132

Table 10 Neighboring intentions towards neighbors with or without mental illness .... 134

Table 11 Results of paired samples t-test and descriptive statistics for $R Q 4$............... 135

Table 12 Impact on the neighborhood, including concerns and benefits ....................... 136

Table 13 Sample of participant responses to $R Q 9$ 9................................................... 137

Table 14 Suggestions for improving neighbor relations.............................................. 138

Table 15 Results of independent samples t-tests and descriptive statistics for $R Q 12 \ldots 139$ 


\section{List of Figures}

Figure 1 Publications by Category over Time ……………………............................. 140

Figure 2 Example housing site location and canvassing quadrants.............................. 141

Figure 3 Study Design …………………............................................................... 142 


\section{Chapter 1. Introduction}

Serious mental illness exacts costly social and economic tolls on individuals and communities. Recent estimates suggest that one in four adults will experience a mental health challenge at some point in their lives (World Health Organization, 2013). In a given year, $4 \%$ of the US population has a psychiatric disability - i.e., a serious mental illness that substantially interferes with major life activities (Substance Abuse and Mental Health Services Administration, 2017). Some estimates suggest that mental illness accounts for one third of global disability - that is, for all the years of life that individuals lose to ill health, disability, or early death, mental illness accounts for one third of them (Vigo, Thornicroft, \& Atun, 2016). Put in economic terms, the cost of mental illness in the US is an estimated $\$ 193.2$ billion in lost earnings every year (Insel, 2008). Personal and social costs are perhaps even higher. Individuals with mental illness die an estimated 10 years earlier than their counterparts without diagnoses (Walker, McGee, \& Druss, 2015); and those served by the public mental health system die 25 years earlier (Colton \& Manderscheid, 2006). Individuals with mental illness frequently experience stigma and discrimination, which negatively impacts their health, wellbeing, quality of life, employment prospects and income (Sharac, McCrone, Clement, \& Thornicroft, 2010). Parents, caregivers, and children share in this burden, and experience significant negative effects on their own wellbeing as a result (Mulud \& McCarthy, 2017; Stein et al., 2014). Fortunately, progress has been made in establishing interventions that promote recovery, community integration, and independence. At the forefront of these are community-based housing solutions designed to facilitate independence and offer individuals the least- 
restrictive environments possible (Wong \& Solomon, 2002). Unfortunately, these housing sites are rarely welcomed by community members, and the consequences of this discrimination only adds to the social and economic strain. Research is needed to understand when and why this discrimination occurs, and how it can be prevented.

The present study explores neighbors' knowledge about mental illness, attitudes and behaviors towards individuals with mental illness, and receptivity to psychiatric supportive housing. This work builds on prior research on stigma and discrimination towards individuals with mental illness, including the history of treatment and housing; the development of community-based housing models; the importance of both physical and social integration in housing; and the role of public policy in shaping integration outcomes. I first discuss current efforts to challenge the stigma of mental illness and improve public knowledge, attitudes, and behavior, as well is what is known about community perceptions to psychiatric housing. I then outline study aims and research questions and describe the methods used in the present study to answer them. In the final chapter, I summarize the key findings and discuss the contributions of this study to informing research, policy, and practice, as well as limitations and future directions for this work.

\section{Origins of Mental Illness Stigma and Discrimination}

Few persons and structures have been as widely discriminated against as individuals with mental illness and psychiatric housing (Dear, 1992). Studies that ask respondents to rank various human service facilities have shown that mental health housing is usually the least (Wilmoth, Silver, \& Severy, 1987) or among the least 
(Borinstein, 1992; Smith \& Hanham, 1981; Solomon \& Davis, 1984; Takahashi \& Dear, 1997) desirable of all facilities, services, and populations. A nationwide telephone survey in the United States found that far fewer respondents were likely to welcome any type of mental health facility or housing than would welcome group homes for the elderly or developmentally delayed, homeless shelters, alcohol rehabilitation centers, or drug treatment centers, among others (Borinstein, 1992). Yet, at the same time, the vast majority of people agree that there is a need to improve community acceptance of mental illness (Gaebel et al., 2002). This NIMBYism - the assertion that a service of public benefit occur 'Not In My Back Yard' - may be due in large part to the negative stereotypes associated with mental illness.

Three core stereotypes underlie the negative attitudes (or stigma) towards and resultant discrimination of individuals with mental illness: they are dangerous and to be feared; they are childlike and incapable; or are to blame for their illness (for a brief review, see Corrigan \& Watson, 2002). These attitudes translate to exclusionary, benevolent (or patronizing), and authoritarian attitudes and behaviors, all of which play a role in community attitudes towards psychiatric housing (Taylor \& Dear, 1981), and are reflected in the progression of mental illness treatments through the ages. In the middle ages in Western countries, mental illness was often thought to be caused by demonic possession or evil forces (Espí Forcén \& Espí Forcén, 2014), and the natural consequence of a moral or religious failing of the individual or their family (U.S. National Library of Medicine, 2006). The fear and blame attributed to these conditions often led to harsh authoritarian treatment, such as excommunication or desertion, and in more extreme 
cases, exorcisms or accusations of witchcraft (Høyersten, 1996). As populations grew, so too did the need for an organized method of handling the needs of individuals with mental illness and their families. The first psychiatric hospital ward in the United States opened in 1752 in Philadelphia, and featured basement rooms outfitted with shackles for restraint ( U.S. National Library of Medicine, 2006). Although they would not be considered as such today, asylums were actually the first step towards humane treatment for individuals with mental illness. They were the result of lay advocacy by individuals such as Dorothea Dix, who vigorously lobbied state legislatures and congress to create more humane treatment settings for individuals with mental illness. Asylums were seen as both benevolent institutions to house individuals who were incapable of caring for themselves or contributing to society, and also as exclusionary necessities to protect the public from the perceived danger of their unpredictable behavior. The shackles are a stark reminder that fear-based exclusionary and authoritarian treatment pervaded these institutions. By 1890, every state had at least one public asylum, housing over half a million inmates by the $20^{\text {th }}$ century (Medicine, 2006).

Deinstitutionalization. With the development of cost-saving (tranquilizing) medications and new interest in investigating the nation's mental health system, the public began to call for the closure of asylums (U.S. National Library of Medicine, 2006). In 1963, the Community Mental Health Act marked the official start of deinstitutionalization, a process intended to end the inhumane treatment in hospitals and restore individuals to life in communities (Carling, 1995). The Act's closure of the institutions left responsibility for service provision to communities, who needed funding 
to be able to supply necessary supportive services. In 1980, President Carter signed the Mental Health Systems Act mandating federal funding to community support services. This plan may have provided adequate resources to states had it not been repealed by the Reagan administration the following year. As a result, the closure of psychiatric hospitals moved individuals out into communities that were largely unprepared for and unable to afford the influx of people needing diverse services, health care and homes. Many individuals with mental illness were left homeless, with no way to pay for treatment or housing.

Significant progress has been made in the nearly six decades since deinstitutionalization began, although the gap in needed resources has never been adequately filled. Mental health care values and policy have shifted towards integrating individuals with psychiatric disabilities into the community (Carling, 1996; Fellin, 1993; Flynn \& Aubry, 1999; Mueser et al., 1998) and offering the "least restrictive environment" possible (Thornicroft, Alem, Santos, Barley, Drake, et al., 2010, p. 68). Wraparound and supportive housing programs emerged to fill the void left by deinstitutionalization and provide community-based environments that are more conducive to recovery and reintegration.

\section{Community Integration}

The goal of deinstitutionalization was to re-integrate individuals back into the community. This was partly based on the recognition that the interdependent settings in which individuals live have the ability to define their overall wellbeing and quality of 
life. Communities and community integration consist of experiences in physical and social environments that are reinforced through interpersonal relationships.

An ecological approach. Ecological systems theory argues that individuals cannot be presumed to be understood as separate from their environments (Bronfenbrenner, 1977). Individuals' ecological environments consist of the relationships between persons and their immediate setting, the interrelations between these settings, the social structures that govern immediate settings, and the overarching institutional patterns, culture, and politics influencing all other levels (Bronfenbrenner, 1977). Experiences in any given setting can impact physical and emotional health, which in turn influence perceptions of and participation in other contexts. Of these settings, community life may be particularly important to individual wellbeing because of its direct and constant influence on day-to-day experiences (Carling, 1993; Sarason, 1974). The theory of interdependence has been adapted to many settings, including community-based housing for individuals with psychiatric disabilities (Kloos \& Shah, 2009). Ecological systems theory is a foundation for research in this area because it recognizes that individuals are influenced by personal characteristics, social relationships with their neighbors, and features of their neighborhood (e.g., housing programs).

Recently, there has been a call for public health interventions to consider this interdependence between people, their health, and the physical and social environments in which individuals live and participate (Maller, Townsend, Pryor, Brown, \& St Leger, 2006). Kloos and Shah (2009) suggest that housing environments in particular should be investigated using an ecological approach that takes into account the multi-layered 
contexts in which individuals are situated. Their social-ecological framework suggests that community-based psychiatric housing environments are influenced by interpersonal relationships and the physical and social environments in which they are situated. In this framework, the physical environment is comprised of the physical quality of the neighborhood (e.g., the quality of sidewalks and availability of transportation) and the housing itself (e.g., quality of the plumbing, presence of pests, etc.). Interpersonal relationships are comprised of relationships with neighbors, landlord, and roommates; and the social environment captures perceptions of neighborhood safety and social climate (i.e., the general character of the social milieu where people live, that is a combination of customs, attitudes, and behaviors) (Kloos \& Shah, 2009).

Supportive independent housing programs - that is, independent housing (usually, apartments) with access to community support services - are widely recognized and utilized as being promotive of community integration. Community integration refers to the ability of individual with psychiatric disabilities to live successfully as participating members of their community, and is an important component of recovery (Wong \& Solomon, 2002). Community integration is comprised of physical placement and social experiences in the community. Wolfensberger and Thomas (1983) explain physical integration for individuals with psychiatric disabilities as the physical presence of individuals in ordinary settings, activities, and contexts, where individuals without mental health conditions are also present. Social integration refers to the inclusion in social aspects of community life, including neighboring, friendships, and social networks formed in the community. In theory, community-based housing provides individuals with 
psychiatric disabilities a support network of services designed to facilitate community integration. Supportive housing services usually include case management, medical, mental health, and substance abuse treatment services; peer support; parenting skills; education; vocational and employment services; money management services; and life skills training and advocacy (Community Supportive Housing, 2013). In reality, full integration is also dependent on neighbors' attitudes and behaviors towards them. Yet, while researchers have recognized the importance of integration that encompasses more than physical presence (Gulcur, Tsemberis, Stefancic, \& Greenwood, 2007; Townley, Kloos, \& Wright, 2009; Wong \& Solomon, 2002), the reality is that integrated housing concepts often still focus on physical rather than social integration (Wong \& Solomon, 2002). More recently, researchers have highlighted the importance of integration that includes more normalized social interactions (such as those that naturally occur outside of a mental health context) (Kloos \& Shah, 2009), and the need for research on effective interventions to address community participation for people with serious mental illness (SMI) (Davidson, Chinman, Sells, Rowe, \& Mckenzie, 2006). However, individuals with psychiatric disabilities continue to face significant barriers to both social and physical integration, often due to the negative perceptions held by other community members.

Social integration. The change in setting from asylums to community-based housing has done little to alleviate the social barriers that individuals with mental illnesses face - i.e., public attitudes shaped by centuries of exclusionary, authoritarian, and patronizing treatment of individuals with mental illness. Because a community consists of a physical locale as well as a social experience (Bromley et al., 2013; Ware, 
Hopper, Tugenberg, Dickey, \& Fisher, 2007), simply housing individuals with psychiatric disabilities in community settings (e.g., supportive or supported housing) is not alone sufficient to ensure that meaningful community engagement will follow. Kloos and Shah (2009) conceptualize the social environment in the context of supportive housing as the "social experiences related to community living" (p. 321), including perceptions of belonging or discrimination, as well as perceptions of safety for both self and property. Social aspects of neighborhoods can impact the functioning of people with serious mental illnesses; and poor quality social environments can have negative effects on a variety of outcomes. Conversely, positive social experiences with neighbors and others in the immediate environment have been shown to be predictive of improved wellbeing (Kloos \& Shah, 2009; Kloos \& Townley, 2011). Housing programs usually achieve the goal of physical integration, but they tend to fall short of full community integration because clients ${ }^{1}$ often remain socially isolated.

It is widely acknowledged that stigma not only deters people from seeking help for a mental illness, but also reduces treatment adherence and actually exacerbates symptoms by contributing to self-stigma and isolation (Kessler et al., 2001), which in turn make social integration in a community more difficult and less likely to occur (Granerud \& Severinsson, 2006). Individuals with psychiatric disabilities not only have fewer opportunities for community engagement (White, Simpson, Gonda, Ravesloot, \& Coble, 2010), but when these opportunities are present they face the additional burden of stigma. For example, people are unwilling to work with or befriend someone with

\footnotetext{
${ }^{1}$ Throughout this document 'client' refers to individuals living in community-based psychiatric housing, and 'neighbor' refers to individuals living in the neighborhood or community surrounding the housing site.
} 
schizophrenia (Pescosolido et al., 2010). Negative attitudes are amplified and perpetuated by harmful portrayals of mental illness in the media, popular culture, and among peer groups (Link et al., 2014). Experiences of stigma and social rejection can permeate the lives of individuals with psychiatric disabilities and create a destructive feedback loop in which rejection leads to self-imposed isolation, fewer opportunities for social support, and greater symptom distress (Kessler et al., 2001). As a result, individuals living in supportive housing report less social contact with neighbors and lower levels of life satisfaction than other community members (Aubry \& Myner, 1996); have smaller, less connected or diverse social networks, and fewer meaningful relationships; and their social networks consist more of family members and relationships formed in mental health contexts (Eklund \& Hansson, 2007; Schwartz \& Gronemann, 2009; Segal, Silverman, \& Temkin, 1997). This lack of integration and full participation in community life comes at a significant cost because individuals are missing out on important opportunities to build social support and engage in meaningful community roles. Experiences of stigma strongly predict poorer quality of life and low self-esteem (Link \& Phelan, 2014; Rüsch et al., 2014).

Community social experiences may be particularly important for individuals with psychiatric disabilities, as perceiving one's neighborhood as welcoming and tolerant is directly associated with less psychiatric distress (Kloos \& Shah, 2009). Previous studies have shown that everyday encounters with other community members in public places increased their sense of connection to the community, and that these naturally existing supports were important to individual recovery and community living (Beal Veldhorst, 
McGrath, Guruge, Grewal, DiNunzio, et al., 2005; Corin and Lauzon, 1992). Community social experiences are sometimes conceptualized as neighborhood social climate, a construct that captures perceptions of tolerance for diversity and community acceptance (Wright \& Kloos, 2009). With regard to housing environments, neighborhood social climate may be the "single most predictive" element in explaining differences in wellbeing for individuals with serious mental illness (Wright \& Kloos, 2007, p. 8), and may fully mediate the relationship between neighborhood experiences and psychiatric distress (Kloos and Townley, 2011). A positive social climate may also impact housing stability; and clients are less likely to move at 12 months if they have favorable opinions of their neighborhood and neighbors at a baseline interview (Kloos and Shah, 2009). There is also some evidence that distal supports, or casual relationships formed in the places individuals frequent in their neighborhood (i.e., baristas at the local coffee shop, pharmacists at the neighborhood drug store), may be particularly important sources of social support for otherwise isolated individuals (Townley, Miller, \& Kloos, 2013). These findings speak to the importance of examining the impact of the neighborhood social environment in and around supportive housing sites.

Physical integration. Physical integration for individuals with psychiatric disabilities refers to the development and provision of community-based care and housing. Despite being protected by international, domestic and local laws, physical integration into a neighborhood is often protested by citizens who believe they are protecting their family, property, and community. In a study of providers, nearly onethird of the housing sites they managed had encountered community resistance or 
opposition (Wenocur \& Belcher, 1990). In the United States, the Fair Housing Amendment Act of 1988 (102 Stat. 1619) prohibits housing discrimination on the basis of disability. Housing programs must often rely on the legal authority afforded by the act to counter community opposition and provide housing to their clients (Arens, 1993).

However, the resultant legal battles and delays can be extremely time-consuming and costly (Arens, 1993; Cheung, 1990). In some cases, additional local laws are needed to provide additional protection from discrimination loopholes. For example, New York State Site Selection Law was enacted to prevent neighborhoods from claiming that group homes violate residential zoning laws by defining any community residence that houses between 4 and 14 people as a single-family dwelling (Arens, 1993).

While some protective laws aid in placement, government support can still be difficult to obtain. The only study to in the last 40 years to attempt to survey all providers of psychiatric group homes in a state regarding neighbor opposition found that only 14 of 171 placement efforts in New Jersey ultimately failed, but only one received prompt and abundant support from the local government (Hogan, 1986). Local officials appear to want to stay out of the fray rather than assert support or opposition, preferring to assume a "wait and see" mindset (Graham \& Hogan, 1990, p. 519). Local government support may be particularly important to secure if a neighborhood is against the development, as local officials can act as intermediaries and reassure neighbors that their concerns are being taken into account. The support of a local official who may already be known or trusted in the community can go a long way to reassuring neighbors that the housing is not being established without oversight or regard to their community. However, 
politicians may be more likely to echo the concerns of their constituents in an attempt to gain popularity. Local government opposition is less frequent than neighborhood opposition, but in the same study of providers at least half of the housing sites (53\%) experienced initial government opposition, compared to resident opposition in $72 \%$ of neighborhoods (Graham \& Hogan, 1990).

Neighborhoods as communities. Defining the physical boundaries of a community is in many ways as complex as measuring its social interactions (Bromley, 2013; Ware et al., 2007). Perhaps for this reason, the majority of previous research on housing for individuals with psychiatric disabilities has been focused on the housing rather than the neighborhood (Metraux, Brusilovskiy, Prvu-Bettger, Wong, \& Salzer, 2012). This is a conspicuous gap in supportive housing literature, given that neighborhood experiences are likely more important to certain mental health recovery outcomes (e.g., community integration) (Metraux et al., 2012). In other fields where health disparities are also of interest, neighborhoods are an increasingly utilized unit of analysis for research, policy, and practice (Coulton, 2012). One of the earliest formalized conceptualizations of what constitutes a neighborhood was proposed in 1906 and utilized by the U.S. Census Bureau in 1910 as a way to study health services in New York City neighborhoods (Krieger, 2006). These areas, originally termed "sanitary areas" because of their utility in planning public health services, are now known as census tracts and are one of the most commonly used conceptualizations of neighborhoods, particularly when divided into smaller block group and census block units (Krieger, 2006). Census tracts were delineated because of the growing understanding of the role that neighborhood 
context plays in shaping individual and community health. While often used out of convenience, census tracts are not always the best method for defining neighborhoods. In fact, there is no one agreed upon metric for defining and bounding a neighborhood.

Resident-defined neighborhoods may be the most conceptually robust methods for analyzing resident perceptions, and could include exercises such as community mapping (i.e. residents draw their neighborhood boundaries on maps) or person-centric buffers (i.e., each individual's neighborhood is defined using digital mapping tools based on their location) (Coulton, 2012). However, these methods can be time consuming and costly. Census-defined neighborhoods may be too broad in scope, and the detail of community-mapping may come at too high a cost. A middle ground is to use Geographic Information Systems (GIS) to map pedestrian street networks, defining and bounding neighborhoods within the confines of larger street networks (Coulton, 2012). Neighborhoods then consist of walkable areas that residents could be reasonably expected to frequent without crossing over highways or major thoroughfares.

A federally released report on population health, Shaping a Vision of Health Statistics for the $21^{\text {st }}$ Century, graphically depicts population health as being encompassed by community attributes (e.g., the built environment, social attributes, and economic resources), which are encircled by the broader cultural, natural and political context (Friedman, Hunter \& Parish, 2002). This speaks to the need to understand individuals as being influenced by their neighborhood contexts, and to therefore use an appropriate level of analysis that captures the nuances of community life (e.g., the 
neighborhood level). Neighborhoods serve as physical bounds of communities in which we can study the social interactions that comprise community life.

The role of community members. Community members play an important role in shaping the social and physical environment of their neighborhood. They may contribute to the social climate of the neighborhood through relationships with others who live, work, or frequent the neighborhood and, conversely, by avoiding or discriminating against others. They may also alter the physical environment by advocating for improvements (e.g., parks or playgrounds) and protesting undesirable structures (e.g., garbage disposal sites, jails) (Heiman, 1990). While some of these activities may improve the neighborhood for those who live there, others can have serious consequences for those seeking to live or participate in the community. NIMBYism refers to the common sentiment that even while community members may see a need for a structure, such as low-cost housing or a recycling facility, they are unwilling to share the perceived burden. This sentiment is so frequent and disruptive that community developers and advocates have come up with numerous ways to describe these attitudes: NIABY (Not in Anybody's Back Yard) (Heiman, 1990), LULU (Locally Unwanted Land Use), NOPE (Not On Planet Earth), and BANANA (Build Absolutely Nothing Anywhere Near Anyone) (Takahashi \& Dear, 1997). This study investigates the important role that community attitudes and receptivity to individuals with psychiatric disabilities and supportive housing play in shaping neighborhoods and the lives of those who live in them.

\section{Combating Stigma and Discrimination}


Stigma is another name for negative stereotypes or prejudice. Stereotypes are not always pernicious; put simply, they are mental shortcuts that can used to make assumptions about virtually everyone and everything. With regards to mental illness, negative stereotypes or stigmas are "invalidating and poorly justified knowledge structures that lead to discrimination" (Corrigan \& Penn, 1999, p. 766). Mental illness stigma is comprised of three constructs: knowledge (ignorance), attitudes (prejudice) and behavior (discrimination) (Thornicroft et al, 2006). Interventions to decrease the stigma of mental illness may address one or more of these constructs. Researchers have developed scales to assess changes in each of these constructs in response to interventions, including the Mental Health Knowledge Schedule (MAKS)(Evans-Lacko et al., 2010), Community Attitudes Towards Mental Illness (Taylor \& Dear, 1981), and the Reported and Intended Behaviors Scale (Evans-Lacko et al., 2011).

Relationships between knowledge, attitudes, and behavior. If the end goal of improved knowledge and attitudes about mental illness is improved behaviors (i.e., increased integration and reduced discrimination for individuals with mental illnesses), then it is necessary to establish the linkages between these constructs and behavior change. Research suggests that lack of knowledge in a subject area is likely to be associated with negative attitudes (Griffith, Hart, \& Brickel, 2010), and in particular, lack of knowledge about mental illness is associated with negative opinions about individuals with mental illness (Simmons, Jones, \& Bradley, 2017). Another term for knowledge about mental health is mental health literacy (Bonabi et al., 2016). Incorrect views about what mental illness is, who it affects, and how it can be addressed all contribute to 
negative attitudes about individuals with mental illness (Corrigan \& Penn, 1999; Rüsch, Evans-Lacko, \& Thornicroft, 2012; Svensson \& Hansson, 2016). Conversely, increases in mental health literacy have the potential to improve attitudes towards people with mental illness (Evans-lacko et al., 2010), and improvements in attitudes may improve intended behaviors (Evans-Lacko, Henderson, \& Thornicroft, 2013).

Numerous studies have shown that behavioral intentions consistently predict future behavior (Webb \& Sheeran, 2006). In a meta-analysis of experimental conditions, a medium to large change in intention (as measured by a Cohen's $d=0.66$ ), lead to a small to medium change in behavior $(d=0.36)$ (Webb \& Sheeran, 2006). The theory of reasoned action (TRA) and the theory of planned behavior (TPB) both suggest that the best predictor of behavior is behavioral intentions, and that attitudes play an essential role in determining behavioral intentions (Azjen \& Fishbein, 1988; Cooke \& French, 2008; Montano \& Kasprzyk, 2015). In these theories, behavioral intentions are determined by an individual's attitude toward performing the behavior (e.g., how they might feel about chatting with a neighbor, and how one might feel chatting with someone with mental illness) and social norms about the behavior (e.g., while there may be social norms about engaging in pleasantries with neighbors, there may also be social norms about socializing with individuals with mental illness). The theory of reasoned action suggests assigning empirically derived weights to each of these attitudes and social norms in order to predict the likelihood of a behavioral intention. The theory of planned behavior is an extension to TRA, and suggests that perceived behavioral control also pays a role in determining behavioral intentions (e.g., whether an individual thinks they can perform the behavior) 
(Azjen, 1985). TPB is particularly relevant for health behavior interventions, where perceived control over an action may vary greatly, such as in anti-smoking campaigns or DUI prevention programs (Montano \& Kasprzyk, 2015). Meta-analyses summarizing hundreds of studies have found that the components of TRA and TPB possess strong relationships with behavioral intentions (Cooke \& French, 2008). In particular, attitudes play the largest role in predicting behavior compared to the other components of TRA and TOB (i.e. subjective norms and perceived behavioral control)(Cooke \& French, 2008). While a few researchers have called TRA and TPB misleading and called for the retirement of these theories because of the correlational nature of much of the research informing these theories (Sniehotta, Pressaur, \& Araujo-Soares, 2014; Weinstein, 2007), intervention studies continue to demonstrate the utility of these theories for effecting health behavior change for public health concerns such as condom use and medication adherence (Montanaro \& Bryan, 2014; Rich, Brandes, Mullan, \& Hagger, 2015; for Azjen's rebuttal to Sniehotta, Pressaur \& Araujo-Soares' assertion that TPB should be retired, see Azjen, 2014).

Stigma reduction interventions. The last two decades have seen an unprecedented amount of national and international attention on interventions to eliminate the stigma associated with mental illness by capitalizing on the theorized linkages between knowledge, attitudes, and behaviors (Thornicroft et al., 2016). Interventions typically rely on three types of strategies: protest, education, and contact (Corrigan \& Penn, 1999). Protest strategies include targeting those who generate or perpetuate negative stereotypes about individuals with mental illness with the intent to 
stop negative portrayals. For example, the National Stigma Clearinghouse collects and responds to negative portrayals of people with mental illness in the media (Warner, 2005). Education strategies aim to inform the public about the facts of mental illness and dispel myths based on lack of knowledge(Simmons et al., 2017). Education strategies may target the public through interventions designed to improve declarative knowledge (i.e., static facts of information stored in memory), like California's Know the Signs or England's Time to Change campaigns (Clark et al., 2013; Sara Evans-Lacko, Malcolm, et al., 2013). Often these campaigns operate under the assumption that improved knowledge will lead to positive opinions and behaviors towards individuals with mental illness (Sara Evans-Lacko, Malcolm, et al., 2013; Thornicroft, Wyllie, Thornicroft, \& Mehta, 2014).

Contact strategies have long been considered one of the most effective ways to improve intergroup relations (Allport, 1954). Contact theory, originally devised to address racial and ethnic bias and discrimination, suggests that contact with members of an outgroup can reduce prejudice when certain optimal conditions are met, including equal status between the groups in a given situation; common goals; intergroup cooperation on a task; and the support of authorities, law or social customs (Allport, 1954). Others have suggested that not all of these conditions are necessary to improve negative attitudes towards outgroups (Pettigrew \& Tropp, 2006). All things being equal, mere exposure to members of an outgroup may improve liking through increased familiarity (Bornstein \& Craver-Lemley, 2016). Contact strategies to improve the stigma of mental illness have shown improvements in behavioral intentions towards individuals with mental illness (Sara Evans-Lacko et al., 2012), and are more effective than 
education strategies for adults ( Corrigan, Morris, Michaels, Rafacz, \& Rüsch, 2012). Mental health stigma-reduction efforts are likely most effective when the contact is credible - i.e., the contact is someone who is similar in ethnicity, religion, and socioeconomic status; in a similar social or professional role; and is in recovery and living and working independently with a satisfactory quality of life (Corrigan, 2011). Many campaigns employ multiple strategies to effect change. Internationally, programs such as Time to Change and Like Minds Like Mine in the UK (Sara EvansLacko, Malcolm, et al., 2013; Thornicroft, Wyllie, Thornicroft, \& Mehta, 2014), Mental Health First Aid (Kitchener \& Jorm, 2002) and beyondblue in Australia (Jorm, Christensen, \& Griffiths, 2005), and public campaigns in Norway (Søgaard \& Fønnebø, 1995) and Germany (Gaebel et al., 2008) have resulted in varying improvements in knowledge and attitudes towards mental illness. In the United States, the National Alliance on Mental Illness' StigmaFree and California's Each Mind Matters campaigns encourage the public to talk about mental health and seek help when needed (Clark et al., 2013). Evidence from studies in other countries indicates that public attitudes have significantly improved over the last 20 years, likely as a result of public anti-stigma campaigns (Ampalam, Padma, Pratheek, \& Bukya, 2018).

While efforts are still underway to evaluate the impact of many of these campaigns, little is known about whether community knowledge, attitudes, and behaviors towards psychiatric housing and clients have shifted as well. The majority of research conducted on neighborhood attitudes towards community-based psychiatric housing was conducted prior to the $21^{\text {st }}$ century (see Figure 1), with only a few recent exceptions in 
the last decade since the majority of these public anti-stigma campaigns began (e.g. Zippay \& Lee, 2008; Zippay \& Son, 2013).

\section{Community Perceptions of Psychiatric Housing}

Research Framing and Context. The differing contexts and framing in which research on community perceptions of psychiatric housing has been conducted has resulted in often unclear and ambivalent recommendations to policymakers and developers. Studies in this field are plagued by seemingly contradictory findings that become meaningful only when they are parsed by the study design and framing. This is because studies of seemingly the same phenomenon are often addressing different questions: "What is it like living near psychiatric housing?", compared to "What do people think it would be like living near psychiatric housing?". In addition, studies of the latter question produce very different results depending on whether the housing site in question is hypothetical or impending. For example, in one study $18 \%$ of respondents believed psychiatric housing would have a negative impact on their home values; yet when asked about the actual group home in their neighborhood, only $10 \%$ felt it had a negative effect (Arens, 1993). Abstracted from reality, opinions about the impact of group homes on property values are markedly different from opinions based on actual experience. This example illustrates the classic tension between applied and basic research and suggests that to understand how communities function in the presence of existing psychiatric housing sites, research should rely on data from participants who currently live near them. 
The research included in this section is discussed as falling into three categories: research on attitudes towards hypothetical psychiatric housing scenarios (i.e., no referent housing site was specified or under consideration in their neighborhood; often, random population surveys utilizing vignettes); research on attitudes and behaviors during the time period before or in the early stages of establishing a housing site (pre-development reactions); and research on attitudes and behaviors in neighborhoods with established psychiatric housing (post-development reactions). The present study aims to understand attitudes and experiences of individuals living near extant housing sites (i.e., postdevelopment reactions). Unfortunately, much of what is known about community attitudes towards psychiatric housing comes from studies that use hypothetical questions or vignettes (Aubry et al., 1995; Borinstein, 1992; Currie et al., 1989; Gaebel, Baumann, Witte, \& Zaeske, 2002; Smith \& Hanham, 1981; Solomon \& Davis, 1984; Takahashi \& Dear, 1997; Smith \& Hanham, 1981; Wilmoth, Silver, \& Severy, 1987). Respondents are asked how they think they would feel or act in various scenarios involving living near individuals with mental illness. The problem with this method is that people are notoriously bad at predicting their own behavior, particularly when they have limited experience with the subject matter (Fowler, 1995).

Previous research on this topic has tended to cover whether respondents are aware of the housing site, and how their awareness is impacted by various physical and demographic features of the neighborhood. Studies have also looked at how demographic characteristics predict positive or negative responses to the housing. Somewhat less is known about actual social interactions between neighbors and clients, and a few findings 
are discussed in the following sections. Lastly, studies have looked at the concerns and benefits that neighbors report about living near the housing site.

Awareness. Awareness of psychiatric housing sites is generally low. Of those who live near one, typically only $13 \%$ to $27 \%$ are aware of it, depending on neighborhood type, analytic approach, and program outreach (Dear, Taylor, \& Hall, 1980; Rabkin, Muhlin, \& Cohen, 1984; Taylor, Dear, \& Hall, 1979; Zippay \& Lee, 2008). Neighbors who know about a site are significantly more likely to have resided in the area more than 10 years and be age 35 or older (Zippay \& Lee, 2008). Zippay and Lee (2008) found that awareness of a housing site was not affected by neighborhood poverty rates, density, racial diversity, or the age, race, or gender of respondents. This study also found that proximity to the housing site was not related to awareness of it, although this may be because half of the housing programs conducted extensive notification and outreach prior to development, and almost half experienced strong opposition (Zippay \& Lee, 2008). Over time as opposition decreases it is likely that attention to and awareness of the housing site will decrease as well (Arens, 1993). Dear et al. (1980) found that the primary determinant of the desirability of a facility appears to be proximity, regardless of whether respondents are aware of one nearby or not. Not surprisingly, findings suggest that respondents would much rather live further away from a psychiatric housing site, whether they know about one nearby or not (Dear et al., 1980).

It may be that even fewer respondents are aware of an actual psychiatric housing site than report knowing about one. In Rabkin et al.'s (1984) study, 13\% of people who did not live near a facility falsely reported one in their neighborhood, suggesting that 
actual awareness may be even lower than reported. In another study, $5 \%$ of individuals in the control neighborhood falsely reported a facility (Wahl, 1993). Zippay and Lee (2008) found that in addition to the $27 \%$ who said they were aware of the housing site, an additional $17 \%$ were not sure, further indicating there may be some confusion among respondents.

Demographics. Some demographic characteristics have been found to correlate with opposition to or support for psychiatric housing sites. In a random phone survey of 1,326 Americans, Borinstein (1992) found that more residents in wealthier neighborhoods said they would oppose mental health facilities than in lower income neighborhoods. Over twenty percent with an annual household income of $\$ 50,000$ and above said that their neighborhood had been involved in opposing a psychiatric facility (including group homes and independent apartments) in the last five years (Borinstein, 1992). Compared to non-suburban areas, suburbs were slightly less accepting of independent apartments and group homes for individuals with psychiatric disabilities, as well as outpatient service facilities; however, these differences were not statistically significant (Takahashi \& Dear, 1997).

A previous study of neighbors of sheltered-care facilities in the United States found that community reactions depended on political views. Liberal, nontraditional neighborhoods were the most inclusive and accepting, while conservative middle class neighborhoods were more likely to have extreme negative reactions (Segal, Baumohl, \& Moyles, 1980). In studies where housing development or siting was underway, conservative neighborhoods were more likely to strongly oppose housing sites. For 
example, a conservative community in Suffolk County, Long Island, New York vehemently opposed and delayed the purchase of a residence for individuals with psychiatric disabilities over a period of three years (Arens, 1993). In a study of siting efforts by 73 agencies to place 171 group homes, Graham and Hogan (1990) found that upper middle class neighborhoods may be better positioned to effectively oppose group homes because they have private access to elected officials. Deteriorating neighborhoods are more likely to organize opposition, but out of necessity often employ less effective protest strategies (Graham \& Hogan, 1990).

In a study of post-development attitudes, non-white neighbors were more likely to say that a housing site had a positive impact on the neighborhood (60\% compared to $42 \%$ of white neighbors; Zippay \& Lee, 2008). Arens (1993) found no differences in attitudes towards psychiatric housing between men and women. However, Taylor and Dear (1981) found gender differences in specific community attitudes towards mental illness; namely, that women tended to be more benevolent, less socially restrictive, and more supportive of community mental health ideology. Similarly, Borinstein (1992) found that American men were more likely to say they would not welcome any type of mental health facility in their neighborhood. In their study, opposers of mental health facilities were also wealthy, educated, professional, married, homeowners, living in big cities or suburbs (Borinstein, 1992). Opposers were also less likely to think anyone can become mentally ill or that people can recover from mental illness (Borinstein, 1992).

Older respondents were more likely to endorse authoritarian and socially restrictive attitudes, and less likely to endorse community mental health ideology or 
benevolent attitudes (Taylor \& Dear, 1981). In Germany, older adults were more likely to be concerned about or oppose group homes (Gaebel et al., 2002). Married and widowed individuals had more sympathetic attitudes than those who were single, separated, or divorced (Taylor \& Dear, 1981). Neighbors with children under the age of 18 had more authoritarian and socially restrictive attitudes towards individuals with mental illness, and were less benevolent or likely to endorse community mental health ideals (Taylor \& Dear, 1981). With regard to geographic differences, group homes and mental health outpatient facilities were statistically more acceptable to respondents in the Northeast and the West compared to the North Central and South census regions (Takahashi \& Dear, 1997).

Those who opposed psychiatric housing also tended to be pessimistic about the future, risk averse, competitive, and less tolerant of non-traditional lifestyles (Borinstein, 1992). Liberal respondents were more likely to be accepting of mental health facilities and half-way houses in their neighborhood than those who identified as 'middle of the roaders' or conservatives (Smith \& Hanham, 1981).

Social interaction. In vignette-based studies, potential neighbors were open to the possibility of social relationships with clients. Wolff et al. (1996b) found that $60 \%$ of respondents said they would make friends with neighbors with psychiatric disabilities (Wolff, Pathare, Craig, \& Leff, 1996b). However, this was not without reservations: $42 \%$ of neighbors said they would treat individuals with psychiatric disabilities differently and - most likely - negatively. One respondent explained, “Most probably deep down in the back of my mind I'd be frightened that they might try and attack me if I said the wrong 
thing"' (Wolff et al., 1996b, p. 195). These negative perceptions of individuals with mental illness impact the relationships that clients of supportive housing are able to develop in their communities and may impede social integration. As noted, less is known about social interactions between clients of supportive housing and their neighbors. This study aims to fill this knowledge gap with analyses of neighboring behaviors and intentions.

Social desirability effects may be of particular concern in research examining social interactions with and attitudes about individuals with mental illnesses. Currie, Trute, Tefft and Segal (1989) observe this limitation, and add that even though respondents' attitudes towards a psychiatric housing facility on their block are favorable (35\%), respondents think their neighbors would find it less desirable (18\%). Asking respondents what they think other people might think about a phenomenon is sometimes used as a way to identify respondents' concealed opinions by allowing respondents to attribute less socially acceptable attitudes to someone else. For example, the DevaluationDiscrimination Scale is a measure of mental illness stigma that attempts to get at implicit attitudes by asking respondents how they think other people feel about individuals with mental illness (Link, Cullen, Frank, \& Wozniak, 1987; Link, Cullen, Struening, Shrout, \& Bruce, 2013; Link, Yang, Phelan, \& Collins, 2004).

Concerns and benefits. A stark contrast can be seen between pre-development and post-development attitudes regarding perceived concerns and benefits of housing. Pre-development studies (i.e., those conducted with neighbors before a planned housing site opens) find starkly negative and even hostile attitudes towards the housing. 
Neighbors voice concerns about their property values, the safety of their children, and the clients themselves; they also voice resentment for their lack of choice in its development. Post-development studies, however, find few concerns or complaints.

Property values and the homeowners dream. A study of 215 families living on the same streets found that neighbors were concerned that the new housing in their neighborhood would spoil the residential feel and peace and tranquility of the area, ultimately "destroying a homeowners dream" (Piat, 2000a, p. 113) and threatening the quality of life in the neighborhood (Arens, 1993). They argued that they had "paid a certain price in order to have a certain lifestyle" (Piat, 2000a, p. 113). They believed the proximity to the housing devalued their homes, and that they would be at a loss if they attempted to sell their house (Piat, 2000a).

Many neighbors reported fearing that their property value would diminish if a group home was established, citing this as a reason for their opposition (Zippay \& Lee, 2008). This concern may be more important than ever as homeowners today are likely to have lived through the housing bubble and resultant financial crisis that peaked in the United States between 2006 and 2012. Apprehension about home values may be particularly salient to those who were affected, and homeowners may be legitimately fearful of additional depreciation. However, post-development studies show that neighbors who are aware of the housing site generally perceive no impact on property values (Rabkin et al., 1984). Robust econometric analyses have also shown that mental health housing has little to no impact on housing prices (Boeckh, 1980; Colwell, Dehring, $\&$ Lash, 2000). Further, negative effects have likely been erroneously concluded because 
housing was developed in areas where property values were already declining over time (Galster, Tatian, \& Pettit, 2004).

Concern for children. Related to the fears about crime and violence, self-reported concerns about mental health housing sites often include appeals to consider the impact on children (Arens, 1993; Cheung, 1990; Cowan, 1999). In one case, a recent high-profile murder case involving a former client had escalated concerns about the perceived danger of individuals with mental illness (Cheung, 1990). Rather than always hinging on physical safety, neighbors are apprehensive of children having any contact with clients. Neighbors express concern that children will be afraid of the clients:

'It is an unfortunate fact that the chronically mentally ill look different and behave both differently and unpredictably. There is a real risk that young and impressionable children may be frightened by contact.' (Cowan, 1999, p. 293).

One might suspect that neighbors are masking their own bias towards individuals with mental illness with the more socially acceptable trait of familial concern. However, Wolff et al. (Wolff, Pathare, Craig, \& Leff, 1996a) found that neighbors with children were eight times more likely than those without to report being afraid of people with mental illness; and they were three times more likely to object to individuals with psychiatric disabilities living in the neighborhood (17\% versus 5\%) (Wolff et al., 1996b). Attitudes were not related to a lack of knowledge about mental illness; rather, people with children were more wary of threats to their children's safety (Wolff et al., 1996b). Therefore, it may be that having children causes respondents to experience heightened vigilance and err on the side of caution at the expense of inclusiveness. 
Concern for the clients. Vocal opponents tended to frame objections as concern for clients regarding heavy traffic or poor sidewalks (Arens, 1993); lack of available support services nearby to meet the needs of the participants (Arens, 1993; Cowan, 1999); and the safety of the "vulnerable" and "disadvantaged patients" (Cowan, 1999). In one study, opponents went so far as to claim that their lack of support for the group home was because the purpose of group homes was to save money for the government and further political goals, and therefore it was not in the best interests of the clients (Piat, 2000b). Staff were accused of mistreatment, and opponents claimed that the group home was not better than being in an institution (Piat, 2000b). Opponents also suggested the group homes be located in lower-income neighborhoods, as they were concerned that the socioeconomic differences between the clients and their neighbors would hinder their rehabilitation (Piat, 2000b). Self-identified supporters and opponents alike said they thought clients were more vulnerable and would feel more secure in a hospital (Cowan, 1999; Piat, 2000b).

Secrecy and lack of choice. A frequently mentioned source of resentment and opposition in pre-development studies was that neighbors felt the housing had been dishonestly snuck into the neighborhood without their knowledge or blessing (Arens, 1993; Cheung, 1990; Cowan, 2003; Piat, 2000a; Wolff, Pathare, Craig, \& Leff, 1996c). In one study, nine out of 10 opposers interviewed felt the housing development was a "violation of their individual rights" (Piat, 2000a); further, they felt the housing program had "parachuted into the community" in a way that was "undemocratic"(Piat, 2000a). Opponents felt they had been "deprived of their right to know," and therefore formulated 
their objection as a moral issue (Cowan, 2002, p. 9). In what might be considered an ironic twist, opponents portrayed themselves as "victims of the system" who were powerless to fight back against a government that was stronger than they were (Piat, 2000a, p. 111). A few respondents in Arens' (1993) retrospective study echoed these sentiments, saying, "It's the way they [the housing providers] do it that upsets people. We don't have any say in it whatsoever" (p. 240). Neighbors were angry that the government had not given them enough information about the issue (Cheung, 1990). Respondents may be overemphasizing their anger at the apparent secrecy of the siting rather than admitting to less socially desirable attitudes. For example, in one study, even though $91 \%$ of respondents said they wanted more information about the proposed sites, only a third actually accepted the offer of educational materials (Wolff et al., 1996a).

Notification strategies. In retrospective post-development studies, housing programs were found to have used different strategies when they first entered the neighborhood, with varying impacts on neighborhood attitudes. Wenocur and Belcher (1990) reported that in a quarter of the sites they studied, neighbors were informed about the housing prior to the clients moving in; in $12 \%$ of the cases, neighbors were informed after the housing was established; and in $47 \%$ of cases, neighbors were never officially informed. They found that the likelihood of opposition was much greater when the community was informed ahead of time (Wenocur \& Belcher, 1990). Based on this information, they recommend a low-profile approach when entering a neighborhood.

In another study, less than half of programs notified the neighbors, and those that did were significantly more likely to encounter neighborhood resistance (Zippay, 2007; 
Zippay \& Lee, 2008). However, there was no relation between notification strategies or initial opposition and current opposition or support (Zippay, 2007). These findings might indicate that a low-profile approach is desirable if the end goal is to avoid initial neighborhood opposition.

However, some evidence points to the benefits of notification. Neighborhoods who were informed of the housing prior to development were more likely to perceive the effect of the housing on the neighborhood as positive (51\%), compared to $39 \%$ in neighborhoods that were not notified (Zippay \& Lee, 2008). Neighbors also dislike being left out of the development process. Wahl (1993) notes that although his study did not specifically gather data on the process of developing the group home, several neighbors gave unsolicited comments indicating that they were unhappy with the way the group home had been established. In particular, respondents felt they had not been communicated with or consulted prior to its development (Wahl, 1993). Housing providers may also elicit significantly greater support from the government when they involve elected officials in initial meetings along with local contacts (Hogan, 1986).

Purposive notification that includes an educational component may have benefits beyond countering initial opposition. Wolff et al. (1996c) evaluated an intervention in which some neighborhoods received educational materials and presentations during development, while others did not. Those in the experimental area (i.e., those who received educational materials and presentations) engaged in significantly more interactions with program staff and clients, including everything from brief contact in the street to forging friendships (Wolff et al., 1996c). They were also more likely to attend 
events at the house, know the names of the staff and clients, and visit the clients (Wolff et al., 1996c). All neighbors who said they were friends with a client found out about the home because of the intervention (Wolff et al., 1996c).

Time. In contrast to pre-development studies, neighbors rarely report concerns about psychiatric housing after it has been established in the neighborhood for some time. In one study, objections centered on abnormal behaviors that they had witnessed from clients on the neighborhood streets (Zippay \& Lee, 2008). A few neighbors felt that the proximity to the housing decreased the value of their homes (Zippay \& Lee, 2008). This opinion appears to be a minority, however, and another study found that $99 \%$ of respondents had not heard of anyone having trouble selling their home because of the housing site in their neighborhood (Arens, 1993). In a few instances of opposition, opposers were either business leaders, elected officials, or realtors, who reported disliking the characteristics of the housing clients (Wenocur \& Belcher, 1990). However, in most cases this opposition was reported to have occurred during the development phase of the housing.

More importantly, negative attitudes about housing tend to become positive over time. Longitudinal post-development studies of attitudes in the same communities show that neighbors who were previously concerned about the housing perceive no adverse effects in the long term. In one study, over a third of neighbors said they had previously held negative or strongly negative attitudes towards the housing, but a few years after development only $2 \%$ currently held negative attitudes (Arens, 1993). Positive attitudes towards the group home increased $22 \%$ - from $46 \%$ initially, to $68 \%$ after a few years 
(Arens, 1993). Another study found that post-development perceptions of housing sites were not statistically different between neighborhoods who had initially opposed it and neighborhoods who had not: in both cases, approximately half of respondents felt the housing had a positive effect on the neighborhood (Zippay \& Lee, 2008).

Altruism and diversity. In some cases, a majority of respondents (68\%) reported that they would advise a friend to support community-based housing in their neighborhood (Arens, 1993). Neighbors who supported the housing program in their community offered altruistic and practical reasons for their opinions. They tended to feel that the housing served the collective good by providing humane services for those who needed it (Zippay \& Lee, 2008). Respondents referred to housing for those in need as a moral responsibility, rather than an issue specific to their neighborhood (Zippay \& Lee, 2008). Others commented on the benefit of the housing to the community, noting: "It is an element of diversity. It is good for the kids to see" (Zippay \& Lee, 2008, p. 410).

Supporters of community-based housing tend to give practical and moral reasons for their opinions. Practical reasons for support included that there had been no problems with the housing, and also that they were supportive of good programs (Arens, 1993). Supporters of group homes endorsed a belief in the rehabilitative value of community life and that the opportunity to still lead a normal life is highly valued (Cowan, 1999). Respondents also pointed out that mental illness was universal and could happen to anyone (Arens, 1993; Cowan, 1999). Respondents were also supportive when they approved of the characteristics of the program and the clients, and in response to special efforts to solicit their support on behalf of the program (Wenocur \& Belcher, 1990). 
Supporters tended to be human service professionals, including mental health professionals and clergy, but surprisingly also included realtors, elected officials, and other neighborhood residents who organized to support the housing site (Wenocur \& Belcher, 1990).

Housing policy. Anti-discriminatory housing policies continue to be necessary to counter opposition and ensure the ability of programs to provide community-based housing. News reports frequently provide anecdotal evidence that fierce opposition continues to be a barrier (e.g., Graves, 2017), and laws and policies like the Americans with Disabilities Act (ADA) and the Olmstead Decision continue to be critical in protecting the right of individuals with disabilities to choose where they live. In the United States, the ADA (1990) requires that individuals with mental illness have the opportunity to live in the least restrictive and most integrated settings possible, as appropriate to their needs. In the Act, Congress describes the isolation and segregation of individuals with disabilities as a "serious and pervasive social problem" (42 U.S.C. § 12101(a)(2), (5)). In 1999, the Supreme Court ruled in Olmstead V. L.C. that states must have comprehensive, effective working plans for placing individuals in the least restrictive community settings, and that segregation in institutions or care homes is a violation of Title II of the ADA 42 U.S.C. § 12132. The Olmstead decision had far reaching implications for the way states were to provide community-based housing and services. Beginning in 2009, investigation by Civil Rights Division of the Department of Justice found that numerous states - including New York, New Jersey Louisiana, North Carolina, Mississippi, Florida, South Dakota, and Oregon - were in violation of this 
integration mandate (United States Department of Justice Civil Rights Division, n.d.). States incurred criticism that congregate housing models where residents are placed by virtue of a shared characteristic, such as a mental illness, are designed to segregate individuals and, therefore, share characteristics with institutions (Martone \& Lerch, n.d.). States such as Oregon negotiated agreements with the Department of Justice to restructure community-based supportive housing so that "no more than $25 \%$ of units in a building or complex [are] used to provide supported housing for tenants with SPMI [serious persistent mental illness]" (Oregon Health Authority, 2016, pg. 4). In addition, a new ruling from the Centers for Medicare and Medicaid state that in order to receive Medicaid funding, housing providers must prove they are complying with requirements to provide services in the most integrated settings possible, with regard for individual preferences and goals (2017). These changes have yet to be implemented in Oregon, and this study can serve as a baseline assessment of community attitudes towards psychiatric housing prior to restructuring of their client populations. 


\section{Chapter 2. Study Overview}

\section{Purpose}

This study explores neighbor awareness of and receptivity to psychiatric housing, knowledge about mental illness, and perceptions and behavioral intentions towards individuals with mental illness who are neighbors. It also compares client and neighbor perceptions of the same neighborhood neighborhoods. Current neighbors residing close to psychiatric housing are interviewed to understand their experiences living near supportive housing sites and interacting with the clients who live in them. Neighbor perceptions are compared to previously collected data from clients living in the supportive housing sites in the same neighborhoods in order to understand how neighborhoods may be perceived differently between stakeholder groups. A combination of quantitative and qualitative measures will be used to uniquely capture and contextualize experiences, and provide avenues for future research.

National and statewide public health campaigns are targeting the stigma of mental illness (Clark et al., 2013; Jorm et al., 2005; Kitchener \& Jorm, 2002; Thornicroft et al., 2014). These campaigns aim to produce positive changes in knowledge, attitudes, and behaviors towards individuals with mental illness. While studies have shown that acceptance of individuals with mental illness may be beginning to change (Thornicroft et al., 2016), it is unclear how these shifts in attitudes have impacted local NIMBYism and receptivity to psychiatric housing, particularly in the absence of a targeted neighborhood intervention. This study provides an analysis of knowledge, attitudes, and behaviors towards individuals with mental illness using measures common in mental health anti- 
stigma campaign research (e.g., Sara Evans-Lacko, Malcolm, et al., 2013), in order to facilitate comparisons and contextualize findings.

Researchers have approached the topic of neighbor perceptions of psychiatric housing from various angles in the decades since deinstitutionalization began, but recent changes in policy and practice have warranted an exploration of current public perceptions. In particular, new mandates in Oregon from the Department of Justice are likely to change the manner in which supportive housing is provided in communities by requiring housing sites to have no more than $25 \%$ occupants with mental illness (Oregon Health Authority, 2016). This study can serve as a baseline assessment of neighborhood attitudes towards psychiatric supportive housing during one of the last time periods in Oregon in which this housing model exclusively served psychiatric clients.

While previous studies have looked at public attitudes towards individuals with mental illness and psychiatric housing programs (Borinstein, 1992; Cheung, 1990; Currie et al., 1989), relatively few have sought out opinions from neighbors and those living in close proximity to an existing housing site. Because of this variance in methodology and sampling, results have been mixed and at times contradictory. For example, numerous studies show that members of the public frequently vehemently reject proposed housing sites (Cheung, 1990; Cowan, 2003; Piat, 2000a; Wolff et al., 1996b), and therefore some researchers recommend that housing developers adopt low-profile approaches to siting (Wenocur \& Belcher, 1990). On the other hand, other studies found that communities that received notification actually had more positive reactions to the housing (Zippay \& Lee, 2008). There is some question about the validity of vignettes and hypothetical 
questioning with participants who do not live near psychiatric housing as indicators of actual behavior. Cheung (1990) found that residents were accepting of the idea of individuals with mental illness living and participating in the community, but vehemently rejected the establishment of community-based psychiatric homes in their neighborhoods. This perfect example of NIMBYism also illustrates the difference between the hypothetical lines of questioning that often occur in basic research (for example, abstracted opinions about community mental health), and applied research on community issues in all their complexity (i.e., the reality of living near a psychiatric housing site). Rather than relying on vignettes or hypothetical questioning of individuals who do not live near a housing site, this study purposively samples from neighbors who live in close proximity to one.

Of the few studies that have sampled neighbors of existing housing sites, almost all were conducted more than two decades ago (e.g., Arens, 1993; Aubry et al., 1995; Dear et al., 1980; Taylor et al., 1979). None use the combination of quantitative and qualitative analytic measures proposed in this study. This mixed-method approach is designed to provide robust and contextualized information to improve the application and utility of the findings.

In addition to understanding how psychiatric supportive housing might be perceived by neighbors, this study compares neighbor and client perceptions of neighborhoods to understand how the same neighborhoods can be experienced differently based on social status. Even if neighbors do not report negative attitudes towards individuals with mental illness, if they internally hold negative beliefs about people with 
mental illness, their perceptions of the neighborhood social quality and climate is likely to be negatively impacted by the presence of the housing site. We might then expect that neighbors would have more negative opinions of the neighborhood than clients. In addition, even if neighbors report being supportive of the psychiatric housing and residents with mental illness, comparing measures of client and neighbor perceptions of the neighborhood social climate and neighbor relationships can help us understand if more positive attitudes correspond with improved social integration for clients.

\section{Study Aims}

The first three aims of this study are centered around understanding what neighbors know about mental illness, and what they think of and how they act towards individuals with mental illness who are neighbors. The fourth aim compares client and neighbor perceptions of individual and neighborhood social experiences to understand how these experiences may differ.

\section{Aim 1: Increase understanding of what neighbors know about mental illness, and how they feel about and act towards individuals with mental illness who are neighbors.}

Research Question 1: What do neighbors know about mental illness, and what is their personal experience with it?

This research question explores how familiar neighbors are with mental illness, and assesses their declarative knowledge of mental illness. Participants were asked to respond to items assessing whether they personally have a diagnosis; who the person closest to them with a diagnosis is; and whether they can correctly identify facts and 
fiction about mental illness. Because knowledge about mental illness may predict attitudes towards individuals with mental illness (Evans-Lacko et al., 2010), it is important to contextualize the following research questions within the framework of how familiar neighbors are with mental illness. These items have also been used in benchmarked population studies (e.g. Evans-Lacko, Malcolm, et al., 2013), and data from the present study can be compared to population distributions to understand if the sample differs in knowledge or personal experience from the average. For example, given the positive relationship between knowledge and improved attitudes (e.g. Evans-Lacko et al., 2010), elevated knowledge or experience with mental illness might help explain positive attitudes about individuals with mental illness or psychiatric housing.

Research Question 2: How aware of the housing site are the neighbors?

Participants were also asked whether they were aware of any housing facility in their neighborhood, and to identify the population they thought resided there (i.e., individuals with mental illnesses, physical disabilities, or low income). Earlier studies of this topic have looked at whether respondents are aware of the housing site, and how proximity impacts awareness (Dear et al., 1980; Rabkin et al., 1984; Taylor et al., 1979; Zippay \& Lee, 2008). Addressing this research question helps to contextualize responses, enable comparisons to prior research, and form respondent groupings for additional analyses based on correct identification of the housing site and client population. Previous studies suggest that neighbors who live closer to a housing site are more likely to be aware of it (Dear et al., 1980). I expect this finding will be replicated in the present study. 
H2. Awareness of the housing site will be associated with proximity to it, such that respondents who live closer to the housing site will be more likely to correctly identify it.

Research Question 3: What attitudes and opinions do neighbors hold about individuals with mental illness?

Central to this study are questions about how attitudes relate to knowledge and behavior towards individuals with mental illness. At the core of the theories of reasoned action and planned behavior is the idea that attitudes play an important role in shaping intended behavior (Azjen, 1985; Azjen \& Fishbein, 1988). Neighbor attitudes are expected to reflect the negative stereotypes, or stigma, associated with mental illness, and behaviors towards clients often reflect the resultant discrimination. Three core stereotypes underlie the stigma of individuals with mental illness: individuals are dangerous and to be feared; they are childlike and incapable; or are to blame for their illness (for a brief review, see Corrigan \& Watson, 2002). These attitudes translate to exclusionary, authoritarian, and benevolent (or patronizing) attitudes and behaviors, all of which play a role in community acceptance of psychiatric housing (Taylor \& Dear, 1981).

Understanding what kinds of attitudes and opinions neighbors have towards individuals with mental illness can provide information on potential areas for intervention. For example, if neighbors do not think individuals with mental illness should be cared for in community settings, this might indicate that an educational program highlighting the role of community placement in mental illness recovery might 
have positive effects. If neighbors report fearful attitudes towards individuals with mental illness, social contact interventions that allow for normalized social interactions with individuals with mental illness might alleviate these negative attitudes; alternatively, a protest strategy targeting local news stories that portray individuals with mental illness as dangerous (with the aim of eliminating this kind of reporting) might have a positive impact on these fearful attitudes.

Research Question 4: How do community members behave towards neighbors and other individuals with mental illness?

This study proposes using behavioral intentions as a proxy for future behavior, as studies have shown that behavioral intentions predict behavior (for a meta-analysis of experimental evidence, see Webb \& Sheeran, 2006). Therefore, neighboring intentions are likely to be a good indicator of actual future neighboring behaviors of those who live near a supportive housing site. Neighboring intentions have been conceptualized as being comprised of close and superficial neighboring activities (Aubry et al., 1995). A previous study using hypothetical vignettes found that while most individuals were willing to engage in superficial neighboring (such as chatting on the street or sharing information) with a client with mental illness, most were not willing to engage in close neighboring (e.g., inviting a client into one's home or going with them to a social outing) with them (Aubry et al., 1995). I expect that neighboring behaviors of those who live near a housing site will echo this finding, in that neighbors would prefer to engage in close neighboring with neighbors who do not have mental illnesses, but that they will be equally likely to 
engage in superficial neighboring with both types of neighbors (i.e., those with and without mental illnesses).

H4a: Neighbors will be equally likely to engage in superficial neighboring activities with neighbors who do not have a mental illness and neighbors who do have a mental illness.

H4b: Neighbors will be more likely to engage in close neighboring activities with neighbors who do not have a mental illness rather than those who do.

\section{Aim 2: Increase understanding of the relationship between knowledge and attitudes about individuals with mental illness who are neighbors (i.e., linking knowledge to attitudes).}

Research Question 5: Do neighbors who have personal experience with mental illness have different opinions of neighbors and other individuals with mental illness?

Neighbors who personally have a mental health diagnosis are likely to have different perceptions of individuals with mental illness than those who do not have a diagnosis, because they have direct understanding of how mental illness may or may not impact their lives. They are presumably privy to more information about at least their own mental illness than other individuals without that personal experience.

H5a: Neighbors who personally have a mental health diagnosis will have different attitudes towards individuals with mental illness than those who do not have a diagnosis.

Intergroup contact theory asserts that contact with individuals from outgroups is an effective method of promoting attitude change (Allport, 1954; Sara Evans-Lacko et 
al., 2012). Evidence suggests that strategies that promote contact with individuals with mental illness at individual and local levels are particularly effective in reducing stigma and discrimination for individuals with mental illnesses (Corrigan, River and Lundin, 2001; Corrigan, Markowitz, Watson, Rowan and Kubiak, 2003a; Yamaguchi, Mino and Uddin, 2011; Corrigan, Thompson, Lambert, Sangster, Noel, \& Campbell, 2003). Therefore, neighbors with a friend or immediate family member with a mental illness are likely to have different beliefs about mental illness by virtue of having had contact with them.

H5b: Neighbors who have a family member or friend with a mental illness will have different attitudes towards individuals with mental illness than those who do not have this relationship to someone with a mental illness.

Research Question 6: Is declarative knowledge about mental illness associated with opinions about individuals with mental illness?

Previous studies have shown that knowledge about mental illness may be associated with attitudes in the general public (Corrigan \& Penn, 1999; Rüsch et al., 2012). This study attempts to replicate these findings with a sample of neighbors who live near a supportive housing site.

H6. Declarative knowledge about mental illness will be associated with opinions about mental illness, such that those with greater knowledge will have more positive opinions. 
Research Question 7: Do neighbors who know about the housing site have different opinions of individuals with mental illness than those who do not know about the housing site?

Some neighbors may have incorrectly identified the primary population of the housing as individuals with physical disabilities or low income, because of the comorbidity of these factors with mental illness (Druss, Chair, \& Walker, 2011; Sharac et al., 2010). The phrasing of the question forces the respondent to make a determination about which of these factors is the primary purpose of the housing and does not capture whether the respondent really felt the housing could cater to a range of individuals (an assumption that would not be incorrect, due to the high co-occurrence rate of low income, physical, and mental disabilities). Earlier studies have shown that residents who live in neighborhoods with mental health facilities have more positive opinions about individuals with mental illness than those who do not have such a facility in their neighborhood (Wahl, 1993). Therefore, neighbors who correctly identified the housing site, regardless of who they thought it was for, are also more likely to have positive opinions about individuals with mental illness:

H7a: Neighbors who correctly identify the housing site will have more positive opinions about individuals with mental illness compared to those who do not identify a housing site in their neighborhood.

As noted above, earlier studies have shown that residents who live in neighborhoods with mental health facilities have more positive opinions about individuals with mental illness than those who do not have such a facility in their 
neighborhood (Wahl, 1993). This hypothesis explores whether being able to correctly identify both the housing location and the primary population as individuals with mental illness is associated with more positive opinions about individuals with mental illness:

H7b: Neighbors who correctly identify both the housing site and the population served by it will have more positive opinions of individuals with mental illness compared to those who incorrectly identify a housing site or population, or do not identify a site at all.

Research Question 8: What concerns or benefits do neighbors who know about the housing site see as a result of living near it?

Qualitative data from neighbors on the concerns they have about living near the housing site may illuminate areas for intervention for current or planned housing sites. For example, if neighbors consistently report concerns that the building is poorly maintained, this would indicate that improved building maintenance might improve neighbor perceptions of the housing site. Similarly, if housing site residents are disruptive, and little oversight is given to rowdy or noisy activities at night, this would indicate that better enforcement of housing rules and regulations would be a leverage point to improving relations with neighbors. Information about the possible benefits or advantages to living near a housing site may be useful information to highlight when bringing a housing proposal to a new neighborhood. Qualitative data have the potential to capture concepts and nuances that are missed by quantitative survey scales because respondents are not constrained to predetermined response options. For example, a closeended survey item assessing whether participants would be willing or unwilling to live 
nearby to a neighbor with mental illness tells us little about the reason behind their response. Open-ended interviews allow the participant to provide more detail about reasoning and rationale, and give the researcher more insight into their thought processes. Data from open-ended questions about what residents like or dislike about living near the housing site has the potential to corroborate quantitative results, or illuminate avenues for future research. For example, if quantitative results show that neighbors generally have very positive opinions about individuals with mental illness but qualitative reports show numerous complaints about living near the supportive housing site, this might suggest that the current measure of attitudes towards mental individuals with mental illness was not sufficiently capturing the full range of attitudes. This might call for future studies to revise or replace the measure to align more closely with opinions expressed in qualitative interviews.

Research Question 9: Do neighbors believe living near the housing site has changed their opinions about individuals with mental illness?

Neighbors in the follow-up qualitative study were asked if they felt their interactions with clients had changed how they perceived individuals with mental illness. Responses will shed more light on neighbor perceptions of supportive housing clients, and potentially capture concepts not otherwise measured by close-ended measures in this study. For example, there may be features of the clients or the neighborhood that contribute more to attitude change, such as client appearance or behaviors. If neighbors do not believe their attitudes have changed, qualitative analysis may help understand which types of attitudes are less likely to have changed (i.e., positive or negative) and 
potential factors that reinforce these beliefs. They may also reinforce existing ideas - for example, if neighbors feel that interactions have improved how they view individuals with mental illness, this may reinforce the theory that social contact reduces stigma (Corrigan, Edwards, Qreen, Thwart, \& Perm, 2001).

\section{Aim 3: Increase understanding of the relationship between attitudes and behaviors towards individuals with mental illness who are neighbors (i.e., linking attitudes to behaviors).}

Research Question 10: Do neighbors who interact more with residents of the housing site have different stigma scores?

Neighbors who interact with clients more frequently are likely to have different attitudes towards individuals with mental illness. Intergroup contact theory asserts that contact with individuals from outgroups is an effective method of promoting attitude change (Allport, 1954; Sara Evans-Lacko et al., 2012). Research on the mere exposure effect would also posits that increased familiarity through exposure increases liking of outgroup members (Bornstein \& Craver-Lemley, 2016). In addition, evidence suggests that strategies that promote contact with individuals with mental illness at individual and local levels are particularly effective in reducing stigma and discrimination for individuals with mental illnesses (Corrigan, River and Lundin, 2001; Corrigan, Markowitz, Watson, Rowan and Kubiak, 2003a; Yamaguchi, Mino and Uddin, 2011; Corrigan, Thompson, Lambert, Sangster, Noel, \& Campbell, 2003). Strategic stigma change theory suggests attitudes are more likely to change when stigma reduction 
strategies are targeted, local, continuous, credible, and focused on contact with individuals with mental illness (Corrigan, 2011).

H10: Neighbors who interact more frequently with clients will have different stigma scores than those who interact with them less frequently.

Research Question 11: What suggestions do neighbors have for improving relationships between the neighborhood residents and housing clients?

Neighbors may serve as key informants to improve community inclusion for housing site clients. Neighbors were asked if they had suggestions on how to improve relationships between housing clients and other community members. Neighbors who know they live near a supportive housing site for individuals with mental illnesses may have unique insights into what can be done to improve relationships between neighbors and clients.

\section{Aim 4: Contextualize neighbor perceptions of the neighborhood by} comparing them with housing client perceptions of the same neighborhoods.

Research Question 12: Do client perceptions of and experiences in the neighborhood differ from their neighbors' perceptions and experiences?

This final research question compares the perceptions of and experiences in the neighborhood between housing clients and neighbors. Neighbors are expected to have worse opinions of the neighborhood safety and social climate than clients. One reason for this is that previous research suggests that clients of supportive housing may overreport satisfaction with their living arrangements. In addition, some neighbors are aware of the housing site and may hold some of the more common negative stereotypes associated 
with individuals with mental illness - for example, that they are dangerous and to be feared. Their responses may reflect implicit bias against individuals with mental illness by stating that they feel the neighborhood is unsafe or has a negative social climate:

H12a: Neighbor perceptions of safety will be significantly lower than client perceptions of safety.

H12b: Neighbor perceptions of the neighborhood's social climate will be significantly lower than client perceptions of the social climate.

Individuals with mental illness tend to have fewer social relationships and be more lonely than non-clinical samples (Aubry \& Myner, 1996; Eklund \& Hansson, 2007; Schwartz \& Gronemann, 2009; Segal, Silverman, \& Temkin, 1997). Even if attitudes towards individuals with mental illness are found to be positive, a better assessment of social integration outcomes is whether client social relationships and rates of loneliness are normalized and comparable to their neighbors':

H12c: Housing site neighbors will report having better relationships with their neighbors than clients report having with theirs.

H12d: Clients will report more loneliness than their neighbors.

Another important measure of whether attitudes towards individuals with mental illness have improved in communities is clients' perceptions of discrimination. Clients are likely to perceive greater discrimination towards individuals with mental illness than their neighbors because of the salience of the experience to their lives:

H12e: Clients will perceive more stigma towards individuals with mental illness than neighbors. 


\section{Chapter 3. Methods}

The proposed research questions are addressed using data collected from two separate but related studies. First, the Neighborhood Attitudes towards Supportive Housing (NASH) study was conducted in the summer of 2016 with neighbors of supportive housing sites and is the primary data source for this study. The purpose of the NASH study is to understand neighbor experiences and perceptions of supportive housing. This study involved two phases of data collection. Phase one focused on a broad sample of neighbors from six neighborhoods and primarily collected quantitative survey information. Phase two of data collection consisted of qualitative interviews with neighbors who had correctly identified the supportive housing site in their neighborhood. Second, the Community Housing and Resident Perspectives (CHARP) study was conducted in the summer of 2013 with clients living in supportive housing sites in the same neighborhoods examined in the NASH study. This study had one phase of data collection that included a combination of closed and open-ended survey items. The participants and methods for the NASH and CHARP studies are described separately below.

\section{Neighborhood and Housing Site Selection}

Neighborhoods. The NASH neighborhoods were defined as half-mile by halfmile quadrants around each of six supportive housing sites included in the CHARP study. All of the supportive housing sites are managed by Cascadia Behavioral Healthcare $(\mathrm{CBH})$. The six neighborhoods were selected out of the total of $16 \mathrm{CBH}$ supportive housing sites in the Portland, Oregon metropolitan area for several reasons. First, they 
represented locations in three of the major residential quadrants of Portland - the northeast, southeast, and southwest (no $\mathrm{CBH}$ supportive housing sites were located in the northwest). To avoid confusion when asking neighbors about the $\mathrm{CBH}$ site in their neighborhood, we selected only those $\mathrm{CBH}$ sites in neighborhoods where there were no other known supportive housing sites, group homes, or other residential care facilities. The principal investigator checked Google maps, housing service websites, and conferred with the Vice President of Housing Services, Jim Hlava, at Cascadia Behavioral Healthcare to confirm that no other housing services were in each neighborhood. Thus, we attempted to ensure that neighbors were not basing their opinions on some other supportive housing or residential facility. During screening, we asked each participant if they knew of any housing site or facilities; if they responded affirmatively we asked them to describe in as much detail as possible the location and appearance of the building. Research Assistants were equipped with neighborhood maps, photos of the housing site, and descriptions of the building and area in order to determine if the participant was, in fact, describing the $\mathrm{CBH}$ housing site in their neighborhood. These materials were not provided to the participant, and every effort was made to protect the privacy of the $\mathrm{CBH}$ clients by neither confirming nor denying the presence of any housing site in the neighborhood during Phase 1 of data collection. Based on the participants' descriptions, Research Assistants made a determination via a hidden survey question whether or not the participant was referring to the $\mathrm{CBH}$ site. Following data collection, the Principal Investigator reviewed the housing descriptions and Research Assistant determinations to confirm whether or not each participant had correctly identified the CBH housing site. 
Housing sites. Each CBH housing site included in this study consisted of an apartment-style building. The smallest site housed nine tenants; one site housed 15 tenants; two sites housed 16 tenants; one had 20 tenants; and the largest had 46 tenants. With the exception of the largest, all housing sites were apartment-style buildings that were relatively indistinguishable from other buildings in the neighborhood. To members of the research team, the largest site was considered somewhat distinct in the neighborhood because of its relative large size, new construction exterior and institutionlike signage (e.g. "Building A" over the main lobby and signage in front indicating the name of the residential community). By comparison, the neighborhood homes were smaller single-family houses, attached two or three-unit single-story homes, or older apartment buildings. However, only about half of the neighbors interviewed in the neighborhood (15 out of 29) said they knew of a housing site, and of those only 10 correctly identified the referent $\mathrm{CBH}$ site. Therefore, the site may not be as visually distinct as it appeared to unblinded researchers.

\section{Participants}

This study draws on data from three participant samples: NASH phase one, NASH phase two, and CHARP. Participants in the NASH phase one and phase two samples were neighbors who lived near one of the six identified Cascadia Behavioral Housing sites. Phase one participants were selected based on their proximity to a housing site, and phase two participants were selected from this sample to participate in a followup qualitative study if they correctly identified the housing site (i.e., they were a subsample of phase one participants). CHARP participants were clients who lived in one 
of the six Cascadia Behavioral Housing sites. These samples are described in more detail below.

NASH phase one participants. In phase one of the NASH study, 142 residents living in six neighborhoods in Portland, Oregon were surveyed in person (i.e., face-toface) or over the phone. Two respondents were removed from the sample when it was determined they lived too far outside of the sampling frame (their home addresses were several miles from the referent housing site), and a third respondent was removed from the sample because she lived at the referent housing site, resulting in a final sample of 139. Phase one data collection began in May 2016 and extended to early October 2016, with the majority of surveys completed between June and August (77\%). Response rates in each neighborhood were between $9.4 \%$ and $17.6 \%$, based on the number of participants in each English-speaking household who completed the survey out of the total number of non-vacant, accessible units (i.e. no "no soliciting" signs) in the neighborhood. The majority of phase one participants (94\%) said they would be interested in participating in the phase two follow-up qualitative interview.

NASH phase two participants. During phase one data collection, 24 individuals correctly identified the $\mathrm{CBH}$ apartment building in their neighborhood. Of these, 22 indicated that they would be interested in participating in a follow up study. In phase two, 20 of the eligible 22 individuals were contacted, and 16 completed the phase two qualitative follow up interview (response rate of $80 \%$ ). Two individuals from the same neighborhood were ultimately not contacted for phase two because several respondents from that neighborhood had already completed the qualitative interview, and we did not 
want to overwhelm the data with interviews from a single neighborhood. Two individuals were not able to be reached because their phone numbers were no longer in service, and two did not respond to repeated phone calls or emails. The response rate of eligible participants who were contacted for phase two was $80 \%$. Phase two data collection ran from November 2016 to January 2017, with half of the qualitative interviews conducted in January and 25\% each in November and December.

CHARP participants. In the CHARP study, we surveyed 68 individuals with mental illness residing in the same six referent housing sites from the NASH study neighborhoods. Data from these 68 clients are used in the analyses described below. All 116 supportive housing clients in each of these six housing sites were invited to participate in the study via a letter that advertised a research project on resident perspectives on housing, and asked interested residents to contact the researchers via a phone number or email address (response rate of 59\%). Residents were offered \$20 in cash as an incentive to participate. Data collection ran from July 2013 to October 2013, with the majority of surveys completed in August and September (79\%).

Residents of Cascadia Behavioral Healthcare's supportive housing hold their own leases and are subject to the same local and federal laws as all rental housing in Portland, Oregon. The housing sites have Resident Service Coordinators who are employed by Cascadia and generally spend 12 to 15 hours a week on-site to help connect residents to community and mental health care services. Residents are not required to be actively utilizing mental health or substance use treatment to live in Cascadia supportive housing, but they must have a diagnosed mental health disability. Residents are allowed to request 
to transfer to a different unit within the same housing site, but transfers to other housing sites require that the individual be placed on a waiting list, which is generally quite lengthy. Resident turnover is very low. Jim Hlava, Vice President of Cascadia Housing, estimates that occupancy remains at 97 to $98 \%$ in a given year (Hlava, personal communication, April 19, 2016).

NASH demographics. NASH participants ranged in age from 19 to 87, with an average age of 47. Most (68.3\%) identified as female, and 31.7\% identified as male. The majority $(71.9 \%)$ were white and $15.8 \%$ were black (for the full breakdown by race, see Table 1). The median monthly income from all sources was $\$ 2,219$, with a range from $\$ 0$ to $\$ 15,000(M=\$ 3,061, S D=\$ 2,870)$. By contrast, the median income for Portland metro area in 2016 was $\$ 5,723$ (US Census Bureau, 2016). The vast majority of the sample (95\%) had at least a high school or GED degree; $74 \%$ had some college or a college degree. Regarding political affiliation, $56.8 \%$ were Democrats, $19.4 \%$ were “other", $15.1 \%$ Independent, $4.3 \%$ were Republican, and $4.3 \%$ declined to answer. NASH participants had lived in their home an average of 8.4 years. Approximately half owned their home (48.2\%) and 46\% rented; $5.8 \%$ said they had some other living arrangement. $27.3 \%$ had ever been homeless.

CHARP demographics. CHARP participants ranged in age from 25 to $70(\mathrm{M}=$ 49.87, $\mathrm{SD}=9.96)$. Most $(60.3 \%)$ identified as male, $36.8 \%$ identified as female, and 2 respondents identified as other (3\%). The most common primary diagnosis was schizophrenia-spectrum (26.9\%), followed by Bipolar 1 or 2 (23.9\%), anxiety (22.4\%), and major depression (17.9\%). The majority of participants were white (60.3\%); $27.9 \%$ 
were black; $4.4 \%$ were Latino; $2.9 \%$ were Native American; $2.9 \%$ were Asian; and $1.5 \%$ were some other ethnicity (see Table 2). Participants had resided in their current housing for an average of 5.2 years. In the last 6 months, $80.9 \%$ had taken psychiatric medication and $70.6 \%$ had participated in individual therapy. Slightly over one-tenth of participants $(11.8 \%)$ reported being hospitalized for a mental health reason in the last year. Most (91\%) were receiving Medicaid, and 95.5\% received food stamps. The majority of participants $(85.3 \%)$ were also receiving a housing subsidy at the time data were collected. Three-quarters (75\%) of participants had ever been homeless.

\section{Design and Procedures}

NASH. The Portland State University Institutional Review Board granted initial approval for the NASH study in January 2016. Participants were recruited from six neighborhoods around supportive housing sites for individuals with psychiatric disabilities in Portland, Oregon. Neighborhoods were defined as half-mile by half-mile quadrants surrounding a supportive housing site for individuals with psychiatric disabilities. During Phase One data collection, the research team concentrated canvassing on the inner quarter-mile by quarter-mile quadrant surrounding each site to maximize the number of participants living closest to the housing (see Figure 2, for an example). Each outer half-mile by half-mile quadrant was canvassed at least once, and inner quadrants were canvassed at least twice. The quadrants were mapped using ArcGIS, and research assistants were given copies of the maps to focus their canvassing. However, the maps were considered guidelines, and research assistants were instructed to conform to the 
natural boundaries of a walkable neighborhood. For example, research assistants did not cross over busy highways or through train yards.

Research assistants walked each neighborhood and knocked on doors to ask residents if they were interested in participating in a neighborhood research study. Research assistants left flyers at each residence advertising a "Neighborhood Attitudes Survey" conducted by researchers at Portland State University. A brief description of the types of questions, time commitment, incentive ( $\$ 25$ in cash or check), and participant requirements (residents age 18 or older) were provided, along with a phone number and email address to reach the survey team. When possible, research assistants completed interviews with participants in person using iPads.

If a resident was willing to participate but unable to complete the interview on the spot, the research assistant scheduled a time to complete the survey over the phone. The majority of surveys (110 out of 139) were completed over the phone. Some interviews were scheduled in-person, but the majority were scheduled over the phone or via email from neighbors who were responding to flyers left at their residence.

CHARP. The CHARP study also utilized cross-sectional design and survey methodology. Approval for the study was granted by the Portland State University IRB in June 2013. Data were collected in a one-on-one interview format, and participants responded verbally to survey measures administered by a research assistant who recorded responses electronically. Participants read and signed an informed consent document, acknowledging the risks involved (minimal discomfort from questions about sensitive issues) and agreeing to participate in exchange for a $\$ 20$ cash incentive. Interviews took 
around 1.5 to 2 hours to complete, and were conducted in the participants' homes or housing site common rooms. Steps were taken to ensure privacy and comfort, including only proceeding with the interview when common rooms were empty of others and participants felt ready to begin.

\section{Measures}

The following measures of knowledge, attitudes, and behavior were used in the NASH study (see Table 3). Measures used in the CHARP study are indicated by the reported internal reliability for the scale (see Table 4).

Knowledge. To assess personal experience with mental illness, participants were asked if they had every been told by a doctor that they themselves have or have had a mental illness (response options: yes or no). Social distance from someone with mental illness was assessed by asking, "Who is the person closest to you who has or has had some kind of mental illness?" (Evans-Lacko, Henderson, et al., 2013).

The Mental Health Knowledge Schedule (MAKS) was developed to measure whether participants can correctly identify major mental illnesses and distinguish them from other conditions, and measure how much participants know about mental illness. Participants are asked to say to what extent they believe schizophrenia, depression, drug addiction, stress, and grief are a type of mental illness (Evans-lacko et al., 2010; Rüsch et al., 2012). An additional 6 items assess stigma-related mental health knowledge (for example, "Most people with a mental illness want to have paid employment") (Evanslacko et al., 2010). The MAKS was not designed to function as a scale and is intended to capture multiple dimensions of mental health knowledge, and items are reported 
individually as percentages (Evans-lacko et al., 2010; Mårtensson, Jacobsson, \& Engström, 2014).

Attitudes. Two measures of attitudes about people with mental illness were used: one measure assesses personal opinions about people with mental illness, and the other asks about opinions the respondent thinks other people might hold. To assess personal opinions, this study uses 27 items from the evaluation of the Time to Change mental illness anti-stigma campaign in the UK (Evans-Lacko, Henderson, et al., 2013). Twentysix of these items are from the 40-item Community Attitudes towards Mental Illness scale (Taylor \& Dear, 1981), which was developed from the original Opinions about Mental Illness Scale (Cohen \& Struening, 1962). Items assess attitudes about fear and exclusion, tolerance, community integration, and benevolence (Evans-Lacko, Henderson, et al., 2013). It should be noted that the underlying factors of their scale differ from those assigned to the same items in the CAMI (Taylor \& Dear, 1981). In addition, the measure includes one item assessing employment attitudes included in the Time to Change evaluation (Evans-Lacko, Henderson, et al., 2013). Items are negatively phrased or negatively coded so that 1 (strong disagreement) indicates more positive attitudes about people with mental illness, and 5 (strong agreement) indicates more negative attitudes. The internal reliability for the NASH study was .89 .

Participants' opinions about attitudes other people might have about mental illness were assessed using the Devaluation-Discrimination Scale (Link, Cullen, Struening, Shrout \& Dohrenwend, 1989). The scale measures the degree to which a participant feels people with mental illness are devalued or discriminated against in 
society. Participants rate 12 statements such as, "Most people would willingly accept a former mental patient as a close friend" on a Likert scale from 1 (strongly agree) to 5 (strongly disagree). The internal reliability for NASH was .88, and .85 for CHARP.

Attitudes about psychiatric housing were assessed using items asking closed and open-ended items. Participants in the follow up qualitative NASH study were asked to describe any concerns or benefits they saw about living near the housing site; what suggestions they had to improve relationships between neighbors and housing clients; and any impacts on their perceptions of individuals with mental illness they saw as a result of living near the housing site. Qualitative interview protocols included prompts to encourage participants to describe and explain their responses in as much detail as they could, and to give examples where possible.

Behavior. Previous, current, and future stigma-related behaviors of neighbors were measured using the Reported and Intended Behavior Scale (RIBS) (Evans-Lacko et al., 2011). It was initially adapted from the Star Social Distance Scale vignettes to be used with general audiences to evaluate the outcomes of anti-stigma campaigns (Phillips, 1967; Star, 1952; Evans-Lacko et al., 2011). The RIBS contains two subscales of 4 items each: reported past or current behavior, and intended future behavior (Evans-Lacko et al., 2011). In the Reported Behavior subscale, participants answer yes or no to a series of questions such as "Are you currently living with, or have you ever lived with, someone with a mental health problem?”. In the Intended Behavior subscale, participants rank their level of agreement (from 1, strongly disagree to 5, strongly agree) with statements such as, "In the future, I would be willing to live nearby to someone with a mental health 
problem". These subscales have been used separately in previous research he measure was not originally intended to function as a scale, but the Reported Behavior Subscale has been used as a scale in previous research (Mårtensson et al., 2014). The alpha for the Reported Behavior subscale in the NASH study was .87. This measure was not used in the CHARP study.

Superficial and close neighboring intentions were measured using the Neighboring Intentions scale (Aubry et al., 1995). In the NASH study, two versions of the scale were used - one assessed neighboring intentions towards any neighbor (general neighboring intentions), and the other assessed neighboring intentions towards individuals with mental illness (mental illness specific intentions). In each scale participants rank how likely they are to engage behaviors such as "[sharing] information about home or yard care" with a neighbor (general intentions) or with a neighbor with mental illness (mental illness specific intentions). Response options range from 1, very unlikely, to 5, very likely. The internal reliability for the general neighboring intentions scale in the NASH sample was .86 , while the reliability alpha for mental illness specific neighboring intentions was .84 .

Neighborhood social context. Perceptions of neighborhood safety were measured using the Housing Environment Scale - Safety (Kloos and Shah, 2009). The nine item scale assesses perceptions of neighborhood safety, and includes items such as "How often have people had things stolen from their apartment (place, home)?" Participants indicate the frequency of crime and safety related events on a scale from (0) Never to (6) Once a day. The internal reliability for NASH was .91 and .89 for CHARP. 
Perceptions of neighborhood social climate were assessed using the Housing Environment Scale - Neighborhood Social Climate (HES-NSC) developed by Kloos et. al (2005). Participants rated 12 statements such as, "Sometimes I feel unwelcome in my neighborhood because of my ethnicity and my cultural background" on a scale from (1) Strongly disagree to (5) Strongly agree. The internal reliability for the NASH sample was .85 and .82 for CHARP.

Relationships with neighbors were measured using the Housing Environment Neighbor (HES-N) measure developed by Kloos and Shah (2009). Participants indicated their level of agreement to each of 9 statements, from (1) Strongly disagree to (5) Strongly agree. Example statements include "I can count on a neighbor for help when I need it" and "My neighbors keep an eye on my apartment when I am gone". The internal reliability for the NASH sample was .86 , and for CHARP it was .76.

Loneliness. A four-item version of the UCLA Loneliness Scale was used to assess feelings of loneliness and isolation in NASH and CHARP participants (Brusilovskiy, Townley, Snethen, \& Salzer, 2016; Russell, Peplau, \& Cutrona, 1980; Russell, 1996). Participants state whether they never, rarely, or sometimes feel left out, isolated, that there are people who really understand them, and that there are people they can talk to. The internal reliability for the NASH sample was .69 , and .81 for CHARP. 


\section{Chapter 4. Analysis and Results}

The following chapter outlines the analytic procedures used to answer the research questions outlined in Chapter 3, and presents the results of these analyses. I first discuss data preparation and screening procedures, including how missing data were addressed. I describe the preliminary analyses conducted to check for effects attributable to the different modes of data collection and explain the approach used in analyzing qualitative findings. The results of each research question are grouped according to the study aim they address: Aim 1 research question results pertain to understanding neighbors' knowledge, attitudes, and behaviors towards individuals with mental illness, independent of associations between these factors; Aim 2 research question results address questions regarding the association between knowledge and attitudes; Aim 3 results answer research questions regarding the association between attitudes and behavior; and Aim 4 results identify similarities and differences between client and neighbor perceptions.

\section{Data Preparation and Screening}

Prior to conducting quantitative analyses, data were screened for any outliers or errors in data entry. No apparent outliers or errors were found. Frequency distributions and summary statistics were examined to ensure data conforms to a plausible range of values for each variable and that the data were normally distributed. Because data were entered into an iPad during data collection, values were limited to specified options available for each survey question and therefore could not exceed the plausible range; i.e., the research assistant selected a radio button on the Likert scale to record each 
response. Data from all measures were approximately normally distributed, and therefore nonparametric tests were deemed unnecessary. In addition, the analyses in this study are t-tests and linear regressions, which are robust to assumptions of normality.

Missing data. Participants missing $25 \%$ of the data on any scale were excluded from analyses. Accordingly, only one participant was excluded from the HES-S scale score because they were missing more than 2 out of 9 responses. No other participants were excluded from scale score calculations due to missing data. The very low rate of missing data is likely due to the manner of data collection. Because surveys were conducted in-person and over-the-phone with a research assistant, most participants responded to all items and were able to ask for clarification if needed in order to provide an answer.

\section{Preliminary Analyses}

NASH participants in phase one had the option to complete the survey in person or over the phone. Preliminary analyses were conducted to determine whether differences in responses could be attributed to mode of data collection. Fisher's exact test showed no significant difference in ability to correctly identify the housing location and population whether the interview was conducted over the phone (34\%) or in-person $(43.8 \%)(p=$ .56). Likewise, independent samples t-tests showed no significant differences between mode of data collection and the responses to the majority of the outcome measures in this study. There were two exceptions in which mode of data collection did have an impact on responses. Participants who completed the survey in-person reported more positive relationships with their neighbors (HES-N) $(M=3.98, S D=0.75)$ compared to those who 
completed the survey over the phone $(M=3.59, S D=0.83), t(137)=2.30, p=.02, d=$ 0.49 . Similarly, participants who completed the survey in-person said they were more likely to engage in various neighboring activities on the Neighboring Intentions scale ( $M$ $=4.21, S D=.85)$ compared to those who completed the survey over the phone $(M=3.74$, $S D=.92), t(137)=2.50, p=.01, d=0.53$ (there were no significant differences between mode of data collection and neighboring intentions towards a neighbor with mental illness, however). It may be that neighbors who completed the survey in person (often on their front porch, in their front yard, or at their front door) were more likely to voice positive opinions about their neighbors and neighboring intentions when those neighbors were potentially within earshot. Due to concerns about statistical power and analytic complexity, the two analyses in which these variables are used will not control for this small influence of data collection mode. These measures are also less central to the aims of the study than the measures of knowledge, attitudes, and behaviors towards individuals with mental illness, which did not show differences attributable to mode of data collection. It is encouraging that the vast majority of measures in this study showed no difference in outcomes attributable to mode of data collection.

The present study employed a combination of data sources and analytic approaches to address the research questions outlined above. The methodological approach for this study was to first analyze the aggregated quantitative survey data from all neighborhoods to answer several descriptive and correlational research questions about neighborhood attitudes and inclusivity. Second, qualitative interviews were analyzed to understand common themes across neighborhoods. Finally, data from the 
NASH sample of neighbors were compared to the CHARP client sample. Research questions 1 through 7 and 10 were tested with the NASH phase 1 sample; 8, 9 and 11 were explored with the NASH qualitative follow up sample; and research question 12 compared NASH and CHARP participant responses.

\section{Qualitative Approach}

Research questions 8, 9, and 11 explored responses from the NASH qualitative follow-up study of 16 neighbors who correctly identified the housing site. Morgan (2013) recommends making a priority decision regarding whether qualitative or quantitative data will be prioritized in a mixed methods study. Broadly, this study prioritized quantitative data, while qualitative data were used as a complementary source of information in order to contextualize those findings. Quantitative data were also used to inform recruitment for the qualitative portion of the study: participants were asked to participate in the qualitative follow-up if they correctly identified the housing site in their neighborhood.

Qualitative data were explored using a relativist perspective, in which it is acknowledged that realities have multiple meanings and depend on the observer (Yin, 2014). This differs from a realist perspective which assumes that a measurable reality exists that is independent of observers (Yin, 2014). The relativist perspective more closely aligns with findings from an earlier study in which perceptions of the neighborhood were more important in predicting satisfaction outcomes for residents living in the supportive housing sites in question (Shearer, 2016). Theoretical thematic analysis, rather than inductive thematic analysis, was employed, as I sought to answer 
specific questions that are guided by existing research and theories (Braun \& Clarke, 2006).

Data were analyzed using an adaptation of the six phases outlined in Braun \& Clarke's (2006) guide to thematic analysis for psychology. These phases describe the process by which initial codes (or rough categorizations of data) are organized and assembled to identify themes (cross-cutting ideas that tell us something about the meaning of the data). During Phase 1 (familiarization with the data), I read through the data several times to develop an understanding of the material. Responses to each of the research questions were extracted and analyzed separately; each of the following processes were repeated for each research question. For example, answers to the questions, "What suggestions do you have for improving the relationships between residents of the housing site and neighborhood residents?" (Research Question 11) were extracted from each participant transcript and pasted into a spreadsheet. I read through each response several times and made notes on potential areas of interest in a spreadsheet column. In Phase 2 (generating initial codes), after reviewing and annotating all of the responses, I reread the annotations and drew out initial codes. While annotations in phase 1 mirrored participant responses and stayed true to semantic meanings, codes in phase two included some latent interpretation (while maintaining a low level of inference)(Braun \& Clarke, 2012). For example, one participant commented, "People are prejudiced. They say they aren't, but they are." Understanding that the context of the conversation was a discussion of individuals with mental illness, I coded this as Prejudice/stigma against people with MI, mirroring the participant's own language 
(prejudice) and incorporating the conceptual framework of this research (mental illness stigma).

In Phase 3 (searching for themes), the codes were sorted into themes and subthemes. Transcripts and annotations were reread to re-contextualize codes and consider the way in which codes did or did not fit together to form themes. A miscellaneous theme, Other, emerged during this stage for each research question, which was useful to capture ideas that did not fit clearly into one theme or another (Braun \& Clarke, 2012). During Phase 4 (reviewing themes), I refined the themes by collapsing categories when there was not enough data to support the theme, or split themes into separate themes when it appeared that the category was too broad. In Phase 5 (defining and naming themes), the themes were named to identify the essence of the data they contain. During this phase I also reread the transcripts to ensure names accurately captured the meaning of the transcript. Some adjustments to theme names were made; for example, the aforementioned theme was renamed to "Housing is not distinguishable; accepted neighborhood feature" to bring it closer to the participants' own words. I wrote descriptions for each theme and subtheme, specifying exactly what the theme is and what it is not.

Peer debriefing, as suggested by Lincoln and Guba (1985), was conducted at this stage to increase trustworthiness of the data. During this process I debriefed with a research assistant who had been involved in both phases of NASH data collection. I explained meanings and application of the themes and subthemes. The RA and I reread transcripts and reviewed the applicability of each theme. Any discrepancies were 
discussed, and we came to consensus. Theme applications were either confirmed or adjusted through this process. We alternated between independently coding transcripts and then comparing notes, and coding transcripts together. This process resulted in the reassignment of one code (an item coded as "Other" was discussed and found to fit well with one of the established themes), and the addition of one subtheme that I had missed. The RA also helped rename a theme that was found to not accurately capture the subtheme contents: in Research Question 11, the theme "Assimilation" was initially called "Building features" because many of the comments related to how well the building fit into the neighborhood. However, some comments also included how well the clients fit into the neighborhood; therefore, the label of "Building features" was not an accurate description. To encompass both the physical and social aspects of the fit with the neighborhood, the theme was renamed to "Assimilation". In Phase 6 (producing the report), I incorporated these descriptions into the overall research project, discussing the findings and using examples to illustrate salient themes.

\section{Results}

\section{Aim 1: Increase understanding of what neighbors know about mental illness, and how they feel about and act towards individuals with mental illness who are neighbors.}

The purpose of Aim 1 is to explore what neighbors know about mental illness and whether they have had any personal experience with it; what they know about the housing site and their perception of who the client population is; the kinds of attitudes 
and opinions they hold about individuals with mental illness; and how they intend to behave towards neighbors with mental illness.

Research Question 1: What do neighbors know about mental illness, and what is their personal experience with it?

When asked if they themselves had ever been told by a doctor or medical professional that they have a mental illness or mental health challenge, $40.3 \%$ of respondents replied affirmatively. This is higher than the current population estimate, which is that $25 \%$ of individuals will have a mental illness at some point in their lives (World Health Organization, 2013). More than half of respondents (52.5\%) indicated that the person closest to them who has or has had some kind of mental illness was someone in their immediate family (i.e., a spouse or partner, child, sibling, or parent). For others, the person closest was a friend (17.3\%), or some other family member (9.4\%). A small percentage indicated they didn't know anyone who had a mental illness (7.2\%).

Most respondents were knowledgeable about mental illness, including which conditions were or were not a mental illness. Knowledge about mental health was assessed using the Mental Health Knowledge Schedule (MAKS) parts A and B (tables 5 and 6). This scale assesses declarative knowledge regarding mental illness treatment, recovery, common myths, and conditions. Responses for each part were summed to form a total score within a possible range of 6 to 30 in which a higher score indicates more knowledge, in accordance with established guidelines for this measure (Henderson, Evans-Lacko, Flach, \& Thornicroft, 2012). The average summed score for the six statements in part A, in which respondents rated statements such as Most people with 
mental health problems want to have paid employment, was 22.94 out of a possible 30 $(S E=.26)$; for Part B, in which respondents stated the degree to which they agreed or disagreed that six different conditions were a type of mental illness, the average score was $23.19(S E=.23)$. Respondents were less knowledgeable about what advice to give a friend with a mental health problem: $64 \%$ agreed they would know what advice to give, but $18.7 \%$ neither agreed or disagreed, and $17.3 \%$ disagreed that they would know what advice to give. Similarly, although almost half of respondents (46.4\%) knew that most people with mental health problems do not go to a healthcare professional to get help, almost a third thought they did (31.1\%), and nearly a quarter were unsure (22.5\%). Almost all respondents correctly agreed or strongly agreed that depression, schizophrenia, and bipolar disorder are types of mental illnesses (79.9\%, 97.9\%, and $96.4 \%$, respectively). However, $41.7 \%$ of respondents were unable to correctly identify drug addiction as a type of mental illness, and $26.6 \%$ of these respondents disagreed or strongly disagreed that drug addiction is a mental illness. In addition, nearly a third of respondents (incorrectly) thought grief (33.1\%) and stress (31.7\%) are mental illnesses.

Research Question 2: How aware of the housing site are the neighbors?

Although a substantial percentage of participants thought they knew of a housing site in their neighborhood, few were able to correctly identify both the Cascadia housing site and the population served by it. Participants were asked if they knew of any kind of housing site intended for individuals with mental illnesses, physical disabilities, or low income in their neighborhood (see Tables 7 and 8). About half of respondents said they were aware of a housing site for one of these populations (51.8\%), and the other half said 
they were not aware of any (48.2\%). When asked who they thought the primary population might be, $40.3 \%$ of those who said yes thought it was for individuals with mental illnesses; $36.1 \%$ thought it was for individuals with low income; $15.3 \%$ said they thought it was for individuals with physical disabilities; and $8.3 \%$ thought it was for some other population. Another way to understand this is that $20.9 \%$ of the total sample indicated that housing was for individuals with mental illnesses, and $26.6 \%$ of the total sample thought it was for some other population; about half of the total sample were not aware of any housing site (48.2\%).

Next, participants were asked to name or describe the housing site to which they were referring. They were prompted for any identifying information, including cross streets and building descriptions. Research assistants entered the descriptive information into response fields on the survey, and the research team later confirmed whether respondents were referring to the Cascadia Behavioral Healthcare $(\mathrm{CBH})$ site in their neighborhood or to something else. If a respondent was aware of multiple sites, the research assistant prompted them to think of the $\mathrm{CBH}$ site without disclosing the study intent (usually by asking them to consider the closest site). About half of respondents who said they knew of a housing site correctly identified the $\mathrm{CBH}$ site (48.6\%); and $51.4 \%$ did not identify it. Altogether, about a quarter of the total sample correctly identified the $\mathrm{CBH}$ site $(\mathrm{n}=35 ; 25.2 \%) ; 26.6 \%$ said they were aware of a housing site but identified something that was not a $\mathrm{CBH}$ site $(\mathrm{n}=37)$; and, again, about half did not identify any housing $(n=67 ; 48.2 \%)$. Of those who correctly identified the housing site, 
65.7\% were correct about the housing population as well (i.e., individuals with mental illness; $\mathrm{n}=23)$, and $34.3 \%$ identified some other population $(\mathrm{n}=12)$.

As was anticipated by hypothesis 2, participants who lived closer to the housing site were more likely to be able to correctly identify it:

H2. Awareness of the housing site will be associated with proximity to it, such that respondents who live closer to the housing site will be more likely to correctly identify it.

Geographic Information Systems (GIS) proximity analysis tools were used to calculate the proximity of respondents to the $\mathrm{CBH}$ site in their neighborhood. Proximity ranged from 0.02 miles to 0.29 miles, with a mean of 0.12 miles $(S D=0.05)$. There were no significant differences across the six neighborhoods in the proximity of participants' homes to the supportive housing sites, $F(5,133)=1.97, p=.09$. An independent samples t-test found a significant positive association between proximity and identification of the housing site, such that those who correctly identified the housing site lived closer to the housing site ( $M=0.1$ miles, $S D=0.05$ miles) than those who did not $(M=0.13$ miles, $S D=0.06), t(137)=2.88, p=0.005, d=0.55$. This analysis provides support for hypothesis 2 .

Research Question 3: What attitudes and opinions do neighbors hold about individuals with mental illness?

Scores on Community Attitudes about Mental Illness items were positive on average ( $M=1.94, S D=.47$, range of 1 to 5 with 1 indicating more positive attitudes) (see Table 9). For example, $90 \%$ of respondents agreed or strongly agreed with the 
statement, "People with mental illness have for too long been the subject of ridicule". The vast majority of respondents did not feel that increased spending on mental health services was a waste of money $(95.7 \%)$, or that people with mental illness don't deserve sympathy (92.1\%); they also disagreed or strongly disagreed with the statement, "People with mental illness should not be given any responsibility" (92.8\%). In contrast to what previous literature has suggested (Arens, 1993), more respondents disagreed that locating mental health facilities in a residential area would downgrade the neighborhood (70.3\% disagreed or strongly disagreed). There were only a few items in which respondents were split on their opinions. Almost equal numbers agreed or strongly agreed (35.5\%), neither agreed nor disagreed (29.7\%), and disagreed or strongly disagreed (34.8\%) with the statement "Less emphasis should be placed on protecting the public from people with mental illnesses". For the item, "Mental hospitals are an outdated means of treating people with mental illness", the spread was similar: 37\% agreed or strongly agreed; $26.8 \%$ neither agreed nor disagreed; and $36.2 \%$ disagreed or strongly disagreed. Similarly, for the statement, "Most people who were once patients in a mental hospital can be trusted as babysitters", $28 \%$ agreed or strongly agreed, $40.3 \%$ neither agreed nor disagreed, and $31.7 \%$ disagreed or strongly disagreed.

When asked what they thought most people think about individuals with mental illnesses (Devaluation-Discrimination Scale; Link et al., 1989), responses were slightly negative on average $(M=3.37, S D=.67$, range of 1 to 5 with 5 indicating more negative attitudes). Respondents thought most people would be unlikely to hire someone with a mental illness to take care of their children, even if they were working towards recovery 
(70.1\% agreed or strongly agreed), and similarly $77.5 \%$ of respondents disagreed or strongly disagreed with the idea that most people would accept someone with a mental illness as a teacher of young children in a public school. Only $21 \%$ of respondents disagreed or strongly disagreed with the statement that "Most people think less of a person who has a mental illness" (55.1\% agreed or strongly agreed). More than half of respondents thought most people would be reluctant to date someone with a mental illness $(58.7 \%)$.

Research Question 4: How do community members behave towards neighbors and other individuals with mental illness?

Responses from the Reported Behaviors items on the Reported and Intended Behaviors Scale (RIBS) showed that almost two-thirds of respondents said they were currently living with or had ever lived with someone with a mental health challenge (65.5\%). Similarly, $64.7 \%$ said they were currently or had ever worked with (64\%), had a close friend (79.1\%), or a neighbor (64\%) with a mental health challenge.

Overall, neighbors had positive intentions regarding future behaviors towards individuals with mental illness (RIBS - Intended Behaviors). The majority of respondents were willing to work with $(84.9 \%)$ or live nearby to $(84.9 \%)$ someone with a mental health challenge. Most would continue a relationship with a friend who developed a mental health challenge (92.8\%). Fewer - but still the majority of - respondents were willing to live with someone with a mental health challenge in the future (53.9\%). This item saw the most negative responses, as $25.1 \%$ or respondents disagreed or strongly 
disagreed that they would be willing to live with someone with a mental health challenge in the future.

Neighbors were asked via the Neighboring Intentions scale (Aubry et al., 1995) how likely they would be to engage in a variety of social activities with a neighbor with mental illness. Neighbors were likely or very likely to engage in superficial neighboring activities with someone with a mental illness, such as sharing information about home or yard care (75.4\%); telling a neighbor about professional services they had used (like a mechanic or dentist) (83.4\%); offering a neighbor a ride if they needed it (72.8\%); or chatting with a neighbor on the street (89.9\%). While the majority of respondents still said they were likely or very likely to invite a neighbor with mental illness into their home $(57.3 \%)$, nearly a quarter said they were unlikely or very unlikely to do so $(24.6 \%)$ (Table 10). The majority of respondents were willing to go with a neighbor to a social outing $(61.6 \%)$, but nearly a quarter were unlikely or very unlikely to do so $(23.2 \%)$. Responses were split as to whether they would talk with a neighbor with mental illness about a personal issue ( $41.3 \%$ unlikely or very unlikely; $42.7 \%$ likely or very likely).

In addition to being asked about their Neighboring Intentions towards a neighbor with a mental illness, respondents were asked about their Neighboring Intentions towards any neighbor. Respondents were asked about superficial and close neighboring intentions.

H4a: Neighbors will be equally likely to engage in superficial neighboring activities with neighbors who do not have a mental illness than neighbors who do have a mental illness. 
A paired-samples t-test found no significant differences between superficial neighboring intentions towards any neighbor $(M=4.08, S D=.95)$ and intentions towards a neighbor with a mental illness $(M=4.19, S D=0.80), t(137)=1.83, p=.07$, indicating that hypothesis 4a was supported.

H4b: Neighbors will be more likely to engage in close neighboring activities with neighbors who do not have a mental illness rather than those who do.

A paired samples t-test found no significant differences between close neighboring intentions towards any neighbor $(M=3.54, S D=1.1)$, and close neighboring intentions towards a neighbor with mental illness $(M=3.41, S D=1.07), t(137)=1.54, p$ $=.13$. This hypothesis was not supported.

\section{Aim 2: Increase understanding of the relationship between knowledge and attitudes about individuals with mental illness who are neighbors (i.e., linking knowledge to attitudes).}

The purpose of Aim 2 is to understand how knowledge about and personal experience with mental illness might be associated with attitudes about it. Research questions address whether personal experience, declarative knowledge, and awareness of the housing site are associated with different attitudes about individuals with mental illness. Information from the phase two qualitative follow up with neighbors who identified the housing site provides information about perceived concerns and benefits to living near the housing site, including the overall impact of the housing on the neighborhood; and whether neighbors themselves believe that living near mental health clients has changed their attitudes or opinions about mental illness. 
Research Question 5: Do neighbors who have personal experience with mental illness have different opinions of neighbors and other individuals with mental illness?

H5a: Neighbors who personally have a mental health diagnosis will have different attitudes towards individuals with mental illness than those who do not have a diagnosis.

An independent samples t-test found no difference in Community Attitudes about Mental Illness scores between those who had a mental health diagnosis $(M=1.98, S D=$ $.56)$ and those who did not $(M=1.93, S D=0.41), t(137)=.608, p=.54$. Similarly, there were no differences between what respondents with a diagnosis thought others thought about individuals with mental illness (Devaluation-Discrimination scale) $(M=3.47, S D=$ $0.62)$ and respondents without a diagnosis $(M=3.3, S D=0.7), t(136)=1.4, p=.17$. Hypothesis 5a was not supported.

H5b: Neighbors who have an immediate family member or a friend with a mental illness will have different attitudes towards individuals with mental illness than those who do not have more distal relationships to someone with a mental illness.

Respondents were asked who the person closest to them was that had a mental illness or mental health challenge. Responses were grouped into whether the respondent was an immediate family member (sibling, parent, child), spouse or partner, or friend, or whether they were an extended family member (grandparent, cousin, etc.) or someone else. An independent samples t-test found that individuals who had an immediate family member or friend with mental illness had more positive opinions about individuals with mental illness $(M=1.89, S D=0.4)$ compared to those with more distant relationships $(M$ 
$=2.18, S D=0.66), t(137)=-3.11, p=.002, d=0.51$, providing support for hypothesis

$5 b$.

Research Question 6: Is declarative knowledge about mental illness associated with opinions about individuals with mental illness?

H6. Declarative knowledge about mental illness will be associated with opinions about mental illness, such that those with greater knowledge will have more positive opinions.

The Mental Health Knowledge Schedule (MAKS) Part A has been used as a measure of mental illness-related knowledge in numerous population benchmark studies and as an outcome measure for interventions designed to improve knowledge about mental illness (Sara Evans-Lacko, Malcolm, et al., 2013; Sara Evans-Lacko, Henderson, et al., 2013; Henderson et al., 2012). While it's reliability as a scale is relatively low with this sample (Cronbach's $\alpha=0.5$ ), it remains currently one of the best measures available for assessing mental illness related knowledge. A simple linear regression was calculated to predict mental illness stigma (CAMI) scores based on knowledge about mental illness (MAKS Part A). Knowledge reported on Part A was significantly negatively associated with opinions about individuals with mental illness on the CAMI $(\beta=-.56)$, such that individuals with more knowledge reported lower CAMI scores (the CAMI is negatively coded, so that lower scores indicate less stigma), $F(1,137)=63.83, p<.001$, with an $R^{2}$ of .31. This analysis provides support for hypothesis 6 . 
Research Question 7: Do neighbors who know about the housing site have different opinions of individuals with mental illness than those who do not know about the housing site?

H7a: Neighbors who correctly identify the housing site will have more positive opinions about individuals with mental illness compared to those who do not identify a housing site in their neighborhood.

Neighbors who correctly identified the CBH housing site in their neighborhood $(M=2.11, S D=.61)$ had significantly lower opinions about individuals with mental illness than those who did not correctly identify the housing site $(\mathrm{M}=2.11, \mathrm{SD}=.41)$, $t(137)=-2.44, p=.02, \mathrm{~d}=0.23$. Hypothesis 7 a was not supported.

H7b: Neighbors who correctly identify both the housing site and the population served by it will have more positive opinions of individuals with mental illness compared to those who incorrectly identify a housing site or population, or do not identify a site at all.

Neighbors were categorized into two groups: those who correctly identified the location of the $\mathrm{CBH}$ housing site in their neighborhood and also correctly identified the population as individuals with mental illness, and those who did not identify a housing site or incorrectly identified the population. An independent samples t-test found no difference in opinions about individuals with mental illness between neighbors who correctly identified the $\mathrm{CBH}$ housing site and the population $(M=2.03, S D=0.66)$ and neighbors who did not identify the housing site or incorrectly identified the population 
$(M=1.88, S D=0.42), t(64)=-1.13, p=.26$, indicating that hypothesis $7 \mathrm{~b}$ was not supported.

Research Question 8: What concerns or benefits do neighbors who know about the housing see as a result of living near it?

Respondents were asked what, if any, impact they thought the housing site had on the neighborhood and prompted to suggest concerns or advantages to living near it. Responses were coded for themes as well as valence (i.e., negative, neutral, or positive; see Table 12). Almost all respondents had positive things to say about the housing site or the residents (14 out of 16 respondents). One person only had negative comments, and one person perceived the housing as completely neutral and having no impact.

Positive comments were grouped into three major themes and six subthemes. Of these, the most common theme was that respondents felt the housing was in line with their Community Values of integration, housing for all, and the importance of diversity (9 respondents). Of these, six were Glad They Have a Home, commenting, "Well, just the fact that they have somewhere to go is really good, you know" and "it's nice to know that there are such facilities in the community". Three valued that the housing and clients Increased Diversity and aligned with their values of Integration. As one respondent commented, "To see people with different abilities...just more integration in a wider community. And Portland is becoming less and less integrated. So it's sort of nice to have a variety of people". The other most common theme was that the Building and Clients are Good Neighbors $(\mathrm{n}=9)$. Within this theme were the subthemes that the building and clients were Well-Managed $(\mathrm{n}=3)$, Good Neighbors $(\mathrm{n}=5)$, and Fit In and 
are Not Disruptive $(\mathrm{n}=5)$. Those who thought the housing was well managed commented that it was "well maintained... it must be well directed". Respondents seemed to greatly value that the building and clients Fit in and were Not Disruptive. As one respondent summed up,

They fit right into the neighborhood... I've never really seen that many people going in and out of the building. There aren't a lot of cars in their parking lot. And it's like I said, they blend into the neighborhood. You don't really even pay any attention to them because there are never any problems.

Similarly, a respondent commented, “It doesn't get a lot of attention, which is probably helpful. You know, it's not singled out as, oh, 'that place'. It's like, oh yeah, back in there, there's this... You know, and it's a very welcoming looking place." Those who thought the clients and building were good neighbors also tended to touch on the ideas that the housing site and clients were Well-Managed and were Not Disruptive, hence the naming of the overall theme (Building and Clients are Good Neighbors). Respondents tended to think that this combination of good management and quiet, unassuming friendliness were the makings of good neighbors:

They're great neighbors as far as I'm concerned, because they're just... They're quiet. And they keep to themselves. And you'll see people out walking. And if you say hi to them, they say hi back... those are the kinds of neighbors that you'd like to have.

The third positive theme was a catchall category for comments in which respondents said they had no concerns, or voiced some other positive comment (No Concerns/Other). The majority of respondents indicated they had no concerns or perceived some other advantage or benefit to having the housing site in the neighborhood $(\mathrm{n}=10)$. The subthemes were No Concerns $(\mathrm{n}=6)$ and Other $(\mathrm{n}=2)$. A comment that indicated the respondent had No Concerns was considered a positive comment if the 
respondent also indicated in some way that the reason they had no concerns was because their experience had been so positive. For example, when asked if they had any concerns, one respondent replied, "No, I'm counting on whoever's keeping it well run, and organized and controlled to continue doing that". In this case, the "No" was coded as a positive No concern because it was in response to a direct question about whether the respondent had any concerns. "I'm counting on whoever's keeping it well run, and organized and controlled to continue doing that" was coded into the theme of Building and Clients are Good Neighbors and the subtheme of Well-Managed. Other examples of No Concern comments included, "None at all, because it's been enough years that we can see they are not a problem". Other positive comments included that it was, " $a$ wonderful thing".

The majority of respondents also reported that the housing had an overall minimal or almost no impact on the neighborhood. They perceived the house as having No Impact $(\mathrm{n}=11)$. There was some slight variation in these comments: the majority of respondents indicated that it had no impact and went unnoticed in the neighborhood $(\mathrm{n}=$ 9), and some felt there was no advantage to it but also nothing to be concerned about, resulting in an overall neutral impact $(\mathrm{n}=5)$.

Fewer than half of the respondents had negative comments regarding the impact of the housing on the neighborhood $(n=6)$; all but one of these respondents also had positive things to say about it. Responses fell into the major themes of Concerns about Safety and Crime $(\mathrm{n}=4)$, Disruptive Impact $(\mathrm{n}=4)$, and Other $(\mathrm{n}=1)$. Of those concerned about safety and crime, three associated the housing with homelessness in the 
neighborhood. Two of these respondents were from the same neighborhood and separately described similar incidents in which they believed individuals had been evicted from the housing site and ended up living on the street outside the housing site. Rather than specific concerns or fears related to safety and crime, residents reported general feelings of unease or discomfort. As one neighbor put it:

Sometimes when I walk by I might feel little funny, if there's a bunch of people kind of together outside... Like I don't feel like they're going to jump me or anything like that. But it just makes me go, 'oh!' you know, 'I didn't know this was the neighborhood I was moving into'.

Another neighbor commented that their only concern was for the discomfort of the neighborhood children, whose school bus stop was near the housing site:

The only thing that I didn't like sometimes is that the children that go to school have bus stops that are outside of the building. And some mornings when someone is in crisis they would have little children going to school. They don't understand it. A lot of times the kids retreated to come back to the houses because they were afraid, you know, because they hadn't encountered people with mental health breakdowns. So some refused to stand at the bus stop or get on the school bus.

Those whose comments indicated they felt the housing had a Disruptive Impact on the neighborhood mentioned an increase in traffic ("Maybe just the whole lots of cars coming and going, you know? More traffic"); the presence of emergency vehicles ("The ambulance, the police, the fire engines, it's pretty busy, you know"); and unusual or disruptive behaviors ("Sometimes there is kind of like people doing weird stuff out there, like yelling a lot or something like that"). There was one Other comment in which a respondent felt there was definitely no benefit to living near the housing site, and that there was no one who lived there that she would want to associate with. 
Research Question 9: Do neighbors believe living near the housing site has changed their opinions about individuals with mental illness?

This question was analyzed slightly differently than questions 8 and 11. During the interview, the respondents were asked a series of questions to understand whether living near the housing site had influenced their opinions of people with mental illness, and rather than removing this context and analyzing the transcript in aggregate, it was useful to view responses in relation to each prompt. To do so, I created a table where each row was a prompt or question and each column was a respondents' coded reply. Coding followed the same process described in the beginning of this chapter, but the result was a matrix of codes rather than a list of codes and tallies. Color coding assisted in understanding the valence of each code at a glance (i.e., whether their opinion had changed for the better or worse). The benefit of this approach was being able to see at a glance the range of responses and follow a participant's responses through each question (for a sample of participant responses in this format see Table 13).

One-quarter of respondents $(n=4)$ reported feeling that living near the housing site had changed their opinions about people with mental illness. Of these, only one person indicated he had a more negative opinion now; the others felt they had become more sensitive to the needs of people with disabilities; they wanted to find a way to help now; and were more aware of their prejudice because the clients seemed so "normal". The majority felt their opinion had remained unchanged $(n=12)$.

When asked whether they thought their opinions about people with mental illness were more based on their experiences living near the housing site or from some other 
personal experience or factor in their life, the majority of respondents indicated their opinions were based on experiences in their professional lives $(n=10)$. Respondents indicated they were social workers, nurses, food stamp case workers, caregivers for individuals with disabilities, or in some other social assistance profession. Seven individuals also indicated their opinions were more based on personal experiences with mental illness (i.e., having a friend or family member with a diagnosis, or personally having a diagnosis or disability). Two respondents indicated their opinions were likely a mix of personal experiences and living near the housing; of these, one individual felt they had become more sensitive to the needs of individuals with disabilities. One person said his (negative) opinion was from interaction with the residents, whom he believed engaged in drug use and homosexual intercourse (of which he disapproved). One individual was unsure what her opinion was based on, as she had had no personal experience with mental illness or interaction with the residents.

Participants were also asked if they thought individuals living in the housing site were likely to be similar or different from other individuals with mental illness (i.e., those not living in a housing site). The majority of respondents thought individuals in the housing site were probably different from others with mental illness $(n=11)$; of these, six thought they were likely to be higher functioning than other individuals with mental illness. Some based their opinions on observations that the clients appeared, "lucid. They're...You know, they're social.... They know appropriate behaviors. They're normal." One respondent commented, "I mean it's a selective community that's very well managed. And I'm guessing that... you know, they live independently. On some level, 
they must because they're very much in and around the community." One respondent thought they may be different because, "they are maybe aware of their illness. And they are taking initiative to get help. Whereas some people aren't doing that."

On the other hand, four respondents thought they were likely to be different from others with mental illness because they were lower functioning, with comments such as, " $I$ figure they keep the ones that are really off there." One person noted:

I think that the reason there's a difference is because the people that are living in a group home like that, it seems to me that they are less capable of being able to take care of them in their own home. Whereas other people with mental illness can still fend for themselves.

Five respondents suggested that the clients in the housing site likely received more support than others with mental illness. As one respondent put it, "They probably have more help. They probably have a lot more resources, if they're living there".

\section{Aim 3: Increase understanding of the relationship between attitudes and behaviors towards individuals with mental illness who are neighbors (i.e., linking attitudes to behaviors).}

The purpose of this aim is to understand the association between attitudes and behaviors towards individuals with mental illness. Research questions address whether the frequency of interaction with housing clients is associated with differences in stigma scores, and whether neighbors have any suggestions for improving neighborhood relations with clients.

Research Question 10: Do neighbors who interact more with clients of the housing site have different stigma scores? 
H10: Neighbors who interact more frequently with clients will have different stigma scores than those who interact with them less frequently.

Neighbors who said they knew of a housing site in their neighborhood were asked how frequently they interacted with the residents from it. Only those participants who knew of a housing site and correctly identified the population as individuals with mental illness were included in the following analysis. Participants were asked whether they interacted with the clients daily or weekly, or whether they interacted with the clients monthly, yearly, or less than that. Because of the unequal differences between response items (e.g. the difference between daily and weekly compared to the distance between weekly and monthly), participants were grouped according to whether they interacted frequently (defined for these analyses as daily or weekly) or infrequently (monthly, yearly, or less than that). An independent samples t-test found no significant differences in attitudes towards individuals with mental illness (e.g., CAMI scores) between neighbors who interacted more frequently $(M=2.17, S D=0.87)$ and neighbors who interacted less frequently $(M=1.92, S D=0.39), \mathrm{t}(33)=1.13, p=.27$, indicating that hypothesis 10 was not supported.

A post-hoc independent samples t-test suggests there might be differences in willingness to live with someone with mental illness in the future between those who had previously lived with someone and those who had not, such that those who had lived with someone with a mental illness before were more willing to do it in the future $(\mathrm{M}=3.59$, $\mathrm{SD}=1.05)$ than those who had not $(\mathrm{M}=2.81, \mathrm{SD}=1.16), t(137)=4.01, p<.001, d=$ 
0.7. These findings suggest that social contact plays an important role in behavioral intentions towards individuals with mental illness.

Research Question 11: What suggestions do neighbors have for improving relationships between the neighborhood residents and housing clients?

Four main themes of suggestions developed out of participants' responses to the question "What suggestions do you have for improving the relationships between residents of the housing site and neighborhood residents?": Awareness and Education, Social Interaction with Residents, and Assimilation (see Table 14). In addition, some responses were grouped into the themes of Nothing (participants did not think anything could be done to improve relationships) and Other (miscellaneous suggestions to improve neighbor relations). Three-quarters of respondents suggested some form of Awareness and Education intervention to improve relationships (12 out of 16 respondents), including educating neighbors about mental illness ( 9 respondents suggested this), informing the neighborhood about the housing $(\mathrm{n}=5)$, and directly addressing concerns and fears $(\mathrm{n}=$ 3). Others acknowledged that prejudice against individuals with mental illness exists ( $\mathrm{n}=$ 3), and a few said they would have preferred to know that the housing existed in the neighborhood before they bought their home $(\mathrm{n}=2)$. Both of these respondents indicated it would not have changed their decision to buy their home.

A majority of respondents (11 out of 16) had suggestions that pertained to Social Interaction with Residents. Over half of these respondents suggested that neighbors should engage in informal pleasantries with housing site clients $(n=6)$, including greeting them in passing or chatting on the bus. Some preferred the idea of an organized 
neighborhood social event, such as a block party $(n=4)$. In these individuals there seemed a nostalgia for neighborhoods where they had lived previously or grown up in, in which neighbors got together socially. However, others felt that there should not be any contrived or forced social interaction $(n=4)$, like an open-house where housing clients might feel as though they were on display: "I wouldn't expect the group home to put a big sign out on the door saying, you know, 'neighborhood meeting or coffee social or whatever, come and meet our residents and employees', like specimens to be examined." They also suggested that it was presumptive to assume that housing clients wanted interaction with their neighbors any more than any other person might. Several neighbors also commented that in their neighborhood most people kept to themselves, including the housing clients $(\mathrm{n}=5)$. Here, too, there was a sense of nostalgia for a time when people knew their neighbors:

In this day and age, I guess, and I blame it on computers and cell phones, there's not a lot of neighborliness. I grew up in an area, you know, with a two-block long street, homes side by side, where everybody knew everybody... You knew their kids. You kind of knew their routine. And this particular section, at least, of town that doesn't happen.

Others suggested that if the housing clients consistently showed appropriate social behavior, this would go a long way in gaining the trust and acceptance of their neighbors $(\mathrm{n}=2)$ :

I think probably good behavior. ... Those residents, those people who are out walking out and about, I think them knowing how to be social in an appropriate way. So if they were to get training and guidance so that the neighbors would trust and respect them for what they are, I think that would help.

The other main theme pertained to Assimilation. Neighbors felt the building and the clients fit in well in their neighborhood. Five of the 16 respondents had suggestions 
based on their positive appraisal of the housing site in their neighborhood. They indicated that having the housing blend in to the neighborhood and be indistinguishable without identifying signage $(n=3)$, as well as well managed and maintained $(n=2)$, helped to increase its acceptance in the neighborhood: "Keeping the place in good repair and clean, which they do a pretty good job, I think that says a lot to the neighborhood." Some neighbors were of the opinion that Nothing could be done to improve neighbor relations $(n=3)$, either because the city officials already had their hands full with other problems; because attitudes and behavior are often shaped in childhood and unlikely to change; or because neighbors generally stay to themselves and were unlikely to want to socialize with anyone (housing resident or anyone else):

I don't know that there's any way to do that [improve neighbor relations]. This particular part of [the neighborhood] that I live in, it's not very cohesive. There's not a lot of interaction. The people seem to stay pretty much to themselves. We've been through hell for the last three years with the campers and the subsequent theft and things that have been going on with the campers on the [bike path]...And that didn't even bring most of the neighbors together.

Several responses fell into a miscellaneous Other category $(n=7)$, because they did not appear to naturally fit within the other themes and were only mentioned once. These suggestions included addressing language barriers in the neighborhood that might be preventing community cohesion; that neighbors should not even try to talk to the clients; and that clients may have self-imposed barriers, such as a lack of confidence, that are preventing them from engaging with their neighbors.

Aim 4: Contextualize neighbor perceptions of the neighborhood by comparing them with housing client perceptions of the same neighborhoods. 
The purpose of Aim 4 is to compare the experiences of housing clients and their neighbors and identify where similarities and discrepancies exist. The overall purpose of this study is to inform social integration research. Because social experiences are subjective, it is important to establish whether neighbor perceptions of the social environment correspond with client experiences. Hypotheses in this section address whether clients and neighbors differ in their perceptions of neighborhood safety, social climate, relationships with neighbors, loneliness, and community stigma towards individuals with mental illness.

Research Question 12: Do client perceptions of the neighborhood differ from their neighbors' perceptions?

The following hypotheses were tested using independent samples t-tests to compare differences in dependent variables between neighbors from the NASH study and supportive housing clients from the CHARP study. Results are shown in Table 15.

H12a: Neighbor perceptions of safety will be lower than client perceptions of safety.

An independent samples t-test showed that NASH neighbor scores on the Housing Environment Ratings Scale - Safety scale $(M=4.03, S D=1.41)$ were significantly lower compared to client scores $(M=4.76, S D=1.26), t(202)=3.58, p<$ $.001, d=0.63$. These results support the hypothesis that neighbor perceptions of safety are lower than client perceptions.

H12b: Neighbor perceptions of neighborhood social climate will be significantly lower than client perceptions of neighborhood social climate. 
An independent t-test did not support the hypothesis that neighbors had different perceptions of the neighborhood social climate $(M=3.93, S D=0.71)$ compared to clients $(M=3.8, S D=0.61), t(205)=-1.33, p=.19$.

H12c: CHARP participants will report worse relationships with their neighbors than NASH participants.

An independent samples t-test showed that NASH neighbor scores on the Housing Environment Rating Scale - Neighbor Relationships scale $(\mathrm{M}=3.67, S D=$ 0.82) were not significantly different from CHARP client scores $(\mathrm{M}=3.49, \mathrm{SD}=0.83)$, $t(205)=-1.47, p=.14$, indicating that this hypothesis was not supported.

H12d: Clients will report more loneliness than their neighbors.

Results from an independent samples t-test supported this hypothesis. Clients reported significantly more loneliness $(\mathrm{M}=2.13, \mathrm{SD}=0.81)$ than their neighbors $(\mathrm{M}=$ $1.9, \mathrm{SD}=0.61), t(102)=2.04, p=.04, d=0.32$

H12e: Clients will perceive more community stigma towards individuals with mental illness than neighbors.

Results from an independent samples t-test did not support the hypothesis that clients $(\mathrm{M}=3.43, \mathrm{SD}=0.67)$ perceived more stigma towards individuals with mental illness (Devaluation-Discrimination scale) than their neighbors (M 3.36, SD =0.68), $t(132)=0.71, p=.48$. 


\section{Chapter 5. Discussion}

This mixed-methods study aimed to investigate the important role that community attitudes and receptivity to individuals with psychiatric disabilities and supportive housing play in shaping neighborhoods and the lives of those who live in them. The preceding chapters described previous research on knowledge, attitudes, and behaviors towards neighbors and clients with mental illnesses; identified research questions to address in the present study; outlined a methodological approach for answering these questions; and described the results of these analyses. In the following chapter, I summarize the key study findings; interpret results and situate them within the broader literature; consider the study limitations; and describe this study's contributions to theory and practice.

\section{Summary of Key Findings}

This study found that a large proportion of neighbors had personal experience with mental illness, and neighbors were knowledgeable about mental health facts and diagnoses. In addition, mental health literacy was associated with more positive attitudes towards individuals with mental illness. Neighbors who had a friend of family member with a mental illness also had more positive attitudes than those who did not have a close relationship to someone with mental illness. Neighbors who correctly identified the housing site had more negative opinions of individuals with mental illness than those who did not identify the site; however, neighbors who both correctly identified the housing site and population as clients with mental illness did not have different opinions of individuals with mental illness. Neighbors were equally likely to engage in 
neighboring activities, regardless of whether the neighbor in question had a mental illness diagnosis or not. Frequency of interaction with clients was not associated with any changes in opinions about individuals with mental illness; and qualitative findings suggest that most opinions were formed through other personal experiences rather than interactions with housing clients. Finally, neighbors and clients had similar perceptions of the neighborhood social climate, relationships with their neighbors, and community stigma towards individuals with mental illness. However, neighbors perceived the neighborhood as being less safe than clients; and clients were lonelier than their neighbors. In the following sections I interpret these study findings and discuss how they inform our understanding of community members' knowledge, attitudes, and behaviors toward clients with mental illness, as well as their receptivity toward supportive housing sites.

\section{Personal Experience, Mental Health Literacy, and Attitudes}

Although estimates suggest that one in four people experience a diagnosable mental illness in their lifetime (World Health Organization, 2013), two-fifths of this sample indicated they had been told by a doctor of mental health professional that they have a mental illness. The prevalence of mental illness increases as income decreases, particularly when individuals earn $\$ 20,000$ or less per year (Sareen, Afifi, McMillan, \& Asmundson, 2011). The median monthly income for neighbors in this study was $\$ 2,219$, which translates to approximately $\$ 26,600$ per year. With $50 \%$ of neighbors earning this amount or less, the greater prevalence of mental illness in the sample is unsurprising. Similarly, it is not unexpected that approximately half of the sample (52.5\%) had an 
immediate family member with a mental illness. In the United States, family income is strongly related to individual income (Chetty, Hendren, Kline, Saez, \& Turner, 2014), and therefore immediate family members are likely to be similarly at greater risk for mental illness.

Previous population studies suggest that, due to prevalence of public education campaigns about mental illness and the prevalence of these conditions in the media and popular culture (Thornicroft et al., 2016), most participants' responses will reflect a basic understanding of the major mental disorders (i.e., depression, schizophrenia, and bipolar disorder) (Sara Evans-Lacko et al., 2012; Rüsch et al., 2012). This was echoed in the present study's findings that almost all participants were able to correctly identify depression (79.9\%), schizophrenia (97.9\%), and bipolar disorder (96.4\%). However, a substantial portion were unable to correctly identify drug addiction as a mental illness, and nearly a third incorrectly thought grief and stress were mental illnesses. Future studies should consider if and how participants who consider grief and stress to be mental illnesses, or those who do not consider drug addiction to be a mental illness, differ in other ways from those who correctly distinguish them. In particular, previous studies have shown that attitudes towards drug treatment facilities are less negative from those associated with mental health facilities (Borinstein, 1992; Takahashi \& Dear, 1997). As was predicted, neighbors with higher mental health literacy scores on the Mental Health Knowledge Schedule also reported less stigma about individuals with mental illness. Approximately $31 \%$ of the variance in stigma was accounted for by knowledge on the 
MAKS Part A, indicating that knowledge plays a large part in attitudes towards individuals with mental illness.

Awareness of the housing site was within the range established by previous literature, which typically falls between 13\% and 27\% (Dear et al., 1980; Rabkin et al., 1984; Taylor et al., 1979; Zippay \& Lee, 2008). Over one-third of respondents who correctly identified the housing site thought it was primarily for either for individuals with low income or individuals with physical disabilities. This may be explained by the fact that more than two-thirds of adults with mental disorders also have comorbid medical conditions, including those that may result in physical disability status (Druss et al., 2011). In addition, housing clients in the CHARP sample reported average monthly incomes of $\$ 700$, or an annual income of $\$ 8,400$, well below the 2013 federal poverty line of $\$ 11,490$ (US Department of Health and Human Services, 2013). Interestingly, neighbors who correctly identified the housing site, regardless of who they thought it was intended for, had more negative opinions of individuals with mental illness. However, attitudes about individuals did not appear to be directly related to knowing that the housing site was intended for this population, as neighbors who correctly identified the population as clients with mental illness did not have different stigma scores from those who did not correctly identify the population. Because this is a correlational study it cannot be concluded that knowing about the housing site caused more stigmatized attitudes about individuals with mental illness, or that those who negative attitudes were more attuned to the population and thus became aware of the housing site because of their negative attitudes. As was expected, proximity to the housing site was associated 
with being able to correctly identify it; that is, the closer neighbors lived to it, the more likely they were to be able to correctly identify it.

Having ever had a personal diagnosis of a mental illness or mental health challenge was not related to opinions about individuals with mental illness. However, having a family member or a friend with a mental health challenge was associated with more positive opinions than those who only had more distal relationships (or no relationship) with an individual with mental illness. Intergroup contact theory and the contact hypothesis would suggest that close contact with an individual from a negatively stereotyped outgroup results in more positive opinions about members of that group (Allport, 1954; Corrigan \& Penn, 1999; Evans-Lacko et al., 2012). However, as this study is correlational in nature, conclusions about causality cannot be inferred.

The majority of neighbors reported positive attitudes about individuals with mental illness. In particular, almost everyone agreed that as a society we have a responsibility to provide the best possible care for individuals with mental illness (96.4\%). This finding may be a leverage point for housing providers facing opposition in neighborhoods. If respondents in those neighborhoods also agree with this item, an educational or awareness strategy that explains why independent supportive housing can be the best possible form of care for many individuals could channel this abstract goodwill into concrete support for housing.

Looking at individual items on the CAMI/Time to Change measure illuminates some areas where neighbors had slightly more variation in their responses. Concerns echo findings from previous literature suggesting that neighbors have some concern 
regarding their children being exposed to individuals with mental illness (Arens, 1993; Cheung, 1990; Cowan, 1999). Nearly a third of respondents disagreed that individuals who used to be patients in a mental hospital could be trusted as babysitters, and a full $40.3 \%$ neither agreed nor disagreed, indicating at least some hesitation to the idea. This finding was corroborated by items on the Devaluation-Discrimination scale, which indicated that neighbors thought other community members would also be unlikely to want someone with a mental illness as a teacher of young children or a babysitter. Similarly, a neighbor in the qualitative follow-up suggested that neighborhood children had been too afraid of the clients to wait at their school bus stop, which was near the housing site.

Neighbors also thought other community members might hold certain negative opinions about individuals with mental illness. In particular, most neighbors thought others would think less of a person with mental illness, and that most people would be reluctant to date someone with mental illness. Another item that reflected some differences of opinion included the idea that less emphasis should be placed on protecting the public from people with mental illness. Responses were nearly evenly split into a third agreeing, a third neutral, and a third disagreeing with the statement. Previous research on stereotypes about individuals with mental illness would suggest the public believes individuals with mental illness are dangerous and to be feared, and that this might explain why some individuals disagreed with this statement (i.e., perhaps they feel more emphasis should be placed on protection). However, anecdotal evidence from research assistants who collected data indicated that respondents were unsure how to 
answer the question, because they didn't know how much emphasis was currently being placed on protecting the public. Some commented that they disagreed with the statement because they felt little emphasis was being placed on protecting the public, and that was just the right amount (i.e., they didn't feel they needed any protection). In survey methodology, this problem is referred to as excessive complexity, in which the underlying structure of the question is obscured and difficult for participants to infer (Groves, Fowler, Couper, Singer, \& Tourangeau, 2009).

Another item with a similar split in responses and apparent confusion among participants was the statement, "Mental hospitals are an outdated means of treating people with mental illness". The creators of the scale suggest in the scoring of this item that disagreement with this statement is a negative attitude. However, anecdotal evidence from some interviews (in some cases, respondents who were nurses or mental health professionals) indicated that while community placement might be the more desirable option, occasionally hospitalization is required for those in crisis. Therefore, they thought mental hospitals might still be necessary. Future research should revise these items for clarity.

Overall, neighbors who knew about the housing site had positive opinions of its impact on the neighborhood. Neighbors appreciated that the housing was in line with their community values of diversity and integration, and were glad the clients had somewhere to call home. They reported feeling that the clients were good neighbors and that they and the building fit in well into the neighborhood. The majority indicated they had no concerns about the housing. A few people were concerned about safety and crime 
as a result of the housing (although this was usually associated with the perceived connection between homelessness and the housing site), and a few thought the clients had a disruptive impact on the neighborhood because of the increase in emergency vehicles and traffic.

Three-quarters of respondents did not think the housing had changed their opinions of people with mental illness. Three of the four who thought it had said their opinions had changed for the better because clients seemed so "normal", by which they meant clients did not display any visible or disturbing symptoms. Neighbors indicated it would be impossible to distinguish them from other community members if they did not otherwise know that they lived in the housing site. This finding is similar to responses regarding the impact of the clients on the neighborhood, in that neighbors found it especially positive that clients fit in to the neighborhood so well; they were indistinguishable from the rest of the neighborhood, and well-integrated. Many of the respondents were social assistance workers familiar with mental illness, which may have colored their perceptions of individual with mental illness (discussed in more detail in the Limitations section).

The majority of respondents thought that clients who lived in the supportive housing site near them were likely to be different from the average person with a mental illness. The reasons they provided may give us a glimpse into how they view not only housing clients but individuals with mental illness in general. More than half of those who thought the clients were likely to be different from others with mental illness thought they were likely to be higher functioning than those not living in supportive housing. This 
is notable given that current estimates are that one in four individuals will have a mental illness at some point in their lives (World Health Organization, 2013), but only one in 25 adults have a psychiatric disability (Substance Abuse and Mental Health Services Administration, 2017). This suggests that while mental illness is a common experience, it most often is not disabling. A requirement of obtaining psychiatric supportive housing is that one has a psychiatric disability, which is defined as a "mental impairment that substantially limits one or more of the major life activities of an individual" (United States Department of Justice Civil Rights Division, n.d.). Future developments could draw on reports such as these to emphasize the success of psychiatric supportive housing in integrating clients, and facilitating independence and recovery. The public may be more receptive to psychiatric housing if messaging emphasizes clients' success and improved functioning.

\section{Relationship Between Attitudes and Neighboring Intentions}

Nearly two thirds of neighbors had lived with, worked with, and had a neighbor with a mental illness. The majority had a close friend with a mental illness. As previously discussed, neighbors who had an immediate family member or friend with mental illness had more positive opinions than those with less proximal relationships. Therefore, the low rate of mental illness stigma reported by neighbors (e.g. scores on the CAMI/Time to Change) may be because so many had or had had personal relationships with someone with mental illness. This interpretation is in line with research on contact theory, which suggests that contact with members of stigmatized groups improves attitudes towards them (Allport, 1954; Evans-Lacko et al., 2012). Similarly, the vast majority of neighbors 
had positive neighboring intentions, and were willing to live next door to, continue relationship with a friend, or with someone with MI. The majority were also willing to live with someone with MI in the future, but a quarter of participants said they would be unwilling to do that in the future. A post-hoc analysis also found that those who had previously lived with someone with a mental illness were more willing to do so in the future, compared to those who had not had that experience.

Whether a neighbor did or did not have a diagnosis did not seem to play a role in whether participants would engage in neighboring behaviors, however. Neighbors were equally likely to engage in both superficial and close neighboring behaviors regardless of whether they thought the neighbor had a mental illness. There is some suggestion of response bias here, given that no respondents said they would be "very unlikely" to chat with a neighbor with mental illness on the street, but $2.9 \%$ of respondents said they would be "very unlikely" to chat with any neighbor on the street. If there was no bias, we would expect respondents to be equally likely to chat with neighbors with or without mental illness. If, as previous research and other areas of this study have shown, neighbors hold some negative attitudes towards individuals with mental illness, we would expect them to be less likely to chat with neighbors with mental illness. While this may not necessarily be social desirability response bias - perhaps respondents really felt they might be slightly less unlikely to chat with a neighbor with mental illness - it is possible participants guessed that the intent of the research was to compare their responses between the two virtually identical measures. It is worth considering that a future measure should attempt more subtlety to make the research intent less apparent. 
Neighbors who interacted more frequently with clients did not have different stigma scores than those who interacted with them less frequently. Although contact theories might suggest that increased contact with a member of an outgroup would promote more positive attitudes, the phrasing of this item does not allow an assessment of the valence of these interactions. Neighbors with more contact may be having a combination of negative and positive interactions. A future study should control for the valence of interactions between neighbors and supportive housing clients.

It is worth considering that neighbors' perceptions of individuals with mental illness and perceptions of the neighborhood safety may be compounded with racial bias, particularly as there were a greater proportion of clients who were black or African American compared to the sample of neighbors, and compared to Portland in general, where only $5.7 \%$ of residents are black or African American ("U.S. Census Bureau QuickFacts: Portland city, Oregon,” 2017). A future study should investigate the role that racial bias may play in influencing attitudes about neighbors who are supporting housing clients.

Neighbors who knew about the housing suggested three categories of ways to improve relationships between the neighborhood and the housing clients: awareness or education strategies to teach neighbors about the housing site and mental illness in general, and address their concerns; strategies to increase social interaction between clients and neighbors, including encouraging informal socialization and planned socialization such as block parties or neighborhood get-togethers; and to continue good management strategies that allowed the building and the client to fit in well and not be 
disruptive in the neighborhood. A handful of neighbors thought that contrived social events would be presumptive and potentially unfair to clients who have the same right to engage or not engage with their neighbors as they want to. Although this was a minority opinion, it is well worth taking into account, as strategies to improve integration should first and foremost take into account client preferences.

\section{Experiences of the Neighborhood as a Housing Client or Neighbor}

An important contribution of this study is that it incorporates clients' perspectives and compares their perceptions of the neighborhood to those of their neighbors. The purpose of this study is ultimately to inform social integration research in order to improve outcomes for clients. Therefore, it is important to consider how neighbors and clients might differ in their perceptions of the same environments. For example, many neighbors in the follow-up qualitative study felt that clients were well-integrated and that nothing needed to be done to improve relationships. However, clients reported more loneliness than their neighbors, suggesting that they were actually experiencing significantly different social situations from their neighbors. Clients and neighbors did not differ on perceptions of the neighborhood social climate, self-reported relationships with their neighbors, or on how much stigma they perceived other people had towards individuals with mental illness (Devaluation-Discrimination scale). The convergence of these opinions from clients and neighbors suggests that these interpersonal and community factors are being perceived similarly, but that the individual impact may be different, as seems to be the case with personal experiences of loneliness. It should also be noted that the measure of loneliness used in this study does not distinguish where the 
source - or lack - of social support comes from. Clients' loneliness is likely the result of social experiences beyond neighboring, and they may be experiencing social deficits in relationships with family, friends, coworkers, or others. The idea that clients' loneliness is influenced by social situations other than neighboring is supported by the finding that neighbors and clients did not differ in their perceptions of relationships with their neighbors.

Clients and neighbors also differed on their perception of neighborhood safety. Neighbors felt less safe in their neighborhoods than clients. One potential explanation for this that requires investigation in future research is that while neighbors were unwilling to report that they had negative opinions about individuals with mental illness, their implicit bias that individuals with mental illness are dangerous led them to report feeling less safe in their neighborhood. Some evidence for this social desirability response bias is that neighbors on average scored low on the measure of stigma towards individuals with mental illness (CAMI/Time to Change scale), but on average reported that "most community members" held negative attitudes towards individuals with mental illness (Devaluation-Discrimination scale). The Devaluation-Discrimination scale allows respondents to report negative attitudes about mental illness without having to endorse whether they themselves believe the negative stereotype. One of the core stereotypes of individuals with mental illness is that they are dangerous and to be feared (Corrigan \& Watson, 2002), so perhaps neighbors felt less safe in their neighborhood because they implicitly believed that clients are dangerous. This may explain why a few respondents in 
the qualitative follow-up study reported feeling unsafe or uneasy as a result of living near the supportive housing site.

In addition, the current measures of stigma available, including those used in this study, do not address how stigma towards individuals with mental illness may differ depending on place or physical location in which individuals are encountered. The measure of safety used in this study is specifically about one's neighborhood; the measures of stigma are about any and all individuals with mental illness, not just neighbors. Future measure development should address how negative attitudes may be place-based, and depend on proximity and relationships (i.e., with neighbors). For example, neighbors may not hold negative opinions about individuals with mental illness in general, but their opinions may change or become more pronounced depending on social or physical distance. Neighbors might feel differently about a mental health client who lives next door compared to a mental health client in general. Measures might take into account feelings of safety; concern for children; or overall social climate in the neighborhood based on the presence or absence of mental health clients or supportive housing.

\section{Limitations}

This study has some design and sampling limitations that should be considered when drawing implications and conclusions about the results of this study. These limitations and their impact on study interpretations are described in this section.

Cross-sectional design. This study utilized a cross-sectional study design. One criticism of cross-sectional designs is the potential for cohort effects to impact findings. 
Historical events have the ability to shape opinions about psychiatric housing. For example, many participants in this study lived through the global recession in the 1980's and the subprime mortgage crisis in the United States in the late 2000's, events which potentially shaped their attitudes towards home ownership and impacts on property values. Economic catastrophes may particularly impact attitudes of conservatives or those who are more likely to be opposed to the provision of free or reduced-rate housing under normal circumstances (Arens, 1993; Piat, 2000b), but particularly when money is tight (Grob, 2005). Participants in this study may have been influenced by any number of current events, including recent media coverage and political attention to the issue of homelessness in the city of Portland. The constantly changing cultural and political milieu is one reason studies of attitudes towards community-based housing continue to be important for informing interventions, policies, and practice.

Correlational research. Because this study is correlational research, this study cannot conclude that the housing or interactions with the clients caused the perceptions or reactions of their neighbors. In the medical sciences, a randomized control trial would be considered the "gold standard" by which to assert causality, and descriptive and case studies would be the least convincing (Concato, 2004). This opinion has carried over to the social sciences, and, for better or worse, influences the way correlational studies are perceived. However, it is less frequently noted that observational studies result in much less heterogeneity in results than do randomized, clinical trials of the same phenomenon; in fact, an exhaustive methodological review found that only RCTs (and never observational studies) reported effects with opposite directionality than the average of all 
the RCTs (Concato, 2004). That is, observational studies of the same topic never found opposite results, whereas RCTs occasionally did. In addition, RCTs are not immune to threats to internal validity, including experimenter effects and attrition; and may be severely lacking in external validity (Bickman \& Reich, 2009). It is also important to note that descriptive and correlational studies are often of more value in understanding complex interactions in localized areas. The results of this study can help inform how psychiatric housing may be perceived in neighborhoods with similar locations and types of housing, client services, neighborhood safety and social climate, and neighbor demographics, and not to one of these factors abstracted from context.

Social desirability response bias. The social desirability response bias may partially explain the low rate of negative opinions about people with mental illness, as neighbors may have felt social pressure to only voice positive opinions to the interviewers. For example, there is some evidence that behavioral intentions toward people with mental health problems should not be assessed in in-person interviews, as face-to-face contact may result in response bias (Henderson et al., 2012). The authors concluded this after comparing in-person and online responses on the same RIBS Neighboring Intentions scale used in the present study. Although the present study found that measures of attitudes and neighboring intentions towards individuals with mental illness did not differ by survey mode, it may be that social desirability bias was present in both interview modes, thus resulting in minimal differences between the two modes). That is, respondents may have been unwilling to voice negative opinions to a researcher regardless of whether it was face-to-face or over-the-phone. Findings from the Henderson 
et al. (2012) study suggest that participants may be more likely to voice less desirable attitudes when a researcher is not verbally asking the questions (e.g., they may be more likely to endorse negative opinions in an anonymous online survey). In addition, there is some evidence that response bias was present in this study, as interview mode did impact the responses to two measures of general neighboring behaviors and intentions, likely because the survey questions were being answered within earshot of participants' neighbors. A future study should compare all three interview modes to determine which results in the least response bias.

Neighborhood variation. An inherent limitation of neighborhood research is the lack of control over natural variation in neighborhood features and demographics. Efforts were made to select neighborhoods where there were no other housing sites or similar structures by searching online maps and directories. One referent housing site was relatively close to another housing site run by the same housing program; however, the two sites were separated by a busy main road, and the two housing sites were deemed by the research team to be logically part of separate and distinct neighborhoods. The two sites are visually distinct, and in asking participants to describe the housing site they were aware of it was possible to determine that almost all neighbors only identified the site the study team had deemed part of their neighborhood. Lastly, this study was conducted in the Northwest, in a city known to be predominantly liberal. Therefore, the results of this study may not generalize to other regions, or to areas with a different political makeup.

Sampling selection bias. This study has several sampling selection issues that should be acknowledged. First, the response rate for NASH phase 1 was relatively low 
(between $9.8 \%$ and $17.6 \%$ ), and thus completed surveys may not be representative of all neighbors within a given neighborhood. This response rate is not unexpected for community research, where some estimates put likely response rates in the range of $1 \%$ to 20\% ("Survey Response Rates," 2017). In addition, neighbors were excluded from the sampling frame if they did not speak English. This study did not have the capacity to translate measures into other languages that may have allowed other community members to be included, and therefore the data only represents opinions about the neighborhood from English speakers. While the recruitment data showed that only a very small number of potential participants were excluded due to language barriers (less than $2 \%$ of neighbors who interacted with researchers during recruitment), this discussion of neighbor attitudes cannot be considered complete because of this systematic exclusion. I am not aware of any studies conducted in the United States that sample non-English speakers regarding their attitudes towards community-based housing, and this is an omission that should be addressed in future studies. Self-selection bias may have meant that neighbors who were willing to be interviewed for this study differed in some significant way from those that did not self-select in. The qualitative interviews suggest that those who responded may be more likely to be social assistance workers (discussed below). The study was billed as a study on neighborhood attitudes, so it could be that our sample includes individuals who are more civically-minded or interested in neighborhood dynamics. In addition, during this time period Portland was experiencing a housing crisis, an increase in homelessness, and an increase in news coverage on homelessness. In qualitative interviews, several neighbors discussed their concerns about the impact of 
homelessness on their neighborhood. It is also possible that those who selected in to the study did so because they believed the study was related to the impacts of homelessness in some way.

High proportion of social assistance workers in the qualitative sample. More than half of the respondents in the follow-up qualitative interviews were social assistance workers of some kind, including social workers and nurses. Oregon is the $44^{\text {th }}$ largest state by population density (US Census Bureau, 2015). Maine is the 43rd and Utah is the $45^{\text {th }}$ (US Census Bureau, 2015). According to 2016 and 2017 estimates (the time frame in which qualitative data were collected) from the US Bureau of Labor Statistics (2017), Oregon has over 2.2 million workers in the fields of Health Care and Social Assistance (which includes social workers, substance abuse counselors, marriage and family therapists, and all helping professions). By comparison, Maine has less than 1 million, and Utah has 1.4 million. Oregon has more than twice the number of Health Care and Social Assistance workers as the more populous Maine, and nearly 1 million more than Utah. Therefore, it is perhaps not unusual that our sample included several individuals who had worked in the fields of mental health or social work. Their informed perspectives were invaluable to the current research, although it must be noted that their responses may not be representative of the general population.

\section{Contributions to Theory, Practice, and Policy}

The findings from this study contribute to theory, practice, and policy pertaining to mental health stigma and supportive housing in a variety of ways. First, this study updates our understanding of neighborhood attitudes towards psychiatric housing. The 
majority of research on attitudes towards community-based psychiatric housing was conducted prior to the $21^{\text {st }}$ century, with only a few exceptions in the last decade (e.g. Zippay \& Lee, 2008; Zippay \& Son, 2013). In addition, the last two decades have seen an unprecedented global effort to reduce the stigma of mental illness by improving knowledge, attitudes, and behaviors(Collins, Wong, Roth, Cerully, \& Marks, 2015; Sara Evans-Lacko, Malcolm, et al., 2013; Jorm et al., 2005; G. Thornicroft et al., 2016). Scholars and advocates do not expect these efforts to have immediate or dramatic effects, and rather consider these incremental shifts in the preferred direction as moving the needle on a dial a fraction at a time (Sullivan \& Wahler, 2017). This study is situated in this evolving macrosystem of cultural attitudes and ideologies towards individuals with mental illness. Although neighbors and neighborhoods were not selected because of exposure to an anti-stigma campaign or intervention, ecological systems theory would suggest that changes in the culture and ideology around mental illness has impacted the individuals through its influences on social settings, interactions, and the institutions with which they interact (Bronfenbrenner, 1977). This study uses benchmarked measures originally used to assess population-level changes in knowledge, attitudes, and behaviors (e.g. Evans-Lacko, Henderson, et al., 2013), making comparisons to national averages possible.

This study also improves upon some of the previous literature in this area in that it purposively samples from individuals who currently live near a supportive housing site to capture actual, as opposed to hypothetical, attitudes and perceptions. Many studies up to this point have used vignettes with participants who were not sampled for their proximity 
to the housing site, or with residents who were dreading an impending placement in their neighborhood, resulting in an emphasis in the literature on negative reactions to housing (Borinstein, 1992; Smith \& Hanham, 1981; Solomon \& Davis, 1984; Takahashi \& Dear, 1997). Given the rising cost of rents and declining incomes of those in the lowest income brackets in the United States (Desmond, 2018), studies that show the acceptability of supportive housing to neighbors and neighborhoods may be of particular utility to affordable housing and mental health advocates alike.

This study can also serve as a baseline analysis of attitudes towards communitybased psychiatric housing in Oregon, prior to housing integration reforms required by the Department of Justice. As changes in housing policies occur within this state and others, it may be important to understand the state of public opinion prior to restructuring housing sites to incorporate other client populations. Neighbors may have specific concerns that would be relevant to any type of housing site (for example, concerns about increased traffic or decreased parking), or they may have concerns that are specific to living near clients with mental illness (for example, negative attitudes rooted in fear or lack of knowledge). On the other hand, they may have positive perceptions relevant to any type of housing site (for example, good building upkeep may engender positive reception), or they maybe have positive attitudes that are specific to individuals with mental illness (for example, attitudes based in a belief in the role of community in mental illness recovery, or personal experience with mental illness that leads to more positive perceptions). New developments or existing housing programs seeking to restructure could potentially harness this information to ease neighborhood transitions and promote 
those factors associated with positive perceptions, and address factors associated with increased concern. Rates of awareness, knowledge, and behaviors may serve as useful comparison points for future studies.

This study uses a unique combination of quantitative and qualitative data sources to provide a full understanding of the range of experiences and perceptions, and to highlight potential areas for future research. In addition to close-ended survey items from well-established scales, participants were asked open-ended questions that probe for concerns about or benefits of living near the housing site; how the housing may have impacted the community; and suggestions for improving relationships between the housing site and the surrounding community.

Lastly, this study also provides a unique opportunity to compare housing client and neighbor perceptions of the same neighborhoods to understand how the same communities may be experienced differently depending on whether one is a supportive housing neighbor or client. This information is important both for understanding ways in which neighbor perceptions may be associated with different types of housing, and also for understanding clients' social integration experiences in the neighborhood.

Addressing NIMBYism. Although the results of this study show overall positive attitudes and behavioral intentions towards individuals with mental illnesses who are neighbors, it should not be concluded that NIMBYism has been eradicated. Numerous studies show that, although the needle is moving in the right direction, members of the general public still have negative stereotypes about individuals with mental illness. Findings from this study suggest that neighbors might be more specifically concerned 
about the impact on children, and perhaps on their own sense of safety. Housing programs may need to tailor focused outreach to specific areas of concern about individuals with mental illness. For example, future interventions may consider allaying concerns from those worried about home value depreciation through an educational campaign drawing on econometric data that show that housing programs have little to no impact on home values (e.g., Galster et al., 2004).

It may be more difficult to dispel fears about children's safety, as this may be based on an instinctual desire to minimize the risk of danger to one's vulnerable family members. This emotionally-charged concern is less likely to be resolved through educational strategies. Fears may not be dispelled until neighbors become familiar and comfortable with the clients of the housing site. Therefore, interventions that encourage contact may promote neighboring relationships that in turn diminish fear and apprehension (as in Wolff et al., 1996c). One way to appeal to those who might be opposed to publicly-funded community housing may be to educate the public that psychiatric supportive housing ultimately saves taxpayers money, even over short periods of time, by diverting individuals away from costly emergency services (Hunter, Harvey, Briscombe, \& Cefalu, 2017). In practice, housing programs often have to contend with opposition that comes both from a lack of knowledge and genuine concern, as well as deeply rooted negative attitudes towards individuals with mental illness. The former may be easier to address locally, while the latter requires ongoing population-level changes in attitudes and norms.

\section{Future Directions}


This study also suggests future directions for research, including new measures to capture place-based stigma; analyses that capture the effect of the mere presence of housing and the role of individual personalities in determining attitudes; and studies that include community members' participation in the research process.

Place-based stigma. One important area for future research may be to consider whether current theoretical frameworks and measures of mental illness stigma adequately capture the full range of concerns pertaining to living near a supportive housing site. Current stigma measures - e.g., CAMI and the Link Devaluation-Discrimination scale rely on general attitudes towards hypothetical individuals with mental illness. As discussed above, a future measure could consider place-based stigma - that is, attitudes that might be related to where one encounters the negatively stereotyped individual. Future measures might consider exploring the impact of place and proximity on specific negative attitudes. In addition, as discussed above, there are conceptual issues associated with several of the items in these scales that should be addressed if these measures are to continue to be relied on as accurate assessments of attitudes towards individuals with mental illness.

Impact of the presence of supportive housing on attitudes. Neighbors in this study had largely positive attitudes towards individuals with mental illness. This is in line with earlier findings that public attitudes towards clients of mental health facilities are more positive in neighborhoods containing facilities than in neighborhoods without them (Wahl, 1993). A future direction for this research might be to compare attitudes in neighborhoods with and without housing facilities, and establish the role (if any) that 
awareness of the facility might play in shaping attitudes in these different neighborhoods. Combining knowledge from previous studies and the current study, we might expect that attitudes in neighborhoods with facilities will be more positive than those without, regardless of awareness of the housing site. This could be because neighbors are aware that individuals with mental illness live in their neighborhood, and they may observe or come into contact with them without knowing exactly where they live.

Influence of individual personalities. An apparently overlooked research question in the literature is the degree to which individual personality traits influence attitudes towards psychiatric housing. Rabkin et al. (1984) make the interesting observation that individuals who did not like having psychiatric housing near them were also displeased with the presence of any social facility in their neighborhood (including housing for older adults, recreational centers for teens, and a group home for individuals with developmental delays). Rabkin et al. (1984) refers to this as an "irritability factor" in which some people seem to be more prone to complain than others (p. 311). This finding, although not statistically significant, may point to the hypothesis that individual differences in neighbors may contribute additional variance in their perception of the neighborhood. Some limited information supporting the importance of this question may be gleaned from studies of hypothetical attitudes. People who were less welcoming of mental health facilities also tended to be pessimistic about the future, competitive, less tolerant of non-traditional lifestyles, and more conservative (Arens, 1993; Borinstein, 1992). The present study found that the majority of respondents had no concerns or complaints about the housing site and found it to be a neutral or positive feature of the 
neighborhood; and only a few had negative comments about the housing or clients. It is unknown to what degree individual personalities may have influenced these perceptions. While personality traits likely play an important role in determining attitudes and behaviors, no studies that this author is aware of investigate the impact of personality variables on receptivity to psychiatric housing (for example, the 'Big Five' personality traits; (Goldberg, 1993). Individual personality characteristics are an untapped area of community-based housing receptivity research, perhaps because of the inherent complexity that would be needed to tailor interventions to individual personalities. However, future research should determine if different personality types are more receptive to particular outreach activities or interventions. Programs could then consider deploying recommended interventions when they encounter types of neighborhood resistance that may be more personality-based.

Community-based participatory research. A future study should consider using community-based participatory research methods with supportive housing clients to examine aspects of neighborhoods that enhance social integration. For example, photovoice methods might be used to identify barriers to social experiences, or factors that promote positive social interactions with neighbors. Participatory research with clients also has the ability to address concerns about stigma that may be missing from the present study, given that it focuses on the experiences of neighbors rather than clients.

\section{Conclusion}

The aims of this mixed-methods study were to increase understanding of what neighbors of supportive housing know about mental illness, and how they feel about and 
act towards clients; and to understand the relationships between knowledge, attitudes and behaviors with regards to individuals with mental illness who are neighbors. In addition, this study contextualized these neighboring experiences by comparing client and neighbor perceptions of the same neighborhoods. Findings suggest that, while neighbors are relatively knowledgeable about mental illness and have generally positive attitudes and behavioral intentions towards individuals with mental illness, there is a continuing need to monitor social progress in this area. Evolving attitudes call for new approaches to more accurately measure attitudes towards supportive housing clients who are neighbors, and to resolve methodological issues present in this and previous studies. Studies of housing and neighborhood environments for individuals with psychiatric disabilities remain important vehicles for change. It is through research in this area that policy and practice is shifting toward housing that protects and promotes the rights of individuals; and interventions are slowly but surely moving the needle towards eliminating the stigma of mental illness. 
Tables

Table 1

\begin{tabular}{lll}
\multicolumn{3}{l}{ NASH participant } \\
\hline Race & Frequency & Percent \\
\hline White & 100 & 71.9 \\
Black & 22 & 15.8 \\
Latino & 5 & 3.6 \\
Native American & 1 & .7 \\
Asian & 3 & 2.2 \\
Multi-racial & 8 & 5.8 \\
Total & 139 & 100 \\
\hline
\end{tabular}


Table 2

CHARP participant breakdown by race

\begin{tabular}{lll}
\hline Race & Frequency & Percent \\
\hline White & 41 & 60.3 \\
Black & 19 & 27.9 \\
Latino & 3 & 4.4 \\
Native American & 2 & 2.9 \\
Asian & 2 & 2.9 \\
Other & 1 & 1.5 \\
Total & 68 & 100 \\
\hline
\end{tabular}


Table 3

Measures: Aims 1 through 3

\begin{tabular}{|c|c|c|c|c|c|}
\hline Measure & $\begin{array}{l}\text { \# of } \\
\text { items }\end{array}$ & Sample item & Response options & Scoring & $\mathrm{NASH} \alpha$ \\
\hline \multicolumn{6}{|c|}{ Knowledge } \\
\hline MAKS - Part A & 6 & $\begin{array}{l}\text { Medication can be an } \\
\text { effective treatment for } \\
\text { people with mental health } \\
\text { problems }\end{array}$ & $\begin{array}{l}1, \text { Strongly } \\
\text { disagree to } 5, \\
\text { Strongly agree }\end{array}$ & $\begin{array}{l}\text { Average } \\
\text { score }\end{array}$ & .5 \\
\hline MAKS - Part B & 6 & $\begin{array}{l}\text { How much do you agree or } \\
\text { disagree that each of the } \\
\text { following is a type of mental } \\
\text { illness: Depression }\end{array}$ & $\begin{array}{l}1, \text { Strongly } \\
\text { disagree to } 5, \\
\text { Strongly agree }\end{array}$ & $\begin{array}{l}\text { Item } \\
\text { percents }\end{array}$ & $\begin{array}{l}\text { Not a } \\
\text { scale }\end{array}$ \\
\hline \multicolumn{6}{|c|}{ Attitudes } \\
\hline $\begin{array}{l}\text { Devaluation- } \\
\text { Discrimination }\end{array}$ & 12 & $\begin{array}{l}\text { Most people would willingly } \\
\text { accept someone with a } \\
\text { mental illness as a close } \\
\text { friend }\end{array}$ & $\begin{array}{l}1, \text { Strongly } \\
\text { disagree to } 5 \text {, } \\
\text { Strongly agree }\end{array}$ & $\begin{array}{l}\text { Average } \\
\text { score }\end{array}$ & .88 \\
\hline CAMI & 27 & $\begin{array}{l}\text { One of the main causes of } \\
\text { mental illness is a lack of } \\
\text { self-discipline and will- } \\
\text { power }\end{array}$ & $\begin{array}{l}\text { 1, Strongly } \\
\text { disagree to } 5, \\
\text { Strongly agree }\end{array}$ & $\begin{array}{l}\text { Average } \\
\text { score }\end{array}$ & .89 \\
\hline \multicolumn{6}{|c|}{ Behavior } \\
\hline $\begin{array}{l}\text { RIBS - Reported } \\
\text { Behavior }\end{array}$ & 4 & $\begin{array}{l}\text { Are you currently living } \\
\text { with, or have you ever lived } \\
\text { with, someone with a mental } \\
\text { health problem? }\end{array}$ & Yes, No & $\begin{array}{l}\text { Item } \\
\text { percents }\end{array}$ & $\begin{array}{l}\text { Not a } \\
\text { scale }\end{array}$ \\
\hline $\begin{array}{l}\text { RIBS - Intended } \\
\text { Behaviors }\end{array}$ & 4 & $\begin{array}{l}\text { In the future, I would be } \\
\text { willing to live with someone } \\
\text { with a mental health problem }\end{array}$ & $\begin{array}{l}1, \text { Strongly } \\
\text { disagree to } 5, \\
\text { Strongly agree }\end{array}$ & $\begin{array}{l}\text { Average } \\
\text { score }\end{array}$ & .87 \\
\hline $\begin{array}{l}\text { Superficial } \\
\text { neighboring } \\
\text { Intentions }\end{array}$ & 4 & $\begin{array}{l}\text { How likely would you be to } \\
\text { do the following with a } \\
\text { neighbor? ...Chat with a } \\
\text { neighbor on the street }\end{array}$ & $\begin{array}{l}1 \text {, Very unlikely } \\
\text { to } 5 \text {, Very likely }\end{array}$ & $\begin{array}{l}\text { Average } \\
\text { score }\end{array}$ & .81 \\
\hline $\begin{array}{l}\text { Superficial } \\
\text { neighboring } \\
\text { Intentions (MI) }\end{array}$ & 4 & $\begin{array}{l}\text { Same as above; Neighbor } \\
\text { with mental illness }\end{array}$ & Same as above & $\begin{array}{l}\text { Same as } \\
\text { above }\end{array}$ & .75 \\
\hline $\begin{array}{l}\text { Close neighboring } \\
\text { Intentions }\end{array}$ & 3 & $\begin{array}{l}\text { How likely would you be to } \\
\text { do the following with a } \\
\text { neighbor?...Go with a } \\
\text { neighbor to a social outing }\end{array}$ & $\begin{array}{l}1 \text {, Very unlikely } \\
\text { to } 5 \text {, Very likely }\end{array}$ & $\begin{array}{l}\text { Average } \\
\text { score }\end{array}$ & .81 \\
\hline $\begin{array}{l}\text { Close neighboring } \\
\text { Intentions (MI) }\end{array}$ & 3 & $\begin{array}{l}\text { Same as above; Neighbor } \\
\text { with mental illness }\end{array}$ & Same as above & $\begin{array}{l}\text { Same as } \\
\text { above }\end{array}$ & .8 \\
\hline
\end{tabular}


NEIGHBOR PERCEPTIONS OF SUPPORTIVE HOUSING

Table 4

Measures: Aim 4

\begin{tabular}{|c|c|c|c|c|c|c|}
\hline Measure & $\begin{array}{l}\# \text { of } \\
\text { items }\end{array}$ & Sample item & $\begin{array}{l}\text { Response } \\
\text { options }\end{array}$ & Scoring & $\begin{array}{l}\text { NASH } \\
\alpha\end{array}$ & $\begin{array}{l}\text { CHARP } \\
\alpha\end{array}$ \\
\hline $\begin{array}{l}\text { Neighboring } \\
\text { Scale (HES- } \\
\text { N) }\end{array}$ & 9 & $\begin{array}{l}\text { I can count on a } \\
\text { neighbor for help when I } \\
\text { need it. }\end{array}$ & $\begin{array}{l}\text { 1, Strongly } \\
\text { disagree to } 5 \text {, } \\
\text { Strongly agree }\end{array}$ & $\begin{array}{l}\text { Average } \\
\text { score }\end{array}$ & .86 & .75 \\
\hline Loneliness & 4 & $\begin{array}{l}\text { How often do you feel } \\
\text { left out? }\end{array}$ & $\begin{array}{l}\text { Never, rarely, } \\
\text { sometimes, } \\
\text { always }\end{array}$ & $\begin{array}{l}\text { Average } \\
\text { score }\end{array}$ & .69 & .81 \\
\hline $\begin{array}{l}\text { Neighborhood } \\
\text { Safety (HES- } \\
\text { S) }\end{array}$ & 9 & $\begin{array}{l}\text { How often are groups of } \\
\text { people just hanging out } \\
\text { and causing problems? }\end{array}$ & $\begin{array}{l}0, \text { Never to } 6 \text {, } \\
\text { Once a day }\end{array}$ & $\begin{array}{l}\text { Average } \\
\text { score }\end{array}$ & .91 & .89 \\
\hline $\begin{array}{l}\text { Devaluation- } \\
\text { Discrimination }\end{array}$ & 12 & $\begin{array}{l}\text { Most people would } \\
\text { willingly accept } \\
\text { someone with a mental } \\
\text { illness as a close friend }\end{array}$ & $\begin{array}{l}\text { 1, Strongly } \\
\text { disagree to } 5 \text {, } \\
\text { Strongly agree }\end{array}$ & $\begin{array}{l}\text { Average } \\
\text { score }\end{array}$ & .88 & .85 \\
\hline $\begin{array}{l}\text { Neighborhood } \\
\text { Social Climate } \\
\text { (HES-NSC) }\end{array}$ & 12 & $\begin{array}{l}\text { Sometimes I feel } \\
\text { unwelcome in my } \\
\text { neighborhood }\end{array}$ & $\begin{array}{l}\text { 1, Strongly } \\
\text { disagree to } 5 \text {, } \\
\text { Strongly agree }\end{array}$ & $\begin{array}{l}\text { Average } \\
\text { score }\end{array}$ & .85 & .82 \\
\hline
\end{tabular}

Note. N/A indicates measure was not included in the CHARP Study. 


\section{Table 5}

\section{Mental Health Knowledge Schedule (MAKS) - Part A}

\begin{tabular}{lcc}
\hline $\begin{array}{l}\text { Participants rated agreement with each of the following } \\
\text { statements: }\end{array}$ & $\begin{array}{c}\text { \% agreeing or } \\
\text { strongly agreeing }\end{array}$ & $\begin{array}{c}\text { \% disagreeing or } \\
\text { strongly disagreeing }\end{array}$ \\
\hline $\begin{array}{l}\text { Most people with mental health problems want to have } \\
\text { paid employment (true) }\end{array}$ & 86.3 & 5.0 \\
$\begin{array}{l}\text { If a friend had a mental health problem, I know what } \\
\text { advice to give them to get professional help (true) }\end{array}$ & 64.0 & 17.3 \\
$\begin{array}{l}\text { Medication can be an effective treatment for people } \\
\text { with mental health problems (true) }\end{array}$ & 81.1 & 5.7 \\
$\begin{array}{l}\text { Psychotherapy (e.g. talking therapy or counselling) can } \\
\text { be an effective treatment for people with mental health } \\
\text { problems (true) }\end{array}$ & 92.7 & $\begin{array}{l}.7 \text { (no one strongly } \\
\text { disagreed) }\end{array}$ \\
$\begin{array}{l}\text { People with severe mental health problems can fully } \\
\text { recover (true) }\end{array}$ & 65.5 & 11.5 \\
$\begin{array}{l}\text { Most people with mental health problems go to a } \\
\text { healthcare professional to get help (false) }\end{array}$ & 31.1 & 46.4 \\
\hline $\begin{array}{l}\text { Notes. } M=22.94, S E=.26 \text {. Responses are summed to form total score within a possible range of } 6 \text { to } 30 . \\
\text { Shading indicates the percent of respondents giving the correct response. }\end{array}$ &
\end{tabular}


Table 6

Mental Health Knowledge Schedule (MAKS) - Part B

\begin{tabular}{lcc}
\hline $\begin{array}{l}\text { Agreement as to whether each condition is a } \\
\text { type of mental illness: }\end{array}$ & $\begin{array}{c}\text { \% agreeing or strongly } \\
\text { agreeing }\end{array}$ & $\begin{array}{c}\text { \% disagreeing or strongly } \\
\text { disagreeing }\end{array}$ \\
\hline Depression (true) & 79.9 & 13.7 \\
Schizophrenia (true) & 97.9 & 0 (no one disagreed at all) \\
Bipolar disorder (manic depression) (true) & 96.4 & .7 (no one strongly disagreed) \\
Drug addiction (true) & 58.3 & 26.6 \\
Grief (false) & 33.1 & 49.7 \\
Stress (false) & 31.7 & 52.5 \\
\hline
\end{tabular}

Notes. $M=23.19, S E=.23$. Responses are summed to form total score within a possible range of 6 to 30 . Shading indicates the percent of respondents giving the correct response. 
Table 7

All neighbors: Housing population identified

\begin{tabular}{|c|c|c|}
\hline Response & Frequency & Percent \\
\hline No housing identified & 67 & 48.2 \\
\hline Low income & 26 & 18.7 \\
\hline Physical disabilities & 11 & 7.9 \\
\hline Mental illnesses & 29 & 20.9 \\
\hline Other & 6 & 4.3 \\
\hline & 139 & 100 \\
\hline
\end{tabular}


NEIGHBOR PERCEPTIONS OF SUPPORTIVE HOUSING

Table 8

Correct identification of location by population identified

\begin{tabular}{|c|c|c|c|c|c|c|}
\hline & $\begin{array}{l}\text { Population is primarily } \\
\text { individuals with: }\end{array}$ & low income & $\begin{array}{c}\text { physical } \\
\text { disabilities }\end{array}$ & $\begin{array}{l}\text { mental } \\
\text { illnesses }\end{array}$ & other & $\begin{array}{c}\text { row } \\
\text { totals }\end{array}$ \\
\hline Incorrectly identified & d Count & 20 & 5 & 6 & 6 & 37 \\
\hline housing location & $\%$ of incorrect & 54.1 & 13.5 & 16.2 & 16.2 & 100 \\
\hline Correctly identified & Count & 6 & 6 & 23 & 0 & 35 \\
\hline \multirow[t]{3}{*}{ housing location } & $\%$ of correct & 17.1 & 17.1 & 65.7 & 0 & 100 \\
\hline & Total & 26 & 11 & 29 & 6 & 72 \\
\hline & Percent of total & 18.7 & 7.9 & 20.9 & 4.3 & 100 \\
\hline
\end{tabular}


NEIGHBOR PERCEPTIONS OF SUPPORTIVE HOUSING

Table 9

Neighbor attitudes towards individuals with mental illness (CAMI/Time to Change)

\begin{tabular}{|c|c|c|c|c|c|}
\hline Please say how much you agree or disagree that... & $\begin{array}{l}\text { Strongly } \\
\text { disagree }\end{array}$ & Disagree & $\begin{array}{l}\text { Neither agree } \\
\text { nor disagree }\end{array}$ & Agree & $\begin{array}{c}\text { Strongly } \\
\text { agree }\end{array}$ \\
\hline $\begin{array}{l}\text {...One of the main causes of mental illness is a lack } \\
\text { of self-discipline and will power }\end{array}$ & 64 & 23.7 & 5 & 4.3 & 2.9 \\
\hline $\begin{array}{l}\text { There is something about people with mental } \\
\text { illness that makes it easy to tell them from normal } \\
\text { people }\end{array}$ & 30.9 & 37.4 & 17.3 & 10.1 & 4.3 \\
\hline $\begin{array}{l}\text {...As soon as a person shows signs of mental } \\
\text { disturbance, he or she should be hospitalized }\end{array}$ & 50.4 & 38.8 & 5.8 & 2.9 & 2.2 \\
\hline ...Mental illness is an illness like any other & 4.3 & 12.2 & 2.9 & 32.4 & 48.2 \\
\hline $\begin{array}{l}\text {...Less emphasis should be placed on protecting } \\
\text { the public from people with mental illnesses }\end{array}$ & 8.7 & 26.1 & 29.7 & 26.8 & 8.7 \\
\hline $\begin{array}{l}\text {...Mental hospitals are an outdated means of } \\
\text { treating people with mental illness }\end{array}$ & 13.0 & 23.2 & 26.8 & 25.4 & 11.6 \\
\hline ...Virtually anyone can become mentally ill & 4.3 & 2.9 & 5.0 & 50.4 & 37.4 \\
\hline $\begin{array}{l}\text {...People with mental illness have for too long } \\
\text { been the subject of ridicule }\end{array}$ & 1.4 & 1.4 & 6.5 & 41.0 & 49.6 \\
\hline $\begin{array}{l}\text {...We need to adopt a far more tolerant attitude } \\
\text { toward people with mental illness in our society }\end{array}$ & .7 & .7 & 2.9 & 42.0 & 53.6 \\
\hline $\begin{array}{l}\text {...We have a responsibility to provide the best } \\
\text { possible care for people with mental }\end{array}$ & .7 & 1.4 & 1.4 & 31.7 & 64.7 \\
\hline $\begin{array}{l}\text {...People with mental illness don't deserve our } \\
\text { sympathy }\end{array}$ & 59.7 & 32.4 & 6.5 & .7 & .7 \\
\hline $\begin{array}{l}\text {...People with mental illness are a burden on } \\
\text { society }\end{array}$ & 37.2 & 40.1 & 14.6 & 6.6 & 1.5 \\
\hline $\begin{array}{l}\text {...Increased spending on mental health services is a } \\
\text { waste of money }\end{array}$ & 61.2 & 34.5 & 2.9 & .7 & .7 \\
\hline $\begin{array}{l}\text {...There are sufficient existing services for people } \\
\text { with mental illness }\end{array}$ & 44.9 & 29.7 & 12.3 & 12.3 & .7 \\
\hline $\begin{array}{l}\text {...People with mental illness should not be given } \\
\text { any responsibility }\end{array}$ & 51.8 & 41.0 & 5.0 & .7 & 1.4 \\
\hline $\begin{array}{l}\text {...A person would be foolish to marry someone } \\
\text { who has suffered from mental illness, even though } \\
\text { he or she seems fully recovered* }\end{array}$ & 51.4 & 34.8 & 9.4 & 3.6 & .7 \\
\hline $\begin{array}{l}\text {...I would not want to live next door to someone } \\
\text { who has been mentally ill }\end{array}$ & 47.5 & 39.6 & 6.5 & 4.3 & 2.2 \\
\hline $\begin{array}{l}\text {...Anyone with a history of mental problems } \\
\text { should be excluded from taking public office }\end{array}$ & 37.4 & 38.1 & 11.5 & 9.7 & 3.6 \\
\hline
\end{tabular}




\begin{tabular}{|c|c|c|c|c|c|}
\hline Please say how much you agree or disagree that. & $\begin{array}{l}\text { Strongly } \\
\text { disagree }\end{array}$ & Disagree & $\begin{array}{l}\text { Neither agree } \\
\text { nor disagree }\end{array}$ & Agree & $\begin{array}{c}\text { Strongly } \\
\text { agree }\end{array}$ \\
\hline $\begin{array}{l}\text {...No-one has the right to exclude people with } \\
\text { mental illness from their neighborhood }\end{array}$ & 2.9 & 5.0 & 4.3 & 37.4 & 50.4 \\
\hline $\begin{array}{l}\text {...People with mental illness are far less of a } \\
\text { danger than most people suppose }\end{array}$ & 2.9 & 9.4 & 14.4 & 42.4 & 30.9 \\
\hline $\begin{array}{l}\text {...Most people who were once patients in a mental } \\
\text { hospital can be trusted as babysitters }\end{array}$ & 7.2 & 24.5 & 40.3 & 23.0 & 5.0 \\
\hline $\begin{array}{l}\text {...The best therapy for many people with mental } \\
\text { illness is to be part of a normal community }\end{array}$ & .7 & 3.6 & 12.2 & 49.6 & 33.8 \\
\hline $\begin{array}{l}\text {...As far as possible, mental health services should } \\
\text { be provided through community-based facilities }\end{array}$ & 2.2 & 2.9 & 16.1 & 43.1 & 35.8 \\
\hline $\begin{array}{l}\text {...Residents have nothing to fear from people } \\
\text { coming into their neighborhood to obtain mental } \\
\text { health services }\end{array}$ & 1.4 & 6.5 & 21.6 & 47.5 & 23.0 \\
\hline $\begin{array}{l}\text {...It is frightening to think of people with mental } \\
\text { problems living in residential neighborhoods }\end{array}$ & 33.8 & 47.5 & 11.5 & 6.5 & .7 \\
\hline $\begin{array}{l}\text {...Locating mental health facilities in a residential } \\
\text { area downgrades the neighborhood }\end{array}$ & 21.0 & 49.3 & 15.2 & 10.9 & 3.6 \\
\hline $\begin{array}{l}\text {...People with mental health problems should have } \\
\text { the same rights to a job as anyone else }\end{array}$ & 2.2 & 3.6 & 10.8 & 43.2 & 40.3 \\
\hline
\end{tabular}


NEIGHBOR PERCEPTIONS OF SUPPORTIVE HOUSING

Table 10

Neighboring intentions towards neighbors with or without mental illness

\begin{tabular}{rrccccc}
\hline $\begin{array}{c}\text { How likely would } \\
\text { you be to do the } \\
\text { following: }\end{array}$ & $\begin{array}{c}\text { With a } \\
\text { neighbor: }\end{array}$ & $\begin{array}{c}\text { Very } \\
\text { unlikely }\end{array}$ & Unlikely & Neither & Likely & $\begin{array}{c}\text { Very } \\
\text { likely }\end{array}$ \\
\hline $\begin{array}{r}\text { Share information } \\
\text { about home or yard } \\
\text { care }\end{array}$ & With MI & 5.8 & 7.2 & 11.6 & 19.6 & 55.8 \\
\hline $\begin{array}{r}\text { Tell neighbor about } \\
\text { professional }\end{array}$ & Without MI & 6.5 & 8.6 & 8.6 & 24.5 & 51.8 \\
services used & Without MI & 6.5 & 10.1 & 7.2 & 23.7 & 52.5 \\
\hline $\begin{array}{r}\text { Offer neighbor a } \\
\text { ride }\end{array}$ & With MI & 7.4 & 5.1 & 14.7 & 32.4 & 40.4 \\
\hline $\begin{array}{r}\text { Converse with } \\
\text { neighbor on the }\end{array}$ & Without MI & 12.9 & 6.5 & 14.4 & 30.9 & 35.3 \\
\hline $\begin{array}{r}\text { Go witheet } \\
\text { to a social outing }\end{array}$ & Without MI & 2.9 & 2.2 & 2.2 & 31.2 & 61.6 \\
$\begin{array}{r}\text { Invite a neighbor } \\
\text { into your home }\end{array}$ & Without MI & 7.9 & 20.1 & 17.3 & 23.7 & 30.9 \\
\hline $\begin{array}{r}\text { Talk with a } \\
\text { neighbor about a } \\
\text { personal issue }\end{array}$ & Without MI & 6.5 & 18.1 & 18.1 & 29.0 & 28.3 \\
\hline
\end{tabular}

Notes. Table reflects response percentages. $n=139$. 
Table 11

Results of paired samples $t$-test and descriptive statistics for $R Q 4$

\begin{tabular}{|c|c|c|c|c|c|c|c|c|c|c|}
\hline \multirow[t]{3}{*}{ Outcome } & \multicolumn{6}{|c|}{ Group } & \multirow{3}{*}{$\begin{array}{c}95 \% \text { CI } \\
\text { for Mean } \\
\text { Difference }\end{array}$} & \multirow[b]{3}{*}{$\mathrm{t}$} & \multirow[b]{3}{*}{ df } & \multirow[b]{3}{*}{$p$} \\
\hline & \multicolumn{3}{|c|}{ Any neighbor } & \multicolumn{3}{|c|}{ Neighbor with MI } & & & & \\
\hline & $\mathrm{M}$ & $\mathrm{SD}$ & $\mathrm{n}$ & $\mathrm{M}$ & $\mathrm{SD}$ & $\mathrm{n}$ & & & & \\
\hline $\begin{array}{l}\text { Superficial } \\
\text { neighboring }\end{array}$ & 4.08 & .95 & 138 & 4.19 & .8 & 138 & $-.01, .23$ & 1.83 & 137 & .07 \\
\hline $\begin{array}{l}\text { Close } \\
\text { neighboring }\end{array}$ & 3.54 & 1.1 & 138 & 3.41 & 1.07 & 138 & $-.3, .04$ & -1.54 & 17 & .13 \\
\hline
\end{tabular}


NEIGHBOR PERCEPTIONS OF SUPPORTIVE HOUSING

Table 12

Impact on the neighborhood, including concerns and benefits

\begin{tabular}{|c|c|c|c|c|}
\hline Theme & $n$ & Subtheme & $n$ & Description \\
\hline \multicolumn{5}{|c|}{ Negative impact $(n=6)$} \\
\hline \multirow[t]{3}{*}{$\begin{array}{l}\text { Concerns } \\
\text { about safety } \\
\text { and crime }\end{array}$} & \multirow[t]{3}{*}{4} & $\begin{array}{l}\text { Association } \\
\text { with } \\
\text { homelessness }\end{array}$ & 3 & $\begin{array}{l}\text { Contributes to homelessness or associated with } \\
\text { homelessness; neighbors discuss the two issues together }\end{array}$ \\
\hline & & $\begin{array}{l}\text { Unease/ } \\
\text { discomfort }\end{array}$ & 3 & $\begin{array}{l}\text { Makes neighbors uncomfortable, feel unsafe, makes } \\
\text { children feel unsafe, uneasy }\end{array}$ \\
\hline & & $\begin{array}{l}\text { Contributes to } \\
\text { crime/ } \\
\text { vandalism }\end{array}$ & 2 & $\begin{array}{l}\text { Suspected or known association to vandalism or crime } \\
\text { in the neighborhood }\end{array}$ \\
\hline \multirow[t]{3}{*}{ Disruptive } & \multirow[t]{3}{*}{4} & $\begin{array}{l}\text { Disruptive - } \\
\text { Traffic }\end{array}$ & 1 & Disruptive traffic \\
\hline & & $\begin{array}{l}\text { Disruptive - } \\
\text { behaviors }\end{array}$ & 3 & Yelling, fights \\
\hline & & $\begin{array}{l}\text { Disruptive - } \\
\text { emergency } \\
\text { vehicles }\end{array}$ & 1 & Disruptive emergency vehicles \\
\hline $\begin{array}{l}\text { Other/ no } \\
\text { advantage }\end{array}$ & 1 & $\begin{array}{l}\text { Other/ no } \\
\text { advantage }\end{array}$ & 1 & Other negative \\
\hline \multicolumn{5}{|c|}{ Neutral or no impact $(n=11)$} \\
\hline \multirow[t]{2}{*}{$\begin{array}{l}\text { No impact/ } \\
\text { Neutral }\end{array}$} & \multirow[t]{2}{*}{11} & Other - neutral & 5 & $\begin{array}{l}\text { Other neutral comment; respondent had no concerns, no } \\
\text { advantages }\end{array}$ \\
\hline & & No impact & 9 & $\begin{array}{l}\text { Goes unnoticed, "none" or "no impact", low profile, } \\
\text { quiet }\end{array}$ \\
\hline \multicolumn{5}{|c|}{ Positive impact $(n=14)$} \\
\hline \multirow{2}{*}{$\begin{array}{l}\text { Community } \\
\text { values } \\
\text { (diversity, } \\
\text { integration, } \\
\text { housing) }\end{array}$} & \multirow[t]{2}{*}{9} & $\begin{array}{l}\text { Increased } \\
\text { diversity, } \\
\text { integration }\end{array}$ & 3 & $\begin{array}{l}\text { Presence of housing site increases diversity, aligned } \\
\text { with personal values of diversity and integration }\end{array}$ \\
\hline & & $\begin{array}{l}\text { Glad they } \\
\text { have a home }\end{array}$ & 6 & $\begin{array}{l}\text { Glad the option exists for people, glad they have } \\
\text { somewhere to go }\end{array}$ \\
\hline \multirow{3}{*}{$\begin{array}{l}\text { Building } \\
\text { and clients } \\
\text { are good } \\
\text { neighbors }\end{array}$} & \multirow[t]{3}{*}{9} & Well managed & 3 & $\begin{array}{l}\text { Building and clients are well managed; building is well } \\
\text { maintained }\end{array}$ \\
\hline & & $\begin{array}{l}\text { Good } \\
\text { neighbors }\end{array}$ & 5 & $\begin{array}{l}\text { They are good neighbors, it's good for the } \\
\text { neighborhood }\end{array}$ \\
\hline & & $\begin{array}{l}\text { Fit in, not } \\
\text { disruptive }\end{array}$ & 5 & Building is quiet, low profile, clients are not disruptive \\
\hline \multirow{2}{*}{$\begin{array}{l}\text { No } \\
\text { concerns/ } \\
\text { Other }\end{array}$} & \multirow[t]{2}{*}{10} & other & 2 & Other positive comment, general positive perception \\
\hline & & No concerns & 6 & $\begin{array}{l}\text { Respondent had no concerns - implication was there } \\
\text { was nothing to worry about }\end{array}$ \\
\hline
\end{tabular}

Notes. $n$ reflects number of participants with a response that was coded into the valence category (negative, neutral, or positive), theme and subtheme. Participants responses may have had multiple valences, themes, or subthemes. 


\section{Table 13}

Sample of participant responses to $R Q 9$

\begin{tabular}{|c|c|c|c|c|}
\hline & Participant 1 & Participant 2 & Participant 3 & Participant 4 \\
\hline Opinion changed? & & $\begin{array}{l}\text { CHANGED - } \\
\text { people seem } \\
\text { normal; more } \\
\text { aware of own } \\
\text { prejudice now }\end{array}$ & & \\
\hline $\begin{array}{r}\text { Opinion } \\
\text { unchanged? }\end{array}$ & $\begin{array}{l}\text { UNCHANGED - } \\
\text { mixed nervous but } \\
\text { they haven't hurt } \\
\text { anyone/ done } \\
\text { anything bad. } \\
\text { Need help, } \\
\text { housing is good } \\
\text { for them }\end{array}$ & & $\begin{array}{l}\text { UNCHANGED - } \\
\text { positive - care } \\
\text { about all people } \\
\text { regardless }\end{array}$ & $\begin{array}{l}\text { UNCHANGED - } \\
\text { personal } \\
\text { experience } \\
\text { growing up }\end{array}$ \\
\hline Opinion based on.. & $\begin{array}{l}\text { Don't know, no } \\
\text { personal } \\
\text { experience or } \\
\text { interaction with } \\
\text { residents }\end{array}$ & $\begin{array}{l}\text { Personal } \\
\text { experiences more } \\
\text { of an impact - } \\
\text { personal disability }\end{array}$ & $\begin{array}{l}\text { Personal } \\
\text { experience } \\
\text { influences opinion } \\
\text { - Job-MH }\end{array}$ & $\begin{array}{l}\text { Personal } \\
\text { experience - } \\
\text { father's drug use, } \\
\text { family MH issues } \\
\text { Personal } \\
\text { experience - job - } \\
\text { medical billing, } \\
\text { but familiar with } \\
\text { client issues }\end{array}$ \\
\hline \multirow[t]{2}{*}{$\begin{array}{l}\text { Housing clients } \\
\text { likely to be same } \\
\text { or different from } \\
\text { others with MI? }\end{array}$} & $\begin{array}{l}\text { DIFFERENT - } \\
\text { more support from } \\
\text { social workers to } \\
\text { be safer with and } \\
\text { in community, } \\
\text { help with nutrition }\end{array}$ & $\begin{array}{l}\text { DIFFERENT - } \\
\text { better off than } \\
\text { others, wouldn't } \\
\text { know they have } \\
\text { MI }\end{array}$ & $\begin{array}{l}\text { DIFFERENT } \\
\text { compared to other } \\
\text { MI - negative - } \\
\text { unusual social } \\
\text { behavior }\end{array}$ & $\begin{array}{l}\text { DIFFERENT - } \\
\text { they're getting } \\
\text { help, are in a safe } \\
\text { place. Others } \\
\text { might not be }\end{array}$ \\
\hline & maybe & $\begin{array}{l}\text { DIFFERENT - } \\
\text { they get more } \\
\text { support }\end{array}$ & $\begin{array}{l}\text { DIFFERENT - } \\
\text { people in housing } \\
\text { have more } \\
\text { problems than } \\
\text { those not in } \\
\text { housing }\end{array}$ & $\begin{array}{l}\text { DIFFERENT - } \\
\text { they are taking } \\
\text { initiative to get } \\
\text { help }\end{array}$ \\
\hline
\end{tabular}


Table 14

\section{Suggestions for improving neighbor relations}

\begin{tabular}{|c|c|c|c|}
\hline Theme & Subtheme & Description & Count \\
\hline \multirow{5}{*}{$\begin{array}{l}\text { Awareness and } \\
\text { education } \\
(\mathrm{n}=12)\end{array}$} & $\begin{array}{l}\text { Inform the neighborhood } \\
\text { about the housing }\end{array}$ & $\begin{array}{l}\text { Tell the neighborhood about the } \\
\text { housing site }\end{array}$ & 5 \\
\hline & Educate neighbors about MI & $\begin{array}{l}\text { Educate the neighbors about mental } \\
\text { illness, the needs of people with MI, } \\
\text { what it is or is not, that they are like } \\
\text { everyone else; educate neighbors about } \\
\text { diversity }\end{array}$ & 9 \\
\hline & $\begin{array}{l}\text { Alleviate fears/address } \\
\text { concerns }\end{array}$ & $\begin{array}{l}\text { Neighbors might be afraid but they } \\
\text { don't need to be; Address their concerns } \\
\text { directly }\end{array}$ & 3 \\
\hline & $\begin{array}{l}\text { Tell people before they buy } \\
\text { a home }\end{array}$ & $\begin{array}{l}\text { Inform people before they buy a home } \\
\text { that the housing is in the neighborhood }\end{array}$ & 2 \\
\hline & $\begin{array}{l}\text { Prejudice/stigma against } \\
\text { people with MI }\end{array}$ & $\begin{array}{l}\mathrm{R} \text { believes people are prejudiced } \\
\text { towards individuals with mental illness }\end{array}$ & 4 \\
\hline \multirow{5}{*}{$\begin{array}{l}\text { Social interaction } \\
\text { with residents } \\
(\mathrm{n}=11)\end{array}$} & Talk to them (informal) & $\begin{array}{l}\text { Talk to the housing site residents; say } \\
\text { "hi" in passing; greet them on the bus }\end{array}$ & 6 \\
\hline & Neighborhood party/events & $\begin{array}{l}\text { Organize neighborhood get-togethers } \\
\text { like block parties, housewarming events }\end{array}$ & 4 \\
\hline & $\begin{array}{l}\text { No contrived/forced social } \\
\text { interactions }\end{array}$ & $\begin{array}{l}\text { Don't assume the housing residents } \\
\text { want to be more integrated; don't put } \\
\text { them on display; don't force social } \\
\text { interactions }\end{array}$ & 4 \\
\hline & $\begin{array}{l}\text { Appropriate resident social } \\
\text { behavior }\end{array}$ & $\begin{array}{l}\text { Residents should display appropriate } \\
\text { social behavior to gain the trust of } \\
\text { neighbors; should have training on } \\
\text { social interaction }\end{array}$ & 2 \\
\hline & $\begin{array}{l}\text { People in the neighborhood } \\
\text { keep to themselves, } \\
\text { including housing residents }\end{array}$ & $\begin{array}{l}\text { The housing residents keep to } \\
\text { themselves; they don't' participate in } \\
\text { the community }\end{array}$ & 4 \\
\hline \multirow[t]{2}{*}{$\begin{array}{l}\text { Assimilation } \\
(\mathrm{n}=5)\end{array}$} & $\begin{array}{l}\text { Housing is not } \\
\text { distinguishable; accepted } \\
\text { neighborhood feature }\end{array}$ & $\begin{array}{l}\text { Building is low profile and has no } \\
\text { impact on the neighborhood; you } \\
\text { wouldn't know it was there or different } \\
\text { from other buildings; } \\
\text { The housing and residents are already } \\
\text { accepted; nothing need be done }\end{array}$ & 3 \\
\hline & Good management & Supervision; clean and in good repair & 2 \\
\hline Nothing & Not possible to do anything & $\begin{array}{l}\text { We lack the resources to address the } \\
\text { problem; can't change how people were } \\
\text { raised and resultant behaviors }\end{array}$ & 3 \\
\hline other & other & $\begin{array}{l}\text { Change opinions one person at a time; } \\
\text { don't talk to them; language barrier } \\
\text { prevents community cohesion; } \\
\text { residents' self-imposed barriers/lack of } \\
\text { self-confidence; other suggestions }\end{array}$ & 7 \\
\hline
\end{tabular}


Table 15

Results of independent samples t-tests and descriptive statistics for RQ 12

\begin{tabular}{|c|c|c|c|c|c|c|c|c|c|}
\hline \multirow[t]{3}{*}{ Outcome } & \multicolumn{6}{|c|}{ Group } & \multirow{3}{*}{$\begin{array}{l}95 \% \text { CI for } \\
\text { Mean } \\
\text { Difference }\end{array}$} & \multirow[b]{3}{*}{$\mathrm{t}$} & \multirow[b]{3}{*}{ df } \\
\hline & \multicolumn{3}{|c|}{ CHARP } & \multicolumn{3}{|c|}{ NASH } & & & \\
\hline & $\mathrm{M}$ & SD & $\mathrm{n}$ & $\mathrm{M}$ & SD & $\mathrm{n}$ & & & \\
\hline $\begin{array}{l}\text { UCLA } \\
\text { Loneliness }\end{array}$ & 2.13 & .81 & 67 & 1.9 & .61 & 139 & $.01, .45$ & $2.04^{*}$ & 102 \\
\hline $\begin{array}{l}\text { Devaluation- } \\
\text { Discrimination }\end{array}$ & 3.43 & .67 & 67 & 3.37 & .67 & 138 & $-.14, .26$ & .61 & 131 \\
\hline $\begin{array}{l}\text { Neighborhood } \\
\text { Social Climate }\end{array}$ & 3.8 & .61 & 68 & 3.93 & .71 & 139 & $-.33, .065$ & -1.33 & 205 \\
\hline $\begin{array}{l}\text { Neighbor } \\
\text { Relations }\end{array}$ & 3.49 & .83 & 68 & 3.67 & .82 & 139 & $-.42, .06$ & -1.47 & 133 \\
\hline Safety & 4.76 & 1.26 & 66 & 4.02 & 1.42 & 137 & $.34,1.14$ & $3.62 * *$ & 201 \\
\hline
\end{tabular}

Note: $* p<.05 . * * p<.001$ 


\section{Figures}

Figure 1

The number of published peer-reviewed articles on neighbor reactions to psychiatric community-based housing declined between 1980 and 2017

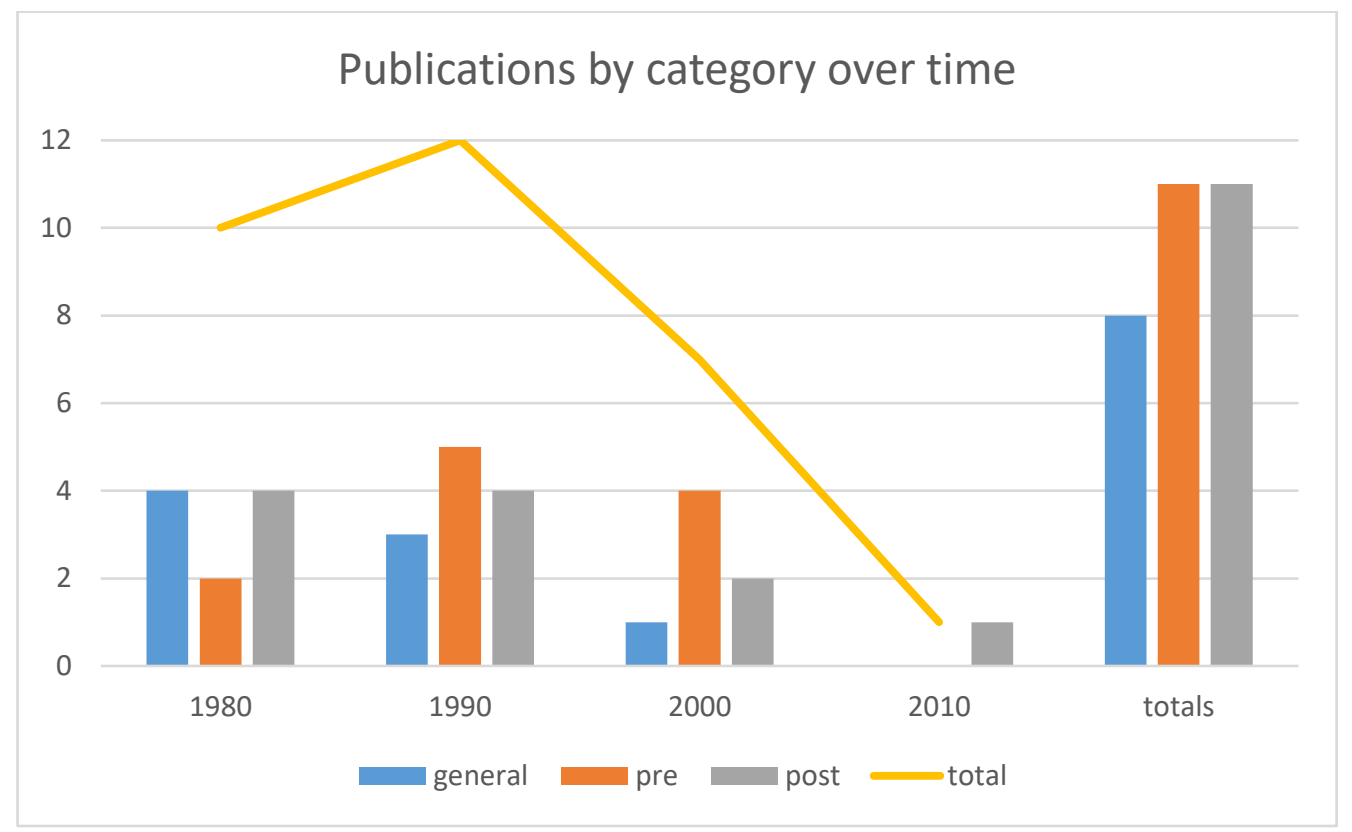

Note: Publications are grouped by general population, pre-development (future neighbors), and post-development (current neighbors) studies. 
Figure 2

Example housing site location and canvassing quadrants

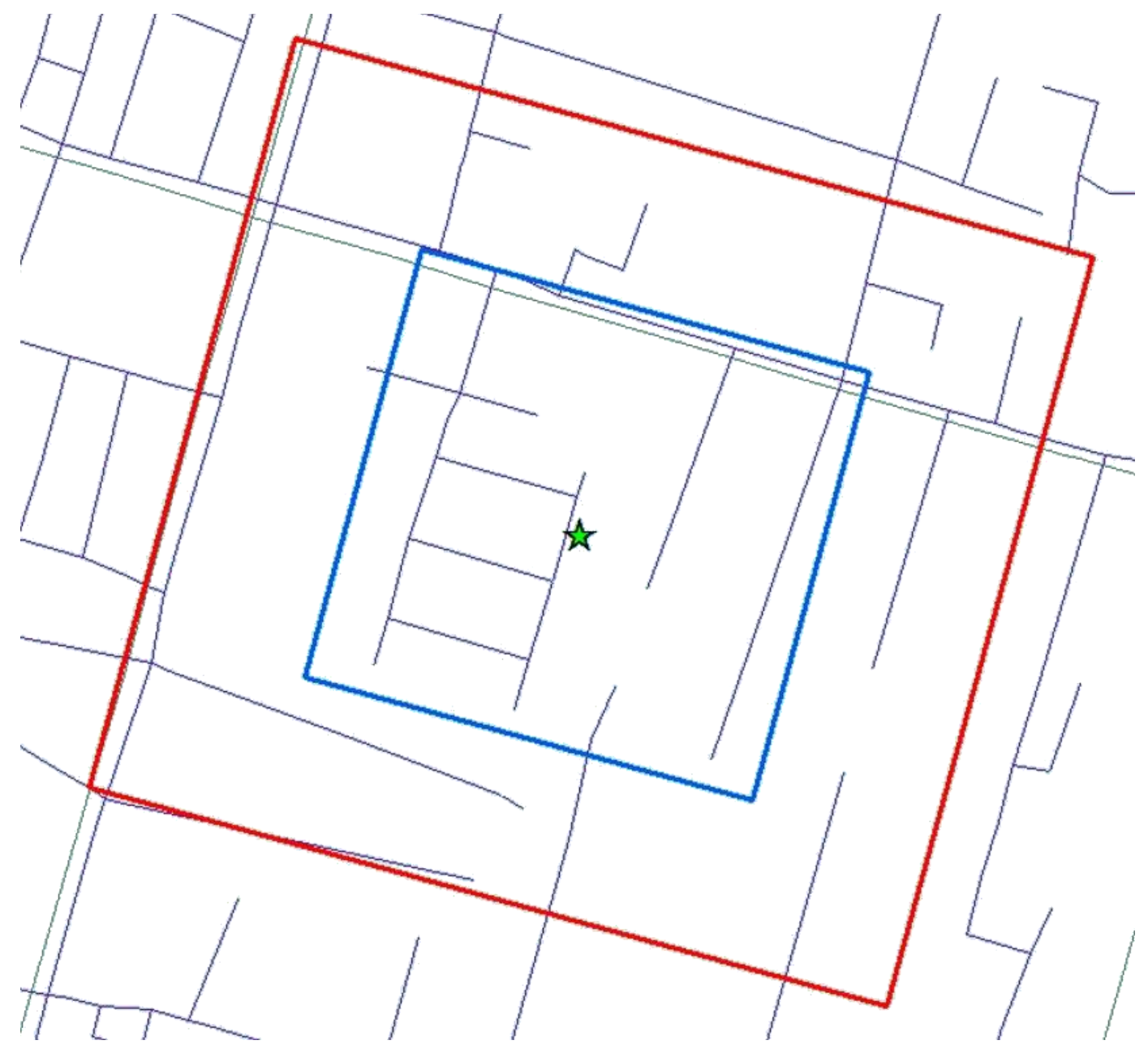


Figure 3

Study design

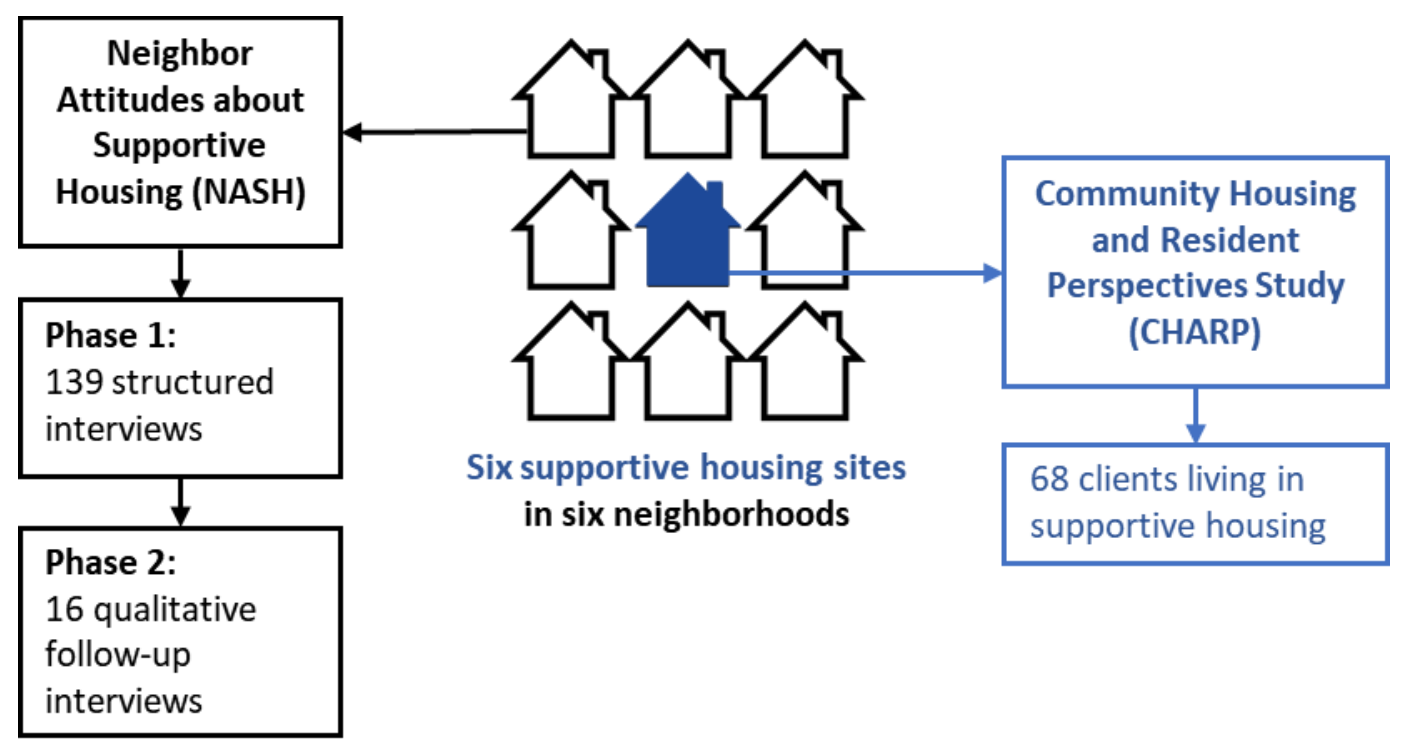




\section{References}

2013 Poverty Guidelines. (2013). Retrieved April 29, 2018, from https://aspe.hhs.gov/2013-poverty-guidelines

Allport, G. (1954). The nature of prejudice. Oxford, England: Addison-Wesley.

Ampalam, P., Padma, V., Pratheek, V. R., \& Bukya, K. (2018). Positive attitudinal trends towards mental illness: Changing scenario. Global Journal for Research Analysis, 7(1). Retrieved from https://wwjournals.com/index.php/gjra/article/view/77

Annual Estimates of the Resident Population: 2015 Population Estimates. (2015). Retrieved March 22, 2017, from https://factfinder.census.gov/faces/tableservices/jsf/pages/productview.xhtml?src=bk $\mathrm{mk}$

Arens, D. A. (1993). What do the neighbors think now? Community residences on Long Island, New York. Community Mental Health Journal, 29(3), 235-245.

Aubry, T. D., Tefft, B., \& Currie, R. F. (1995). Public attitudes and intentions regarding tenants of community mental health residences who are neighbours. Community Mental Health Journal, 31(1), 39-52. https://doi.org/10.1007/BF02188979

Aubry, T., \& Myner, J. (1996). Community integration and quality of life: a comparison of persons with psychiatric disabilities in housing programs and community residents who are neighbors. Canadian Journal of Community Mental Health $=$ Revue Canadienne de Sante Mentale Communautaire, 15(1), 5-20. Retrieved from http://www.ncbi.nlm.nih.gov/pubmed/10163559

Azjen, I. (1985). From intentions to actions: A theory of planned behavior. In Action Control (pp. 11-39). Berlin, Heidelberg: Springer Berlin Heidelberg.

Azjen, I. (2014). The theory of planned behaviour is alive and well, and not ready to retire: a commentary on Sniehotta, Presseau, and Araújo-Soares. Health Psychology Review. Retrieved from https://www.researchgate.net/profile/Icek_Ajzen/publication/263228691_The_Theor y_of_Planned_Behaviour_is_Alive_and_Well_and_not_Ready_to_Retire_A_Comm entary_on_Sniehotta_Presseau_and_Araujo-

Soares/links/0c96053a305faae8a1000000/The-Theory-of-Planned-Behav

Azjen, I., \& Fishbein, M. (1988). Theory of reasoned action - Theory of planned behavior.

Bickman, I. L., \& Reich, S. M. (2009). Randomized Controlled Trials: A gold standard or gold plated? In What Counts as Credible Evidence in Applied Research and Evaluation Practice? Thousand Oaks, CA: Sage. Retrieved from http://sites.uci.edu/disc/files/2016/10/RCT-Bickman-_-Reich-2015.pdf

Boeckh, J. (1980). Property values and mental health facilities in metropolitan Toronto. The Canadian Geographer, 24(3), 270-285.

Bonabi, H. ;, Müller, M. ;, Ajdacic-Gross, V. ;, Eisele, J. ;, Rodgers, S. ;, Seifritz, E. ;, ... 
Rüsch, N. (2016). Mental Health Literacy, Attitudes to Help Seeking, and Perceived Need as Predictors of Mental Health Service Use: A Longitudinal Study. Journal of Nervous and Mental Disease, 204(4), 321-324. Retrieved from https://doi.org/10.1097/NMD.0000000000000488

Borinstein, A. B. (1992). Public attitudes towards persons with mental illness. Health Affairs, 11(3), 186-196. https://doi.org/10.1377/hlthaff.11.3.186

Bornstein, R., \& Craver-Lemley, C. (2016). Mere Exposure Effect. In Cognitive Illusions: Intriguing Phenomena in Judgement,Thinking and Memory (p. 256).

Braun, V., \& Clarke, V. (2006). Using thematic analysis in psychology. Qualitative Research in Psychology, 3(2), 77-101. https://doi.org/10.1191/1478088706qp063oa

Braun, V., \& Clarke, V. (2012). Thematic Analysis. In APA handbook of research methods in psychology, Vol 2: Research designs: Quantitative, qualitative, neuropsychological, and biological. (Vol. 2, pp. 57-71). https://doi.org/10.1037/13620-004

Bromley, E., Gabrielian, S., Brekke, B., Pahwa, R., Daly, K. a, Brekke, J. S., \& Braslow, J. T. (2013). Experiencing community: Perspectives of individuals diagnosed as having serious mental illness. Psychiatric Services, 64(7), 672-679. https://doi.org/http://dx.doi.org/10.1176/appi.ps.201200235

Bronfenbrenner, U. (1977). Toward an experimental ecology of human development. American Psychologist, 32(7), 513-531. Retrieved from http://maft.dept.uncg.edu/hdf/facultystaff/Tudge/Bronfenbrenner 1977.pdf

Brusilovskiy, E., Townley, G., Snethen, G., \& Salzer, M. S. (2016). Social media use, community participation and psychological well-being among individuals with serious mental illnesses. Computers in Human Behavior, 65, 232-240. https://doi.org/10.1016/j.chb.2016.08.036

Bureau, U. S. C. (2016). American Community Survey 1 Year Estimates. Retrieved from https://factfinder.census.gov/faces/tableservices/jsf/pages/productview.xhtml?pid=A CS_16_1YR_S1903\&prodType $=$ table

Carling, P. J. (1993). Housing and supports for persons with mental illness: emerging approaches to research and practice. Hospital \& Community Psychiatry, 44(5), 439449. https://doi.org/10.1176/ps.44.5.439

Chetty, R., Hendren, N., Kline, P., Saez, E., \& Turner, N. (2014). Is the United States Still a Land of Opportunity? Recent Trends in Intergenerational Mobility. NBER Working Paper Series, 19844. Retrieved from http://www.nber.org/papers/w19844

Cheung, F. M. (1990). People against the mentally ill: Community opposition to residential treatment facilities. Community Mental Health Journal, 26(2), 205-212. Retrieved from https://ill.lib.pdx.edu/PDF/434797.pdf

Clark, W., Welch, S. N., Berry, S. H., Collentine, A. M., Collins, R., Lebron, D., \& Shearer, A. L. (2013). California's historic effort to reduce the stigma of mental 
NEIGHBOR PERCEPTIONS OF SUPPORTIVE HOUSING

illness: the Mental Health Services Act. American Journal of Public Health, 103(5), 786-794. https://doi.org/10.2105/AJPH.2013.301225

Cohen, J., \& Struening, E. L. (1962). Opinions about mental illness in the personnel of two large mental hospitals. The Journal of Abnormal and Social Psychology, 64(5), 349-360. https://doi.org/10.1037/h0045526

Collins, R. L., Wong, E. C., Roth, E., Cerully, J. L., \& Marks, J. (2015). Changes in Mental Illness Stigma in California During the Statewide Stigma and Discrimination Reduction Initiative. Rand Health Quarterly, 5(2), 10. Retrieved from http://www.ncbi.nlm.nih.gov/pubmed/28083386

Colton, C. W., \& Manderscheid, R. W. (2006). Congruencies in increased mortality rates, years of potential life lost, and causes of death among public mental health clients in eight states. Preventing Chronic Disease, 3(2), A42. Retrieved from http://www.ncbi.nlm.nih.gov/pubmed/16539783

Colwell, P. F., Dehring, C. A., \& Lash, N. A. (2000). The effect of group homes on neighborhood property values. Land Economics, 76(4), 615-637.

Concato, J. (2004). Observational versus experimental studies: what's the evidence for a hierarchy? NeuroRx: The Journal of the American Society for Experimental NeuroTherapeutics, 1(3), 341-347. https://doi.org/10.1602/neurorx.1.3.341

Cooke, R., \& French, D. P. (2008). How well do the theory of reasoned action and the theory of planned behaviour predict intentions and attendance at screening programmes? A meta-analysis. Psychology and Health, 23, 745-765. Retrieved from http://publications.aston.ac.uk/16782/1/Intentions_and_attendance_at_screening_pro grammes.pdf

Corrigan, P. W. (2011). Best Practices: Strategic Stigma Change (SSC): Five Principles for Social Marketing Campaigns to Reduce Stigma. Psychiatric Services, 62(8), 824-826. https://doi.org/10.1176/ps.62.8.pss6208_0824

Corrigan, P. W., Edwards, A. B., Qreen, A., Thwart, S. L., \& Perm, D. L. (2001). Prejudice, Social Distance, and Familiarity with Mental Illness. Schizophrenia Bulletin, 27(2), 219-225.

Corrigan, P. W., Morris, S. B., Michaels, P. J., Rafacz, J. D., \& Rüsch, N. (2012). Challenging the Public Stigma of Mental Illness: A Meta-Analysis of Outcome Studies. Psychiatric Services, 63(10), 963-973. https://doi.org/10.1176/appi.ps.201100529

Corrigan, P. W., \& Penn, D. L. (1999). Lessons from social psychology on discrediting psychiatric stigma. American Psychologist, 54(9), 765-776. Retrieved from https://search-proquestcom.proxy.lib.pdx.edu/docview/614335521/fulltextPDF/D276D65F7EAB46B8PQ/1 ?accountid $=13265$

Corrigan, P. W., \& Penn, D. L. (1999). Lessons from social psychology on discrediting 
psychiatric stigma. The American Psychologist, 54(9), 765-776.

https://doi.org/10.1037/0003-066X.54.9.765

Corrigan, P. W., \& Watson, A. C. (2002). Understanding the impact of stigma on people with mental illness. World Psychiatry.

Coulton, C. (2012). Defining neighborhoods for research and policy. Cityscape: A Journal of Policy Development and Research, 14(2), 231-236. Retrieved from http://citeseerx.ist.psu.edu/viewdoc/download?doi=10.1.1.306.5464\&rep=rep1\&typ $\mathrm{e}=$ pdf $\#$ page $=237$

Cowan, S. (1999). Understanding public opinion relating to the establishment of community mental health facilities: Implications of a discourse analytic approach. Journal of Community and Applied Social Psychology, 9(4), 289-306. https://doi.org/10.1002/(SICI)1099-1298(199907/08)9:4<289::AIDCASP513>3.0.CO;2-R

Cowan, S. (2003). NIMBY syndrome and public consultation policy: the implications of a discourse analysis of local responses to the establishment of a community mental health facility. Health and Social Care in the Community, 11(5), 379-386.

Currie, R. F., Trute, B., Tefft, B., \& Segall, A. (1989). Maybe on my street: The politics of community placement of the mentally disabled. Urban Affairs Quarterly, 25(2), 298-321.

Davidson, L., Chinman, M., Sells, D., Rowe, M., \& Mckenzie, D. B. (2006). Peer Support Among Adults With Serious Mental Illness: A Report From the Field. Schizophrenia Bulletin, 32(3), 443-450. https://doi.org/10.1093/schbul/sbj043

Dear, M. J. (1992). Understanding and Overcoming the NIMBY Syndrome. Journal of the American Planning Association Summer, 58(3), 288-300.

Dear, M. J., Taylor, S. M., \& Hall, G. B. (1980). External effects of mental health facilities. Annals of the Association of American Geographers, 70(3), 342-352.

Desmond, M. (2018). Heavy is the House: Rent Burden among the American Urban Poor. International Journal of Urban and Regional Research, 42(1), 160-170. https://doi.org/10.1111/1468-2427.12529

Dimensions of Quality Supportive Housing, Second Edition. (2013).

Druss, B. G., Chair, R. C., \& Walker, E. R. (2011). Mental disorders and medical comorbidity. Princeton, NJ. Retrieved from https://www.integration.samhsa.gov/workforce/mental_disorders_and_medical_com orbidity.pdf

Eklund, M., \& Hansson, L. (2007). Social Network Among People With Persistent Mental Illness: Associations With Sociodemographic, Clinical and Health-Related Factors. International Journal of Social Psychiatry, 53(4), 293-305. https://doi.org/10.1177/0020764006074540

Espí Forcén, C., \& Espí Forcén, F. (2014). Demonic possessions and mental illness: 
discussion of selected cases in late medieval hagiographical literature. Early Science and Medicine, 19(3), 258-279. Retrieved from http://www.ncbi.nlm.nih.gov/pubmed/25208453

Evans-Lacko, S., Henderson, C., \& Thornicroft, G. (2013). Public knowledge, attitudes and behaviour regarding people with mental illness in England 2009-2012. British Journal of Psychiatry, 202(SUPPL.55), 51-58. https://doi.org/10.1192/bjp.bp.112.112979

Evans-lacko, S., Little, K., Meltzer, H., Rose, D., Rhydderch, D., Henderson, C., \& Thornicroft, G. (2010). Mental Health Knowledge Schedule. Canadian Journal of Psychiatry, 55(7), 157-165.

Evans-Lacko, S., London, J., Japhet, S., Rüsch, N., Flach, C., Corker, E., ... Thornicroft, G. (2012). Mass social contact interventions and their effect on mental health related stigma and intended discrimination. BMC Public Health, 12(489).

https://doi.org/10.1186/1471-2458-12-489

Evans-Lacko, S., Malcolm, E., West, K., Rose, D., London, J., Rüsch, N., ... Thornicroft, G. (2013). Influence of Time to Change's social marketing interventions on stigma in England 2009-2011. The British Journal of Psychiatry. Supplement, 55(s55), s7788. https://doi.org/10.1192/bjp.bp.113.126672

Evans-Lacko, S., Rose, D., Little, K., Flach, C., Rhydderch, D., Henderson, C., \& Thornicroft, G. (2011). Development and psychometric properties of the Reported and Intended Behaviour Scale (RIBS): A stigma-related behaviour measure. Epidemiology and Psychiatric Sciences, 20(3), 263-271. https://doi.org/10.1017/S2045796011000308

Fowler, F. J. (1995). Improving survey questions : design and evaluation. Sage Publications.

Gaebel, W., Baumann, A., Witte, A. M., \& Zaeske, · H. (2002). Public attitudes towards people with mental illness in six German cities Results of a public survey under special consideration of schizophrenia. Eur Arch Psychiatry Clin Neurosci, 252, 278-287. https://doi.org/10.1007/s00406-002-0393-2

Gaebel, W., Zäske, H., Baumann, A. E., Klosterkötter, J., Maier, W., Decker, P., \& Möller, H.-J. (2008). Evaluation of the German WPA "Program against stigma and discrimination because of schizophrenia - Open the Doors": Results from representative telephone surveys before and after three years of antistigma interventions. Schizophrenia Research, 98(1-3), 184-193. https://doi.org/10.1016/J.SCHRES.2007.09.013

Galster, G., Tatian, P., \& Pettit, K. (2004). Supportive housing and neighborhood property value externalities. Land Economics, 80(1), 33-54.

Goldberg, L. R. (1993). The structure of phenotypic personality traits. American Psychologist, 48(1), 26-34. Retrieved from http://psych.colorado.edu/ carey/courses/psyc5112/readings/psnstructure_goldberg. 
NEIGHBOR PERCEPTIONS OF SUPPORTIVE HOUSING

pdf

Graham, L., \& Hogan, R. (1990). Social class and tactics: Neighborhood opposition to group homes. Sociological Quarterly, 31(4), 513-529. https://doi.org/10.1111/j.1533-8525.1990.tb00726.x

Granerud, A., \& Severinsson, E. (2006). The struggle for social integration in the community - the experiences of people with mental health problems. Journal of Psychiatric and Mental Health Nursing, 13(3), 288-293. https://doi.org/10.1111/j.1365-2850.2006.00950.x

Graves, L. (2017, February 21). Proposed transitional housing leads to contentious community meeting in Aloha|KATU. KATU News. Retrieved from http://katu.com/news/local/proposed-transitional-housing-leads-to-contentiouscommunity-meeting-in-aloha

Griffith, J. D., Hart, C. L., \& Brickel, M. (2010). Using vignettes to change knowledge and attitudes about rape. College Student Journal, 44(2), 515-528. Retrieved from http://go.galegroup.com/ps/anonymous?id=GALE\%7CA228428437\&sid=googleSc holar\&v=2.1\&it=r\&linkaccess $=$ fulltext $\&$ issn $=01463934 \& p=A O N E \& s w=w \&$ authC ount $=1 \&$ isAnonymousEntry=true

Grob, G. N. (2005). Public policy and mental illnesses: Jimmy Carter's Presidential Commission on Mental Health. The Milbank Quarterly, 83(3), 425-456. https://doi.org/10.1111/j.1468-0009.2005.00408.x

Groves, Fowler, Couper, Singer, \& Tourangeau. (2009). Chapter One an Introduction To Survey Methodology. Surthey Methods.

Gulcur, L., Tsemberis, S., Stefancic, A., \& Greenwood, R. M. (2007). Community integration of adults with psychiatric disabilities and histories of homelessness. Community Mental Health Journal, 43(3), 211-228. https://doi.org/10.1007/s10597006-9073-4

Heiman, M. (1990). From "Not in My Backyard!” to "Not in Anybody"s Backyard!'. Journal of the American Planning Association, 56(3), 359-362. https://doi.org/10.1080/01944369008975779

Henderson, C., Evans-Lacko, S., Flach, C., \& Thornicroft, G. (2012). Responses to Mental Health Stigma Questions: The Importance of Social Desirability and Data Collection Method. Canadian Journal of Psychiatry, 57(3), 152-160. Retrieved from http://journals.sagepub.com/doi/pdf/10.1177/070674371205700304

Hogan, R. (1986). Gaining community support for group homes. Community Mental Health Journal, 22(2), 117-126. https://doi.org/10.1007/BF00754550

Home and Community Based Services. (2017). Baltimore, MD. Retrieved from https://www.cms.gov/Newsroom/MediaReleaseDatabase/Fact-sheets/2014-Factsheets-items/2014-01-10-2.html

Høyersten, J. G. (1996). Possessed! Some historical, psychiatric and curent moments of 
demonic possession. Tidsskrift for Den Norske Laegeforening : Tidsskrift for Praktisk Medicin, Ny Raekke, 116(30), 3602.

Hunter, S., Harvey, M., Briscombe, B., \& Cefalu, M. (2017). Evaluation of Housing for Health Permanent Supportive Housing Program. RAND Corporation. https://doi.org/10.7249/RR1694

Insel, T. R. (2008). Assessing the Economic Costs of Serious Mental Illness. American Journal of Psychiatry, 165(6), 663-665. https://doi.org/10.1176/appi.ajp.2008.08030366

Jorm, A. F., Christensen, H., \& Griffiths, K. M. (2005). The impact of beyondblue: the national depression initiative on the Australian public's recognition of depression and beliefs about treatments. Australian and New Zealand Journal of Psychiatry, 39(4), 248-254. https://doi.org/10.1111/j.1440-1614.2005.01561.X

Kessler, R. C., Berglund, P. A., Bruce, M. L., Koch, J. R., Laska, E. M., Leaf, P., ... Wang, P. S. (2001). Articles The Prevalence and Correlates of Untreated Serious Mental Illness. Health Services Research, 36(6), 987-1007. Retrieved from https://www.ncbi.nlm.nih.gov/pmc/articles/PMC1089274/pdf/hsresearch000070020.pdf

Key substance use and mental health indicators in the United States: Results from the 2016 National Survey on Drug Use and Health (HHS Publication No. SMA 17-5044, NSDUH Series H-52). (2017). Rockville, MD: Center for Behavioral Health Statistics and Quality, Substance Abuse and Mental Health Services Administration.

Kitchener, B. A., \& Jorm, A. F. (2002). Mental health first aid training for the public: evaluation of effects on knowledge, attitudes and helping behavior. $B M C$ Psychiatry, 2, 10. https://doi.org/10.1186/1471-244X-2-10

Kloos, B., \& Shah, S. (2009). A social ecological approach to investigating relationships between housing and adaptive functioning for persons with serious mental illness. American Journal of Community Psychology, 44(3), 316-326. https://doi.org/10.1007/s10464-009-9277-1

Krieger, N. (2006). A century of census tracts: Health \& the body politic (1906-2006). Journal of Urban Health, 83(3), 355-361. https://doi.org/10.1007/s11524-006-9040$\mathrm{y}$

Lincoln, Y., \& Guba, E. (1985). Naturalistic Inquiry. Naturalistic Inquiry. Beverly Hills: Sage. Retrieved from https://files.eric.ed.gov/fulltext/ED216019.pdf

Link, B. G., Cullen, F. T., Frank, J., \& Wozniak, J. F. (1987). The social rejection of former mental patients: Understanding why labels matter. Source: American Journal of Sociology, 92(6), 1461-1500. https://doi.org/10.1086/228672

Link, B. G., Cullen, F. T., Struening, E., Shrout, P. E., \& Bruce, P. (2013). A modified labeling theory approach to mental disorders: An empirical assessment, 54(3), 400423. 
Link, B. G., \& Phelan, J. (2014). Stigma power. Social Science \& Medicine (1982), 103, 24-32. https://doi.org/10.1016/j.socscimed.2013.07.035

Link, B. G., Yang, L. H., Phelan, J. C., \& Collins, P. Y. (2004). Measuring mental illness stigma. Schizophrenia Bulletin, 30(3), 511-541.

Maller, C., Townsend, M., Pryor, A., Brown, P., \& St Leger, L. (2006). Healthy nature healthy people: "contact with nature" as an upstream health promotion intervention for populations. Health Promotion International, 21(1), 45-54. https://doi.org/10.1093/heapro/dai032

Mårtensson, G., Jacobsson, J. W., \& Engström, M. (2014). Mental health nursing staff’s attitudes towards mental illness: an analysis of related factors. Journal of Psychiatric and Mental Health Nursing, 21(9), n/a-n/a. https://doi.org/10.1111/jpm.12145

Martone, K., \& Lerch, S. (n.d.). Olmstead Implementation. Retrieved from http://nlihc.org/sites/default/files/AG-2017/2017AG_Ch06-S04_OlmsteadImplementation.pdf

Medicine, U. S. N. L. of. (2006). Diseases of the Mind: Highlights of American Psychiatry through 1900 - Early Psychiatric Hospitals and Asylums. Retrieved February 7, 2018, from https://www.nlm.nih.gov/hmd/diseases/early.html

Metraux, S., Brusilovskiy, E., Prvu-Bettger, J. A., Irene Wong, Y. L., \& Salzer, M. S. (2012). Geographic access to and availability of community resources for persons diagnosed with severe mental illness in Philadelphia, USA. Health and Place, 18(3), 621-629. https://doi.org/10.1016/j.healthplace.2011.12.011

Montanaro, E. A., \& Bryan, A. D. (2014). Comparing Theory-Based Condom Interventions: Health Belief Model Versus Theory of Planned Behavior. Health Psychology, 33(10), 1251-1260. https://doi.org/10.1037/a0033969

Montano, D. E., \& Kasprzyk, D. (2015). Health Behavior and Health Education: Theory, Research and Practice. (K. Glanz, B. K. Rimer, \& K. Viswanath, Eds.) (5th editio). San Francisco, CA: Jossey-Bass. Retrieved from http://repository.poltekkesmajapahit.ac.id/index.php/EPOL/article/viewFile/595/507\#page $=105$

Mulud, Z. A., \& McCarthy, G. (2017). Caregiver Burden Among Caregivers of Individuals With Severe Mental Illness: Testing the Moderation and Mediation Models of Resilience. Archives of Psychiatric Nursing, 31(1), 24-30. https://doi.org/10.1016/j.apnu.2016.07.019

Occupational Employment Statistics. (2017). Retrieved April 22, 2018, from https://www.bls.gov/oes/current/oes_research_estimates.htm

Oregon Performance Plan. Retrieved from http://www.oregon.gov/oha/HPA/CSIBHP/Oregon Performance Plan/Oregon-Performance-Plan.pdf

Patrick Sullivan, W., \& Wahler, E. A. (2017). Chronic care, integrated care and mental health: Moving the needle now. Social Work in Mental Health, 1-14. 
NEIGHBOR PERCEPTIONS OF SUPPORTIVE HOUSING

https://doi.org/10.1080/15332985.2016.1265636

Pescosolido, B. A., Martin, J. K., Long, J. S., Medina, T. R., Phelan, J. C., \& Link, B. G. (2010). A Disease Like Any Other? A Decade of Change in Public Reactions to Schizophrenia, Depression, and Alcohol Dependence. American Journal of Psychiatry, 167(11), 1321-1330. https://doi.org/10.1176/appi.ajp.2010.09121743

Pettigrew, T. F., \& Tropp, L. R. (2006). A meta-analytic test of intergroup contact theory. Journal of Personality and Social Psychology, 90(5), 751-783. https://doi.org/10.1037/0022-3514.90.5.751

Phillips, D. L. (1967). Identification of mental illness: Its consequences for rejection. Community Mental Health Journal, 3(3), 262-266. https://doi.org/10.1007/BF01434882

Piat, M. (2000a). Becoming the victim: A study on community reactions towards group homes. Psychiatric Rehabilitation Journal, 24(2), 108-116.

Piat, M. (2000b). The NIMBY phenomenon: Community residents' concerns about housing for deinstitutionalized people. Health and Social Work, 25(2), 127-138.

Rabkin, J. G., Muhlin, G., \& Cohen, P. W. (1984). What the neighbors think: Community attitudes toward local psychiatric facilities. Community Mental Health Journal, 20(4), 304-312. Retrieved from https://ill.lib.pdx.edu/PDF/434793.pdf

Rich, A., Brandes, K., Mullan, B. A., \& Hagger, M. S. (2015). Theory of Planned Behavior and Adherence in Chronic Illness: A Meta-Analysis. Journal of Behavioral Medicine, 38(4), 673-688. https://doi.org/10.1007/s10865-015-9644-3

Rüsch, N., Evans-Lacko, S., \& Thornicroft, G. (2012). What is a mental illness? Public views and their effects on attitudes and disclosure. Australian and New Zealand Journal of Psychiatry, 46(7), 641-650. https://doi.org/10.1177/0004867412438873

Rüsch, N., Müller, M., Lay, B., Corrigan, P. W., Zahn, R., Schönenberger, T., ... Rössler, W. (2014). Emotional reactions to involuntary psychiatric hospitalization and stigma-related stress among people with mental illness. European Archives of Psychiatry and Clinical Neuroscience, 264(1), 35-43. https://doi.org/10.1007/s00406-013-0412-5

Russell, D., Peplau, L. a, \& Cutrona, C. E. (1980). The revised UCLA Loneliness Scale: concurrent and discriminant validity evidence. Journal of Personality and Social Psychology, 39(3), 472-480. Retrieved from http://www.ncbi.nlm.nih.gov/pubmed/7431205

Russell, D. W. (1996). UCLA v3 Reliability Validity and Factor Structure.pdf. Journal of Personality Assessment, 66(1), 20-40.

Sarason, S. B. (1974). The psychological sense of community: Prospects for a community psychology. Jossey-Bass. Retrieved from http://psycnet.apa.org/psycinfo/197501813-000

Sareen, J., Afifi, T. O., McMillan, K. A., \& Asmundson, G. J. G. (2011). Relationship 
Between Household Income and Mental Disorders. Archives of General Psychiatry, 68(4), 419. https://doi.org/10.1001/archgenpsychiatry.2011.15

Schwartz, C., \& Gronemann, O. C. (2009). The Contribution of Self-efficacy, Social Support and Participation in the Community to Predicting Loneliness among Persons with Schizophrenia Living in Supported Residences. Isr J Psychiatry Relat Sci, 46(2), 120-129. Retrieved from https://doctorsonly.co.il/wpcontent/uploads/2011/12/2009_2_6.pdf

Segal, S. P., Baumohl, J., \& Moyles, E. W. (1980). Neighborhood types and community reaction to the mentally ill: A paradox of intensity. Journal of Health and Social Behavior, 21(4), 345-359. https://doi.org/10.2307/2136411

Segal, S. P., Silverman, C., \& Temkin, T. (1997). Social Networks and Psychological Disability Among Housed and Homeless Users of Self-Help Agencies. Social Work in Health Care, 25(3), 49-61. https://doi.org/10.1300/J010v25n03_05

Sharac, J., McCrone, P., Clement, S., \& Thornicroft, G. (2010). The economic impact of mental health stigma and discrimination: A systematic review. Epidemiologia $E$ Psichiatria Sociale, 19(3), 223-232. https://doi.org/10.1017/S1121189X00001159

Simmons, L., Jones, T., \& Bradley, E. (2017). Reducing mental health stigma: The relationship between knowledge and attitude change. European Journal of Mental Health, 12(2), 25-40. https://doi.org/10.5708/EJMH.12.2017.1.2

Smith, C. J., \& Hanham, R. Q. (1981). Any place but here! Mental health facilities as noxious neighbors. Professional Geographer, 33(3), 326-334.

Sniehotta, F. F., Pressaur, J., \& Araujo-Soares, V. (2014). Time to retire the theory of planned behaviour. Health Psychology Review, 8(1), 1-7. Retrieved from https://www.tandfonline.com/doi/pdf/10.1080/17437199.2013.869710?needAccess= true

Søgaard, A. J., \& Fønnebø, V. (1995). The Norwegian Mental Health Campaign in 1992. Part II: changes in knowledge and attitudes. Health Education Research, 10(3), 267278. https://doi.org/10.1093/her/10.3.267

Solomon, P. L., \& Davis, J. M. (1984). Community attitudes toward residential facilities for psychiatric patients. Psychosocial Rehabiliation Journal, 8(2), 38-41. Retrieved from http://search.proquest.com.proxy.lib.pdx.edu/docview/1504149257?accountid=1326 5

Stein, A., Pearson, R. M., Goodman, S. H., Rapa, E., Rahman, A., Mccallum, M., ... Pariante, C. M. (2014). Perinatal mental health 3 Eff ects of perinatal mental disorders on the fetus and child. The Lancet, 384, 1800-1819. https://doi.org/10.1016/S0140-6736(14)61277-0

Survey Response Rates - Center for Innovation in Research and Teaching. (2017). Retrieved May 2, 2018, from https://cirt.gcu.edu/research/developmentresources/research_ready/designing_survey 
NEIGHBOR PERCEPTIONS OF SUPPORTIVE HOUSING

S/response_rates

Svensson, B., \& Hansson, L. (2016). How mental health literacy and experience of mental illness relate to stigmatizing attitudes and social distance towards people with depression or psychosis: A cross-sectional study. Nordic Journal of Psychiatry, 70(4), 309-313. https://doi.org/10.3109/08039488.2015.1109140

Takahashi, L. M., \& Dear, M. J. (1997). The changing dynamics of community opposition to human service facilities. Journal of the American Planning Association, 63(1), 79-93. https://doi.org/10.1080/01944369708975725

Taylor, S. M., \& Dear, M. J. (1981). Scaling community attitudes toward the mentally ill. Schizophrenia Bulletin, 7(2), 225-240. https://doi.org/10.1093/schbul/7.2.225

Taylor, S. M., Dear, M. J., \& Hall, G. B. (1979). Attitudes toward the mentally ill and reactions to mental health facilities. Social Science and Medicine, 13(4), 281-290. Retrieved from https://ill.lib.pdx.edu/PDF/435166.pdf

Thornicroft, C., Wyllie, A., Thornicroft, G., \& Mehta, N. (2014). Impact of the "Like Minds, Like Mine" anti-stigma and discrimination campaign in New Zealand on anticipated and experienced discrimination. Australian \& New Zealand Journal of Psychiatry, 48(484), 360-370. https://doi.org/10.1177/0004867413512687

Thornicroft, G., Mehta, N., Clement, S., Evans-Lacko, S., Doherty, M., Rose, D., ... Henderson, C. (2016). Evidence for eff ective interventions to reduce mental-healthrelated stigma and discrimination. The Lancet, 387(10023), 1123-1132. https://doi.org/10.1016/S0140-6736(15)00298-6

Townley, G., Kloos, B., \& Wright, P. A. (2009). Understanding the experience of place: Expanding methods to conceptualize and measure community integration of persons with serious mental illness. Health and Place, 15(2), 520-531. https://doi.org/10.1016/j.healthplace.2008.08.011

Townley, G., Miller, H., \& Kloos, B. (2013). A Little Goes a Long Way: The Impact of Distal Social Support on Community Integration and Recovery of Individuals with Psychiatric Disabilities. American Journal of Community Psychology, 52(1-2), 8496. https://doi.org/10.1007/s10464-013-9578-2

U.S. Census Bureau QuickFacts: Portland city, Oregon. (n.d.). Retrieved June 17, 2018, from https://www.census.gov/quickfacts/fact/table/portlandcityoregon/PST045217

United States Department of Justice Civil Rights Division. (n.d.). Olmstead: Community Integration for Everyone. Retrieved December 14, 2017, from https://www.ada.gov/olmstead/

Vigo, D., Thornicroft, G., \& Atun, R. (2016). Estimating the true global burden of mental illness. Lancet Psychiatry, 3, 171-178. Retrieved from https://www.emeraldproject.eu/fileadmin/websites/emerald/media/Policy_briefs/Emerald_policy_brief_ 03_March_2016.pdf

Wahl, O. F. (1993). Community impact of group homes for mentally ill adults. 
NEIGHBOR PERCEPTIONS OF SUPPORTIVE HOUSING

Community Mental Health Journal, 29(3), 247-259.

https://doi.org/10.1007/BF00778810

Walker, E. R., McGee, R. E., \& Druss, B. G. (2015). Mortality in Mental Disorders and Global Disease Burden Implications. JAMA Psychiatry, 72(4), 334.

https://doi.org/10.1001/jamapsychiatry.2014.2502

Ware, N. C., Hopper, K., Tugenberg, T., Dickey, B., \& Fisher, D. (2007). Connectedness and citizenship: redefining social integration. Psychiatric Services (Washington, D.C.), 58(4), 469-474. https://doi.org/10.1176/appi.ps.58.4.469

Warner, R. (2005). Local Projects of the World Psychiatric Association Programme to Reduce Stigma and Discrimination. Psychiatric Services, 56(5), 570-575. https://doi.org/10.1176/appi.ps.56.5.570

Webb, T. L., \& Sheeran, P. (2006). Does Changing Behavioral Intentions Engender Behavior Change? A Meta-Analysis of the Experimental Evidence. Psychological Bulletin, 132(2), 249-268. https://doi.org/10.1037/0033-2909.132.2.249

Weinstein, N. D. (2007). Misleading tests of health behavior theories. Annals of Behavioral Medicine, 33(1), 1-10. https://doi.org/10.1207/s15324796abm3301_1

Wenocur, S., \& Belcher, J. R. (1990). Strategies for overcoming barriers to communitybased housing for the chronically mentally ill. Community Mental Health Journal, 26(4), 319-333. https://doi.org/10.1007/BF00752723

White, G. W., Simpson, J. L., Gonda, C., Ravesloot, C., \& Coble, Z. (2010). Moving from Independence to Interdependence: A Conceptual Model for Better Understanding Community Participation of Centers for Independent Living Consumers. Journal of Disability Policy Studies, 20(4), 233-240. Retrieved from https://www.researchgate.net/profile/Glen_White/publication/260290129_Moving_ From_Independence_to_Interdependence_A_Conceptual_Model_for_Better_Unders tanding_Community_Participation_of_Centers_for_Independent_Living_Consumer s/links/5632317108ae506cea6a485

Wilmoth, G. H., Silver, S., \& Severy, L. J. (1987). Receptivity and planned change: Community attitudes and deinstitutionalization. Journal of Applied Psychology, 72(1), 138-145. https://doi.org/http://dx.doi.org/10.1037/0021-9010.72.1.138

Wolff, G., Pathare, S., Craig, T., \& Leff, J. (1996a). Community attitudes to mental illness. The British Journal of Psychiatry, 168(2), 183-190. https://doi.org/10.1192/bjp.168.2.183

Wolff, G., Pathare, S., Craig, T., \& Leff, J. (1996b). Community knowledge of mental illness and reaction to mentally ill people. British Journal of Psychiatry, 168, 191198. https://doi.org/10.1192/bjp.168.2.191

Wolff, G., Pathare, S., Craig, T., \& Leff, J. (1996c). Public education for community care: A new approach. British Journal of Psychiatry, 168(4), 441-447. https://doi.org/10.1192/bjp.168.4.441 
Wong, Y. L. I., \& Solomon, P. L. (2002). Community integration of persons with psychiatric disabilities in supportive independent housing: A conceptual model and methodological considerations. Mental Health Services Research, 4(1), 13-28. https://doi.org/10.1023/A:1014093008857

World Health Organization. (2013). Mental disorders affect one in four people. World Health Organization. Retrieved from http://www.who.int/whr/2001/media_centre/press_release/en/

Wright, P. A., \& Kloos, B. (2007). Housing environment and mental health outcomes: A levels of analysis perspective. Journal of Environmental Psychology, 27(1), 79-89. https://doi.org/10.1016/j.jenvp.2006.12.001

Zippay, A. L. (2007). Psychiatric residences: notification, NIMBY, and neighborhood relations. Psychiatric Services, 58(1), 109-113. https://doi.org/10.1176/appi.ps.58.1.109-a

Zippay, A. L., \& Lee, S. K. (2008). Neighbors' perceptions of community-based psychiatric housing. Social Service Review, 82(3), 395-417. https://doi.org/http://dx.doi.org/10.1086/592857

Zippay, A. L., \& Son, E. (2013). Community approaches to the siting of psychiatric housing. Journal of Community Practice, 21(1-2), 87-104. https://doi.org/10.1080/10705422.2013.788338 
NEIGHBOR PERCEPTIONS OF SUPPORTIVE HOUSING

\section{Appendix. Measures}

\section{Screening questions (NASH)}

Now I'm going to ask a few questions about your opinion of certain types of housing.

(If for any of these the RP says, "I live in that type of housing," please make a note of this but ask them if there are other example of those housing types in their neighborhood.)

1. Do you believe that the government should help provide housing for people...
a. ...with low income?
$1=\mathrm{YES} \quad 2=\mathrm{NO}$
b. ...with physical disabilities?
$1=\mathrm{YES} \quad 2=\mathrm{NO}$
c. ...with mental illnesses?
$1=\mathrm{YES} \quad 2=\mathrm{NO}$

2. Would you welcome a housing site intended for people...
a. ...with low income?
$1=$ YES
$2=\mathrm{NO}$
b. ...with physical disabilities?
$1=$ YES
$2=\mathrm{NO}$
c. ...with mental illnesses?
$1=$ YES
$2=\mathrm{NO}$

3. Are you aware of any housing sites intended for people with mental illnesses, physical disabilities, or low income in your neighborhood? $\quad 1=$ YES $\quad 2=\mathrm{NO}$

If RP says yes, ask questions 4-7 below. If not, skip ahead to Neighbor Scale (HES-N).

4. To the best of your knowledge, is this housing primarily for people with (check which applies):
a. Low income
b. Physical disabilities
c. Mental illnesses
d. Other

5. Approximately where is the housing site located (indicate cross streets or describe appearance)? 
6. How did you find out that this housing site was intended for members of that group (or population)? (Pick all that apply; don't read the option unless the individual has a hard time producing their own answers - please take notes after 'other' of any answers provided that aren't clearly captured by the response choices below.)
a. Observation of people
b. Observation of structure (e.g., ramps, size or appearance)
c. Observation of signage
d. Social interaction with residents
e. Social interaction with non-residents
f. Official communication (e.g., info from Cascadia, neighborhood associations, flyers)
g. Other

7. How often do you interact with individuals from this housing site?
a. Daily
b. Weekly
c. Monthly
d. A few times a year
e. Once a year
f. Never

\section{Reported and Intended Behaviors Scale (RIBS) (NASH)}

Q.3 Are you currently living with, or have you ever lived with, someone with a mental health problem?

$1=$ Yes, 2 = No, 3 = Don't Know

Q.4 Are you currently working, or have you ever worked, with someone with a mental health problem?

$1=$ Yes, 2 = No, 3 = Don't Know

Q.5 Do you currently, or have you ever, had a neighbour with a mental health problem?

1 = Yes, 2 = No, 3 = Don't Know

Q.6 Do you currently have, or have you ever had, a close friend with a mental health problem?

$1=$ Yes, 2 = No, 3 = Don't Know 
Q.7 The following statements ask about any future relationships you may experience with people with mental health problems. Please tell me how much you agree or disagree with each one.

\begin{tabular}{|c|c|c|c|c|c|}
\hline & \multicolumn{5}{|c|}{$\begin{array}{l}1=\text { Strongly Disagree } \\
2=\text { Disagree } \\
3=\text { Neither Disagree or Agree } \\
4=\text { Agree } \\
5=\text { Strongly Agree }\end{array}$} \\
\hline $\begin{array}{l}\text { In the future, I would be willing to live with someone } \\
\text { with a mental health problem }\end{array}$ & 1 & 2 & 3 & 4 & 5 \\
\hline $\begin{array}{l}\text { In the future, I would be willing to work with someone } \\
\text { with a mental health problem }\end{array}$ & 1 & 2 & 3 & 4 & 5 \\
\hline $\begin{array}{l}\text { In the future, I would be willing to live nearby to } \\
\text { someone with a mental health problem }\end{array}$ & 1 & 2 & 3 & 4 & 5 \\
\hline $\begin{array}{l}\text { In the future, I would be willing to continue a } \\
\text { relationship with a friend who developed a mental health } \\
\text { problem }\end{array}$ & 1 & 2 & 3 & 4 & 5 \\
\hline
\end{tabular}




\section{Mental Health Knowledge Schedule (MAKS)}

Q.8 I am now going to read out some more statements about mental health problems, again that is conditions for which an individual would be seen by healthcare staff. Please tell me how much you agree or disagree with each one.

\begin{tabular}{|c|c|c|c|c|c|}
\hline & \multicolumn{5}{|c|}{$\begin{array}{l}1=\text { Strongly Disagree } \\
2=\text { Disagree } \\
3=\text { Neither Disagree or Agree } \\
4=\text { Agree } \\
5=\text { Strongly Agree }\end{array}$} \\
\hline $\begin{array}{l}\text { Most people with mental health problems want to have } \\
\text { paid employment }\end{array}$ & 1 & 2 & 3 & 4 & 5 \\
\hline $\begin{array}{l}\text { If a friend had a mental health problem, I know what } \\
\text { advice to give them to get professional help }\end{array}$ & 1 & 2 & 3 & 4 & 5 \\
\hline $\begin{array}{l}\text { Medication can be an effective treatment for people with } \\
\text { mental health problems }\end{array}$ & 1 & 2 & 3 & 4 & 5 \\
\hline $\begin{array}{l}\text { Psychotherapy (e.g., talk therapy or counseling) can be } \\
\text { an effective treatment for people with mental health } \\
\text { problems }\end{array}$ & 1 & 2 & 3 & 4 & 5 \\
\hline $\begin{array}{l}\text { People with severe mental health problems can fully } \\
\text { recover }\end{array}$ & 1 & 2 & 3 & 4 & 5 \\
\hline $\begin{array}{l}\text { Most people with mental health problems go to a } \\
\text { healthcare professional to get help }\end{array}$ & 1 & 2 & 3 & 4 & 5 \\
\hline
\end{tabular}


Q.9 Please say to what extent you agree or disagree that each of the following conditions is a type of mental illness.

\begin{tabular}{|c|c|c|c|c|c|}
\hline & \multicolumn{5}{|c|}{$\begin{array}{l}1=\text { Strongly Disagree } \\
2=\text { Disagree } \\
3=\text { Neither Disagree or Agree } \\
4=\text { Agree } \\
5=\text { Strongly Agree }\end{array}$} \\
\hline Depression & 1 & 2 & 3 & 4 & 5 \\
\hline Stress & 1 & 2 & 3 & 4 & 5 \\
\hline Schizophrenia & 1 & 2 & 3 & 4 & 5 \\
\hline Bipolar disorder (manic-depression) & 1 & 2 & 3 & 4 & 5 \\
\hline Drug addiction & 1 & 2 & 3 & 4 & 5 \\
\hline Grief & 1 & 2 & 3 & 4 & 5 \\
\hline
\end{tabular}

Q.10 Who is the person closest to you who has or has had some kind of mental illness? ('Closest' as defined by participant.)

1 = Immediate family (spouselchild lsisterlbrotherlparent etc)

$2=$ Partner (living with you)

$3=$ Partner (not living with you)

$4=$ Other family (unclelauntlcousinlgrand parent etc)

$5=$ Friend

$6=$ Acquaintance

$7=$ Work colleague

$8=$ Self

$9=$ Other (please specify)

$10=$ No-one known 


\section{Devaluation-Discrimination Scale (NASH and CHARP)}

Thanks for answering those questions. Now I will ask your opinion about attitudes from community members about mental illness. Please let me know how much you agree or disagree with the following statements. For these questions, I'm interested in what you think most community member believe-not necessarily what you believe.

\begin{tabular}{|c|c|c|c|c|c|}
\hline \multirow[b]{2}{*}{$\begin{array}{l}\text { 1. Most people would willingly accept someone with a } \\
\text { mental illness as a close friend }\end{array}$} & \multicolumn{5}{|c|}{$\begin{array}{l}1=\text { Strongly Disagree } \\
2=\text { Disagree } \\
3=\text { Neither Disagree or Agree } \\
4=\text { Agree } \\
5=\text { Strongly Agree }\end{array}$} \\
\hline & 1 & 2 & 3 & 4 & 5 \\
\hline $\begin{array}{l}\text { 2. Most people believe that a person with a mental illness } \\
\text { is just as intelligent as the average person }\end{array}$ & 1 & 2 & 3 & 4 & 5 \\
\hline $\begin{array}{l}\text { 3. Most people believe that someone with a mental illness } \\
\text { is just as trustworthy as the average citizen }\end{array}$ & 1 & 2 & 3 & 4 & 5 \\
\hline $\begin{array}{l}\text { 4. Most people would accept someone with a mental } \\
\text { illness as a teacher of young children in a public school }\end{array}$ & 1 & 2 & 3 & 4 & 5 \\
\hline $\begin{array}{l}\text { 5. Most people feel that having a mental illness is a sign } \\
\text { of personal failure }\end{array}$ & 1 & 2 & 3 & 4 & 5 \\
\hline $\begin{array}{l}\text { 6. Most people would not hire someone with a mental } \\
\text { illness to take care of their children, even if he or she is } \\
\text { working toward recovery }\end{array}$ & 1 & 2 & 3 & 4 & 5 \\
\hline $\begin{array}{l}\text { 7. Most people think less of a person who has a mental } \\
\text { illness }\end{array}$ & 1 & 2 & 3 & 4 & 5 \\
\hline $\begin{array}{l}\text { 8. Most employers will hire someone with a mental illness } \\
\text { if he or she is qualified for the job }\end{array}$ & 1 & 2 & 3 & 4 & 5 \\
\hline $\begin{array}{l}\text { 9. Most employers will pass over the application of } \\
\text { someone with a mental illness in favor of another } \\
\text { applicant }\end{array}$ & 1 & 2 & 3 & 4 & 5 \\
\hline $\begin{array}{l}\text { 10. Most people in my community would treat someone } \\
\text { with a mental illness just as they would treat anyone }\end{array}$ & 1 & 2 & 3 & 4 & 5 \\
\hline $\begin{array}{l}\text { 11. Most people would be reluctant to date someone with } \\
\text { a mental illness }\end{array}$ & 1 & 2 & 3 & 4 & 5 \\
\hline $\begin{array}{l}\text { 12. Once community members know a person has a } \\
\text { mental illness they will take his or her opinions less } \\
\text { seriously }\end{array}$ & 1 & 2 & 3 & 4 & 5 \\
\hline
\end{tabular}




\section{Stigma (CAMI/Time to change)(NASH)}

Q.1 I am going to read out some opinions which other people hold about mental illness and would like you to tell me how much you agree or disagree with each one. (Be sure to clarify that these questions ask how they actually feel—not what they think others think/feel.)

\begin{tabular}{|c|c|c|c|c|c|}
\hline & \multicolumn{5}{|c|}{$\begin{array}{l}1=\text { Strongly Disagree } \\
2=\text { Disagree } \\
3=\text { Neither Disagree or Agree } \\
4=\text { Agree } \\
5=\text { Strongly Agree }\end{array}$} \\
\hline $\begin{array}{l}\text { One of the main causes of mental illness is a lack of } \\
\text { self-discipline and will-power }\end{array}$ & 1 & 2 & 3 & 4 & 5 \\
\hline $\begin{array}{l}\text { There is something about people with mental illness } \\
\text { that makes it easy to tell them from normal people }\end{array}$ & 1 & 2 & 3 & 4 & 5 \\
\hline $\begin{array}{l}\text { As soon as a person shows signs of mental disturbance, } \\
\text { he should be hospitalized }\end{array}$ & 1 & 2 & 3 & 4 & 5 \\
\hline Mental illness is an illness like any other & 1 & 2 & 3 & 4 & 5 \\
\hline $\begin{array}{l}\text { Less emphasis should be placed on protecting the } \\
\text { public from people with mental illness }\end{array}$ & 1 & 2 & 3 & 4 & 5 \\
\hline $\begin{array}{l}\text { Mental hospitals are an outdated means of treating } \\
\text { people with mental illness }\end{array}$ & 1 & 2 & 3 & 4 & 5 \\
\hline Virtually anyone can become mentally ill & 1 & 2 & 3 & 4 & 5 \\
\hline $\begin{array}{l}\text { People with mental illness have for too long been the } \\
\text { subject of ridicule }\end{array}$ & 1 & 2 & 3 & 4 & 5 \\
\hline $\begin{array}{l}\text { We need to adopt a far more tolerant attitude toward } \\
\text { people with mental illness in our society }\end{array}$ & 1 & 2 & 3 & 4 & 5 \\
\hline $\begin{array}{l}\text { We have a responsibility to provide the best possible } \\
\text { care for people with mental illness }\end{array}$ & 1 & 2 & 3 & 4 & 5 \\
\hline People with mental illness don't deserve our sympathy & 1 & 2 & 3 & 4 & 5 \\
\hline People with mental illness are a burden on society & 1 & 2 & 3 & 4 & 5 \\
\hline $\begin{array}{l}\text { Increased spending on mental health services is a waste } \\
\text { of money }\end{array}$ & 1 & 2 & 3 & 4 & 5 \\
\hline $\begin{array}{l}\text { There are sufficient existing services for people with } \\
\text { mental illness }\end{array}$ & 1 & 2 & 3 & 4 & 5 \\
\hline People with mental illness should not be given any & 1 & 2 & 3 & 4 & 5 \\
\hline
\end{tabular}




\begin{tabular}{|c|c|c|c|c|c|}
\hline responsibility & & & & & \\
\hline $\begin{array}{l}\text { A person would be foolish to marry someone who has } \\
\text { suffered from mental illness, even though he seems } \\
\text { fully recovered }\end{array}$ & 1 & 2 & 3 & 4 & 5 \\
\hline $\begin{array}{l}\text { I would not want to live next door to someone who has } \\
\text { been mentally ill }\end{array}$ & 1 & 2 & 3 & 4 & 5 \\
\hline $\begin{array}{l}\text { Anyone with a history of mental problems should be } \\
\text { excluded from taking public office }\end{array}$ & 1 & 2 & 3 & 4 & 5 \\
\hline $\begin{array}{l}\text { No-one has the right to exclude people with mental } \\
\text { illness from their neighbourhood }\end{array}$ & 1 & 2 & 3 & 4 & 5 \\
\hline $\begin{array}{l}\text { People with mental illness are far less of a danger than } \\
\text { most people suppose }\end{array}$ & 1 & 2 & 3 & 4 & 5 \\
\hline $\begin{array}{l}\text { Most people who were once patients in a mental } \\
\text { hospital can be trusted as babysitters }\end{array}$ & 1 & 2 & 3 & 4 & 5 \\
\hline $\begin{array}{l}\text { The best therapy for many people with mental illness is } \\
\text { to be part of a normal community }\end{array}$ & 1 & 2 & 3 & 4 & 5 \\
\hline $\begin{array}{l}\text { As far as possible, mental health services should be } \\
\text { provided through community based facilities }\end{array}$ & 1 & 2 & 3 & 4 & 5 \\
\hline $\begin{array}{l}\text { Residents have nothing to fear from people coming into } \\
\text { their neighbourhood to obtain mental health services }\end{array}$ & 1 & 2 & 3 & 4 & 5 \\
\hline $\begin{array}{l}\text { It is frightening to think of people with mental } \\
\text { problems living in residential neighbourhoods }\end{array}$ & 1 & 2 & 3 & 4 & 5 \\
\hline $\begin{array}{l}\text { Locating mental health facilities in a residential area } \\
\text { downgrades the neighbourhood }\end{array}$ & 1 & 2 & 3 & 4 & 5 \\
\hline $\begin{array}{l}\text { People with mental health problems should have the } \\
\text { same rights to a job as anyone else }\end{array}$ & 1 & 2 & 3 & 4 & 5 \\
\hline
\end{tabular}

Q.10 Who is the person closest to you who has or has had some kind of mental illness? ('Closest' as defined by participant.)

$1=$ Immediate family (spouselchildlsisterlbrotherlparent etc)

$2=$ Partner (living with you)

$3=$ Partner (not living with you)

$4=$ Other family (unclelauntlcousin|grand parent etc)

$5=$ Friend 
$6=$ Acquaintance

$7=$ Work colleague

$8=$ Self

$9=$ Other (please specify)

$10=$ No-one known

\section{NASH Neighbor Scale (HES-N)}

Now I have some questions about your neighbors.

1. How many of your neighbors do you know well?

2. How well do you and your neighbors know each other?

\begin{tabular}{|c|c|c|c|c|}
\hline Not at All & Slightly & Somewhat & Pretty Well & Very Well \\
\hline 1 & 2 & 3 & 4 & 5 \\
\hline
\end{tabular}

3. Over the last six months (or since you have moved in), how often have you talked in person with a neighbor?

\begin{tabular}{|c|c|c|c|c|}
\hline Not at All & $\begin{array}{c}\text { At least ONCE in } \\
\text { Past 6 Months }\end{array}$ & $\begin{array}{c}\text { At least } \\
\text { ONCE a Month }\end{array}$ & $\begin{array}{c}\text { At least } \\
\text { ONCE a Week }\end{array}$ & $\begin{array}{c}\text { At least } \\
\text { ONCE a Day }\end{array}$ \\
\hline 1 & 2 & 3 & 4 & 5 \\
\hline
\end{tabular}

For these next questions, how much you AGREE or DISAGREE with the following statements?

\begin{tabular}{|l|lllll|}
\hline & $\begin{array}{l}\text { 1 = Strongly Disagree } \\
\text { 2= Disagree } \\
\text { 3= Neither Disagree or Agree } \\
\text { 4= Agree } \\
\text { 5= Strongly Agree }\end{array}$ & \\
\hline & 1 & 2 & 3 & 4 & 5 \\
\hline 4. I can count on a neighbor for help when I need it. & 1 & 2 & 3 & 4 & 5 \\
\hline $\begin{array}{l}\text { 5. There is no one in my neighborhood with whom I'm } \\
\text { close. }\end{array}$ & 1 & & & & \\
\hline $\begin{array}{l}\text { 6. I have a close relationship with a neighbor (not } \\
\text { necessarily a romantic relationship). }\end{array}$ & 1 & 2 & 3 & 4 & 5 \\
\hline 7. If I needed it, a neighbor would give me a ride to an & 1 & 2 & 3 & 4 & 5 \\
\hline
\end{tabular}




\begin{tabular}{|c|c|c|c|c|c|}
\hline \multicolumn{6}{|l|}{ appointment. } \\
\hline 8. My neighbors and I argue a lot. & 1 & 2 & 3 & 4 & 5 \\
\hline $\begin{array}{l}\text { 9. If I needed someone to talk to about a problem, I could } \\
\text { talk with one of my neighbors. }\end{array}$ & 1 & 2 & 3 & 4 & 5 \\
\hline $\begin{array}{l}\text { 10. My neighbors keep an eye on my place when I am } \\
\text { gone. }\end{array}$ & 1 & 2 & 3 & 4 & 5 \\
\hline 11. My neighbors invite me to do things with them. & 1 & 2 & 3 & 4 & 5 \\
\hline $\begin{array}{l}\text { 12. My neighbors complain about me or my apartment } \\
\text { (house, or home). }\end{array}$ & 1 & 2 & 3 & 4 & 5 \\
\hline
\end{tabular}

13. How important to you are your relationship with neighbors?

\begin{tabular}{|c|c|c|c|c|}
\hline $\begin{array}{c}\text { Not at All } \\
\text { Important }\end{array}$ & $\begin{array}{c}\text { Slightly } \\
\text { Important }\end{array}$ & $\begin{array}{c}\text { Somewhat } \\
\text { Important }\end{array}$ & Very Important & $\begin{array}{c}\text { Extremely } \\
\text { Important }\end{array}$ \\
\hline 1 & 2 & 3 & 4 & 5 \\
\hline
\end{tabular}

14. Overall, how satisfied are you with your relationship with your neighbors? (Choose one)

\begin{tabular}{|c|c|c|c|c|}
\hline Very Dissatisfied & Dissatisfied & $\begin{array}{c}\text { Neither } \\
\text { Dissatisfied or } \\
\text { Satisfied }\end{array}$ & Satisfied & Very Satisfied \\
\hline 1 & 2 & 3 & 4 & 5 \\
\hline
\end{tabular}

\section{CHARP Neighbor Scale (HES-N)}

Now I have some questions about your neighbors.

For these next questions, how much you AGREE or DISAGREE with the following statements?

1. How many of your neighbors do you know well?

2. How well do you and your neighbors know each other?

\begin{tabular}{|c|c|c|c|c|}
\hline Not at All & Slightly & Somewhat & Pretty Well & Very Well \\
\hline 1 & 2 & 3 & 4 & 5 \\
\hline
\end{tabular}


3. Over the last six months (or since you have moved in), how often have you talked in person with a neighbor?

\begin{tabular}{|c|c|c|c|c|}
\hline Not at All & $\begin{array}{c}\text { At least ONCE in } \\
\text { Past 6 Months }\end{array}$ & $\begin{array}{c}\text { At least } \\
\text { ONCE a Month }\end{array}$ & $\begin{array}{c}\text { At least } \\
\text { ONCE a Week }\end{array}$ & $\begin{array}{c}\text { At least } \\
\text { ONCE a Day }\end{array}$ \\
\hline 1 & 2 & 3 & 4 & 5 \\
\hline
\end{tabular}

For these next questions, how much you AGREE or DISAGREE with the following statements?

\begin{tabular}{|c|c|c|c|c|c|}
\hline \multirow[b]{2}{*}{ 4. I can count on a neighbor for help when I need it. } & & \multicolumn{4}{|c|}{$\begin{array}{l}1=\text { Strongly Disagree } \\
2=\text { Disagree } \\
3=\text { Neither Disagree or Agree } \\
4=\text { Agree } \\
5=\text { Strongly Agree }\end{array}$} \\
\hline & 1 & 2 & 3 & 4 & 5 \\
\hline $\begin{array}{l}\text { 5. There is no one in my neighborhood with whom I'm } \\
\text { close. }\end{array}$ & 1 & 2 & 3 & 4 & 5 \\
\hline $\begin{array}{l}\text { 6. I have a close relationship with a neighbor (not } \\
\text { necessarily a romantic relationship). }\end{array}$ & 1 & 2 & 3 & 4 & 5 \\
\hline $\begin{array}{l}\text { 7. If I needed it, a neighbor would give me a ride to an } \\
\text { appointment. }\end{array}$ & 1 & 2 & 3 & 4 & 5 \\
\hline 8. My neighbors and I argue a lot. & 1 & 2 & 3 & 4 & 5 \\
\hline $\begin{array}{l}\text { 9. If I needed someone to talk to about a problem, I could } \\
\text { talk with one of my neighbors. }\end{array}$ & 1 & 2 & 3 & 4 & 5 \\
\hline $\begin{array}{l}\text { 10. My neighbors keep an eye on my place when I am } \\
\text { gone. }\end{array}$ & 1 & 2 & 3 & 4 & 5 \\
\hline 11. My neighbors invite me to do things with them. & 1 & 2 & 3 & 4 & 5 \\
\hline $\begin{array}{l}\text { 12. My neighbors complain about me or my apartment } \\
\text { (house, or home). }\end{array}$ & 1 & 2 & 3 & 4 & 5 \\
\hline
\end{tabular}

13. How important to you are your relationship with neighbors?

\begin{tabular}{|c|c|c|c|c|}
\hline $\begin{array}{c}\text { Not at All } \\
\text { Important }\end{array}$ & $\begin{array}{c}\text { Slightly } \\
\text { Important }\end{array}$ & $\begin{array}{c}\text { Somewhat } \\
\text { Important }\end{array}$ & Very Important & $\begin{array}{c}\text { Extremely } \\
\text { Important }\end{array}$ \\
\hline 1 & 2 & 3 & 4 & 5 \\
\hline
\end{tabular}


14. Overall, how satisfied are you with your relationship with your neighbors? (Choose one)

\begin{tabular}{|c|c|c|c|c|}
\hline Very Dissatisfied & Dissatisfied & $\begin{array}{c}\text { Neither } \\
\text { Dissatisfied or } \\
\text { Satisfied }\end{array}$ & Satisfied & Very Satisfied \\
\hline 1 & 2 & 3 & 4 & 5 \\
\hline
\end{tabular}

\section{Neighboring intentions- Mental Illness (NASH)}

How likely would you be to do the following with a neighbor who has a mental illness:

\begin{tabular}{|c|c|c|c|c|c|}
\hline \multirow[b]{2}{*}{ 1- Share information about home or yard care } & \multicolumn{5}{|c|}{$\begin{array}{l}1=\text { Very Unlikely } \\
2=\text { Unlikely } \\
3=\text { Neither Unlikely nor Likely } \\
4=\text { Likely } \\
5=\text { Very Likely }\end{array}$} \\
\hline & 1 & 2 & 3 & 4 & 5 \\
\hline $\begin{array}{l}\text { 2- Tell neighbor about professional services } \\
\text { (e.g., mechanics, dentist, hair) used }\end{array}$ & 1 & 2 & 3 & 4 & 5 \\
\hline 3- Offer neighbors a ride & 1 & 2 & 3 & 4 & 5 \\
\hline 4- Converse with a neighbor on the street & 1 & 2 & 3 & 4 & 5 \\
\hline 5- Go with a neighbor to a social outing & 1 & 2 & 3 & 4 & 5 \\
\hline 6- Invite a neighbor into your home & 1 & 2 & 3 & 4 & 5 \\
\hline 7- Talk with a neighbor about a personal issue & 1 & 2 & 3 & 4 & 5 \\
\hline
\end{tabular}




\section{Neighboring intentions (NASH)}

How likely would you be to do the following with a neighbor:

\begin{tabular}{|c|c|c|c|c|c|}
\hline \multirow[b]{2}{*}{ 1- Share information about home or yard care } & \multicolumn{5}{|c|}{$\begin{array}{l}1=\text { Very Unlikely } \\
2=\text { Unlikely } \\
3=\text { Neither Likely nor Unlikely } \\
4=\text { Likely } \\
5=\text { Very Likely }\end{array}$} \\
\hline & 1 & 2 & 3 & 4 & 5 \\
\hline $\begin{array}{l}\text { 2- Tell neighbor about professional services } \\
\text { (e.g., mechanics, dentist, hair) used }\end{array}$ & 1 & 2 & 3 & 4 & 5 \\
\hline 3- Offer neighbors a ride & 1 & 2 & 3 & 4 & 5 \\
\hline 4- Converse with a neighbor on the street & 1 & 2 & 3 & 4 & 5 \\
\hline 5- Go with a neighbor to a social outing & 1 & 2 & 3 & 4 & 5 \\
\hline 6- Invite a neighbor into your home & 1 & 2 & 3 & 4 & 5 \\
\hline 7- Talk with a neighbor about a personal issue & 1 & 2 & 3 & 4 & 5 \\
\hline
\end{tabular}

\section{UCLA- Loneliness (NASH and CHARP)}

Now I am going to read to you some statements about how people sometimes feel. For each statement, please indicate how often you feel the way described.

\begin{tabular}{|c|c|c|c|c|}
\hline & 3 & \multicolumn{2}{|c|}{$\begin{array}{l}\text { Never } \\
\text { Rarely } \\
\text { Sometimes } \\
\text { Always }\end{array}$} & \\
\hline 1. How often do you feel left out? & 1 & 2 & 3 & 4 \\
\hline 2. How often do you feel isolated from others? & 1 & 2 & 3 & 4 \\
\hline $\begin{array}{l}\text { 3. How often do you feel that there are people that really } \\
\text { understand you? }\end{array}$ & 1 & 2 & 3 & 4 \\
\hline 4. How often do you feel that there are people you can talk to? & 1 & 2 & 3 & 4 \\
\hline
\end{tabular}




\section{Neighborhood Social Climate (HES-NSC) (NASH and CHARP)}

Okay, now I will ask about how much you AGREE or DISAGREE with the following statements about your neighborhood.

\begin{tabular}{|c|c|c|c|c|c|}
\hline & \multicolumn{5}{|c|}{$\begin{array}{l}1=\text { Strongly Disagree } \\
2=\text { Disagree } \\
3=\text { Neither Disagree or Agree } \\
4=\text { Agree } \\
5=\text { Strongly Agree }\end{array}$} \\
\hline 1. I feel safe in my neighborhood. & 1 & 2 & 3 & 4 & 5 \\
\hline $\begin{array}{l}\text { 2. Sometimes I feel unwelcome in my } \\
\text { neighborhood because of my ethnicity and my } \\
\text { cultural background. }\end{array}$ & 1 & 2 & 3 & 4 & 5 \\
\hline $\begin{array}{l}\text { 3. People in my neighborhood are friendly to } \\
\text { everybody no matter what the person's skin color or } \\
\text { ethnic background. }\end{array}$ & 1 & 2 & 3 & 4 & 5 \\
\hline $\begin{array}{l}\text { 4. Police treat people differently in my } \\
\text { neighborhood because of the color of their skin. }\end{array}$ & 1 & 2 & 3 & 4 & 5 \\
\hline $\begin{array}{l}\text { 5. Sometimes, people in my neighborhood hassle } \\
\text { me when I'm out walking. }\end{array}$ & 1 & 2 & 3 & 4 & 5 \\
\hline $\begin{array}{l}\text { 6. I need to be careful who I talk to in my } \\
\text { neighborhood. }\end{array}$ & 1 & 2 & 3 & 4 & 5 \\
\hline 7. My neighborhood is an easy place to live. & 1 & 2 & 3 & 4 & 5 \\
\hline 8. People in my neighborhood treat me as an equal. & 1 & 2 & 3 & 4 & 5 \\
\hline $\begin{array}{l}\text { 9. Sometimes I feel unwelcome in my } \\
\text { neighborhood because of my mental illness.* }\end{array}$ & 1 & 2 & 3 & 4 & 5 \\
\hline $\begin{array}{l}\text { 10. People in this neighborhood know that I have a } \\
\text { mental illness. }\end{array}$ & 1 & 2 & 3 & 4 & 5 \\
\hline $\begin{array}{l}\text { 11. Some people in my neighborhood give me a } \\
\text { hard time because of my mental illness. }\end{array}$ & 1 & 2 & 3 & 4 & 5 \\
\hline $\begin{array}{l}\text { 12. People in this neighborhood are afraid of me } \\
\text { because of my mental illness. }\end{array}$ & 1 & 2 & 3 & 4 & 5 \\
\hline
\end{tabular}

*Italicized phrases and questions do not appear in the NASH survey (unique to CHARP survey)

For the next two questions, please answer what you believe is true or your perception of what is true; you do not need to have accurate facts.

13. How many people in your neighborhood have either the same race or ethnic background as you? (Please answer to the best of your ability even if you are not sure.)

\begin{tabular}{|c|c|c|c|c|}
\hline No One & A Few & About Half & Most & Everybody \\
\hline 1 & 2 & 3 & 4 & 5 \\
\hline
\end{tabular}


14. How many people in your neighborhood use mental health services?

\begin{tabular}{|c|c|c|c|c|}
\hline No One & A Few & About Half & Most & Everybody \\
\hline 1 & 2 & 3 & 4 & 5 \\
\hline
\end{tabular}

\section{Neighborhood Safety (HES-S) (NASH and CHARP)}

Next I will ask about activity in your neighborhood. Please think about the area right outside of or in your building.

\begin{tabular}{|c|c|c|c|c|c|c|c|}
\hline \multirow[b]{2}{*}{$\begin{array}{l}\text { 1. How often are people attacked right around your } \\
\text { building? }\end{array}$} & \multirow[t]{2}{*}{$\begin{array}{l}0 \\
1 \\
2 \\
3 \\
4 \\
5 \\
6\end{array}$} & \multicolumn{6}{|c|}{$\begin{array}{l}\text { Never } \\
\text { Few Times a Year } \\
\text { Once Per Month or Less } \\
\text { 2-3 Times a Month } \\
\text { Once a Week } \\
\text { 2-3 Times a Week } \\
\text { Once a Day }\end{array}$} \\
\hline & & 1 & 2 & 3 & 4 & 5 & 6 \\
\hline 2. How often are people selling drugs? & 0 & 1 & 2 & 3 & 4 & 5 & 6 \\
\hline 3. How often are people using drugs? & 0 & 1 & 2 & 3 & 4 & 5 & 6 \\
\hline $\begin{array}{l}\text { 4. How often are people robbed around your } \\
\text { building? }\end{array}$ & 0 & 1 & 2 & 3 & 4 & 5 & 6 \\
\hline $\begin{array}{l}\text { 5. How often have people had things stolen from } \\
\text { their apartment (place, home)? }\end{array}$ & 0 & 1 & 2 & J & 4 & 5 & 6 \\
\hline 6. How often does destruction of property happen? & 0 & 1 & 2 & 3 & 4 & 5 & 6 \\
\hline $\begin{array}{l}\text { 7. How often are groups of people just hanging out } \\
\text { and causing problems? }\end{array}$ & 0 & 1 & 2 & 3 & 4 & 5 & 6 \\
\hline $\begin{array}{l}\text { 8. How often does new graffiti appear (painting or } \\
\text { writing on walls)? }\end{array}$ & 0 & 1 & 2 & 3 & 4 & 5 & 6 \\
\hline 9. How often are weapons used (guns, knives)? & 0 & 1 & 2 & 3 & 4 & 5 & 6 \\
\hline
\end{tabular}

\section{Demographics}

1. What is your gender?

2. How old are you? 
3. Which of the following best describes your racial background (please select one)?

\begin{tabular}{|c|c|c|c|c|c|c|}
\hline White & Black & Latino & $\begin{array}{c}\text { Alaskan Native/Native } \\
\text { American }\end{array}$ & $\begin{array}{c}\text { Native Hawaiian of other } \\
\text { Pacific Islander }\end{array}$ & Asian & Other \\
\hline 1 & 2 & 3 & 4 & 5 & 6 & 7 \\
\hline
\end{tabular}

3a. If other, please specify:

4. What is the highest level of schooling you have completed?
口 8th Grade or Less
$\square \quad$ Some High School
口 High school diploma
口 Completed GED
口 Voc/Trade/Business School
口 Some College or 2 year degree
口 Finished 4 year degree
$\square \quad$ Master's degree or equivalent
口 Other Advanced degree

5. How would you describe your relationship status?

$\begin{array}{ll}\square & \text { Married or living with someone in a romantic relationship } \\ \square & \text { In a relationship but not living together } \\ \square & \text { Single (includes separated and divorced) } \\ \square & \text { Widowed } \\ \square & \text { Other }\end{array}$

6. Do you have children under the age of $18 ? \quad 1=$ YES $2=$ NO

6a. If yes, how many children under age 18 are living with you?

7. What is your present religion, if any?

$\begin{array}{ll}\square & \text { Protestant (e.g., Baptist, Presbyterian, Lutheran, Methodist) } \\ \square & \text { Catholic } \\ \square & \text { Mormon }\end{array}$




$\begin{array}{ll}\square & \text { Orthodox such as Greek or Russian Orthodox } \\ \square & \text { Jewish } \\ \square & \text { Muslim } \\ \square & \text { Buddhist } \\ \square & \text { Hindu } \\ \square & \text { Atheist } \\ \square & \text { Agnostic } \\ \square & \text { Other } \\ \square & \text { Refuse to answer }\end{array}$

8. What is your political party affiliation?

$\begin{array}{ll}\square & \text { Republican } \\ \square & \text { Democrat } \\ \square & \text { Independent } \\ \square & \text { Other } \\ \square & \text { Refuse to answer }\end{array}$

9. What is your average monthly income for all sources? 